\title{
Do I Really Want to Hear The News? Public Information Arrival and Investor Beliefs
}

\author{
Azi Ben-Rephael* J. Anthony Cookson ${ }^{\dagger}$ and Yehuda Izhakian ${ }^{\ddagger}$
}

August 3, 2022

\begin{abstract}
This paper shows that public information arrival affects investor beliefs and disagreement through a new channel: the uncertainty of beliefs (UOB). Based on novel daily measurement of belief uncertainty and disagreement, disagreement and trading are lower when UOB is higher. Higher UOB also dampens the relationship between disagreement and trading volume. The paper also highlights novel patterns of disagreement and trading around public news. For clarifying news like earnings announcements, information arrival reduces UOB, which naturally amplifies disagreement and trading. Consistent with learning, UOB decreases more for events with more attentive investors and for firms with a better information environment. By contrast, unscheduled events with opaque information information increase UOB while decreasing disagreement and trading.
\end{abstract}

Keywords and Phrases: Investor Disagreement, Investor Beliefs, Differences of Opinions, Gradual Information Diffusion, Knightian Uncertainty, Ambiguity, News, Investor Attention

JEL Classification Numbers: D83, G11, G12, G40

\footnotetext{
*Rutgers Business School, Rutgers University, 1 Washington Park, Newark, NJ 07102; Email: abenrephael@business.rutgers.edu

${ }^{\dagger}$ University of Colorado, Leeds School of Business, 995 Regent Dr, Boulder, CO 80309; Email: tony.cookson@colorado.edu

${ }^{\ddagger}$ Zicklin School of Business, Baruch College, 1 Bernard Baruch Way, New York, NY 10010; Email: yudizh@gmail.com

${ }^{\S}$ We thank Snehal Banerjee, Zahi Ben-David, Jules van Binsbergen, Richard Herron, Avri Ravid, Andrea Tamoni, Jaime Zender, and seminar participants at Erasmus University Rotterdam, University of Amsterdam, University of Colorado, University of Mannheim, Virginia Tech and Rutgers University for valuable discussions and suggestions. Izhakian acknowledges hosting by the Stern School of Business, New York University.
} 


\section{Introduction}

How the arrival of news affects investor beliefs, disagreement, and trading is of central importance in financial markets. Despite significant attention, the literature is divided about whether information arrival leads investor beliefs to diverge (e.g., Harris and Raviv, 1993; Kandel and Pearson, 1995) or converge (e.g., He and Wang, 1995; Tetlock, 2010), with evidence supporting each perspective. Moreover, recent work using linked survey and administrative data has shown a weak connection between investor beliefs and trading, leading to new questions about what motivates trading (Giglio, Maggiori, Stroebel, and Utkus, 2021).

In this paper, we show that understanding how firm-specific news affects investors' uncertainty of beliefs helps to resolve these apparent tensions in the literature. Specifically, we introduce new daily measurement of uncertainty of beliefs (or UOB) and conduct a systematic empirical evaluation of how firm news events affect UOB, disagreement, and trading. We find that UOB can either increase or decrease in response to news, depending on whether news clarifies or opens up new possibilities. ${ }^{1}$ Empirically, these changes to belief uncertainty matter for disagreement and trading around news events because the connection between disagreement and trading is stronger when UOB is low.

The main empirical challenge is in measuring UOB and disagreement at the daily frequency, which is crucial to provide an empirical link to public information arrival. We measure UOB using a newly developed measure from the ambiguity literature (Izhakian, 2017, 2020). This measure quantifies the degree of daily variation in outcome probabilities (ambiguity) based on intraday realized returns available in the Trade and Quote (TAQ) database. The resulting measure of investor belief uncertainty is both high-frequency and applies to a broad set of firms. Similarly, we measure disagreement at the daily frequency using user-classified bullish and bearish messages from the investor social network StockTwits, a measure that has been developed recently by Cookson and Niessner (2020).

To highlight the advantages of our daily measurement of UOB and disagreement, it is instructive to contrast with existing approaches. For example, the literature has long proxied for disagreement by using the dispersion in analyst forecasts (e.g., Diether, Malloy, and Scherbina, 2002). However,

\footnotetext{
${ }^{1}$ This perspective is consistent with the literature on learning and ambiguity (e.g., Epstein and Schneider, 2007), which shows that belief uncertainty can increase or decrease upon the arrival of information.
} 
in contrast to our daily measure, analyst forecasts are updated too infrequently to provide insight into how disagreement evolves in the days around public news arrival. Measurement of belief uncertainty faces similar challenges: prior work has elicited uncertainty of beliefs from surveys (Ben-David, Fermand, Kuhnen, and Li, 2018; Giglio et al., 2021). Though these surveys generated important insights, their selective and infrequent nature makes it impossible to explore short-term effects around daily firm events. By contrast, our daily measurement of UOB facilitates this analysis via a standard event window approach.

We begin by highlighting several pervasive features of how UOB, disagreement, and trading relate to each other using a series of daily panel regressions. We estimate a tight link between disagreement and UOB at the daily frequency, consistent with the intuition that uncertainty of beliefs discourages investors from disagreeing in the first place. Specifically, a standard deviation increase in UOB is associated with one-tenth of a standard deviation lower disagreement. This relationship is strikingly pervasive: Our estimates are insensitive to controlling for a wide variety of proxies for market and firm risk, as well as their 21-day trailing averages. Further, we find that UOB relates to disagreement whether disagreement originates from within-group differences or across-group differences.

Next, we show that UOB has a tight relationship to daily trading, even holding constant daily disagreement. For a standardized movement in each, the implied change in trading from UOB is roughly one third of that implied by disagreement. Digging deeper, we consider an interactive specification and find that high UOB significantly dampens the relationship between disagreement and trading. For a high UOB (low UOB) stock, we estimate a standard deviation increase in disagreement is associated with a $0.085(0.213)$ standard deviation increase in daily stock turnover. This result sheds new light into the connection between investor beliefs and trading. Specifically, our finding shows how uncertainty of beliefs drives a wedge between disagreement and trading, consistent with recent linked administrative and survey evidence (Giglio et al., 2021).

In the second part of the paper, we study how UOB, disagreement and trading evolve around a broad set of firm news events, taking an event window approach. Specifically, we evaluate how UOB changes in a $t-5$ to $t+20$ window around earnings announcements, $8-\mathrm{K}$ disclosures, and other firm new events identifiable in media coverage. Our tests reveal substantial heterogeneity in how belief uncertainty responds to the arrival of firm-specific news. For example, earnings news 
events substantially and temporarily decrease UOB, whereas 8-K filings persistently increase UOB. The contrast between earnings news and 8-K disclosures highlights a consistent theme behind the heterogeneity across news events: For news that clarifies the prospects of investors, such as earnings news, we see that arrival of information reduces UOB. By contrast, news that is opaque or news that opens up new possibilities (e.g., news of a firm being a merger target or being assigned a credit watch), the arrival of news leads to greater UOB that is not quickly resolved. We see this pattern in three different settings: contrasting earnings announcements and 8-K disclosures, contrasting different kinds of 8-K disclosures, and contrasting different types of news events extracted from the news media database RavenPack. ${ }^{2}$

We subject these main findings to a variety of robustness exercises. Most importantly, we mitigate concerns that UOB is confounded by other known uncertainty measures by controlling for these variables (e.g., volatility, volatility-of-mean, volatility-of-volatility, skewness, and kurtosis), liquidity measures, and dispersion of analyst forecasts. Together, all these measures only explain about $10 \%$ of the variation in UOB. All of the main conclusions hold whether or not we control for measures of market and firm uncertainty and their 21-day trailing averages, and the estimated magnitudes are stable upon enriching the specification with controls. This combination of robustness and coefficient stability greatly enhances our confidence that our findings are not driven by an omitted driver of risk or liquidity (Oster, 2019). ${ }^{3}$

Further, several supplemental tests point to an informational channel for our results. For example, when we split disagreement into within-group versus across-group measures as in Cookson and Niessner (2020), we observe that the trading results are driven almost entirely by the withingroup (informational) component of disagreement. We also see that the arrival of news reduces UOB by more in the presence of greater institutional attention, consistent with an informational channel moderated by attention (Ben-Rephael, Da, and Israelsen, 2017). Finally, we take advantage of firm earnings guidance to revisit how UOB changes around earnings announcement days. We

\footnotetext{
${ }^{2}$ In a supplemental exercise, we also show that UOB responds to macroeconomic news announcements, such as FOMC announcements. This evidence confirms the intuition that market-wide events may also affect the way investors process firm-specific information, consistent with research on the information content of these macro events (e.g., Ai and Bansal, 2018; Savor and Wilson, 2013)

${ }^{3}$ Separately, to alleviate concerns that time-varying patterns affect UOB, Izhakian and Izhakian (2020) construct an option-based UOB measure using options contracts written on the S\&P 500 Index, measuring ambiguity at a fixed point in time. They show that the option-based UOB is highly correlated with the S\&P 500 Index intraday-based measure.
} 
find a 3-4 times larger decrease in UOB (relative to the base case) for firms that issue earnings guidance with low dispersion. In contrast, there is a small and insignificant decrease in UOB for firms with highly dispersed earnings guidance.

Our UOB measure may reflect individual or collective uncertainty because it is measured at the stock-day level from the TAQ database without any investor-level information. Individually, an investor may not be sure about her beliefs (Gilboa and Schmeidler, 1989). Collectively, a group of individuals may have different beliefs ("group ambiguity", Garlappi, Giammarino, and Lazrak, 2017). Both generate uncertainty of probabilities of future outcomes and are not mutually exclusive. In finding a negative relation between UOB and disagreement (particularly within-group disagreement), our findings are more consistent with individual uncertainty about beliefs (ambiguity) than group disagreement. Beyond this point of interpretation, we present ample evidence that UOB is not subsumed by some other uncertainty measure in the literature when we construct and describe several of the measure's properties in Section 2.1.

Our paper makes several contributions to the finance literature. First, we contribute new evidence at the daily frequency on how investor beliefs and uncertainty of beliefs relate to trading in financial markets. The finance literature has had a longstanding interest in understanding daily trading patterns, and dispersion of beliefs has been thought to be crucial to understand such daily trading (e.g., Hong and Stein, 2007; Xiong, 2013). However, recent survey and experimental evidence has revealed that there is a weak link between belief updates and trades by individual investors (Giglio et al., 2021; Charles, Frydman, and Kilic, 2021) and has also suggested that investor portfolio decisions are influenced by the uncertainty investors face (Ben-David et al., 2018). Because even these repeated surveys occur infrequently, this evidence is silent about whether belief uncertainty is important at the daily frequency for trading and disagreement. As our results highlight, this is an important gap. Not only do we find that UOB matters for how disagreement relates to trading, but also, disagreement matters for trading roughly three times more for a stock with low UOB versus a stock with high UOB.

Second, our paper provides a novel perspective on how investors update beliefs when information arrives. Existing work is divided about whether information arrival leads to belief convergence (e.g., Kim and Verrecchia, 1991; Tetlock, 2010), or to greater disagreement (e.g., Kim and Verrecchia, 1994; Kandel and Pearson, 1995; Hong and Stein, 1999). Moreover, much of previous work in 
this domain focuses on the uncertainty of outcomes, such as the dispersion of analyst forecasts (e.g., Diether et al., 2002). By contrast, in studying belief uncertainty, we focus on uncertainty of the probabilities of outcomes. This aspect of uncertainty, which has not been explored in the literature, brings new insights about the implications of public information arrival. Specifically, we show that different events have different implications for beliefs and their uncertainty. For example, anticipated and scheduled events mitigate UOB, while unexpected, opaque and voluntarily disclosed information amplifies UOB. These results provide one rationale - heterogeneity in the nature of news - for the tension inherent in the literature's findings about the impacts of information arrival.

Third, our findings also inform the literature on the persistence of disagreement and trading (e.g., Harris and Raviv, 1993). This literature has emphasized behavioral frictions, which lead investors to disagree and trade persistently due to the arrival of public news (Kandel and Pearson, 1995; Carlin, Longstaff, and Matoba, 2014; Cookson, Engelberg, and Mullins, 2022). This literature has proposed two broad classes of explanations for how disagreement can persist and sustain trading - gradual information diffusion (Barberis, Shleifer, and Vishny, 1998; Daniel, Hirshleifer, and Subrahmanyam, 1998; Hong and Stein, 1999; Fedyk, 2021) and differential interpretation of public signals (Cookson, Engelberg, and Mullins, 2020; Meeuwis, Parker, Schoar, and Simester, 2021). In either case, this existing work implies that disagreement and trading emerge due to some kind of inefficiency in how the market incorporates information. In our setting, information arrival leads to more information available to investors, but the information affects investor uncertainty of beliefs. For an earnings announcement that reduces UOB, we see more disagreement and trade, not because of informational inefficiency, but because there is more information in the market. In this respect, our findings provide evidence akin to the rational updating channels modeled in Banerjee and Kremer (2010).

Lastly, in applying recently developed daily measures of belief uncertainty and disagreement, our paper joins a recent set of studies that have made progress on similar issues via developing trading motives and investor beliefs. Our use of the TAQ database to proxy for belief uncertainty at a daily frequency is akin to recent work that tracks retail investors using detailed information in TAQ (Boehmer, Jones, Zhang, and Zhang, 2021) and is related to other work that has studied ambiguity in other settings (Izhakian, Yermack, and Zender, 2021; Izhakian and Yermack, 2017; Ben-Rephael, Cookson, and Izhakian, 2022a). In a similar vein, our disagreement measurement 
using StockTwits highlights the value of extracting information from investor social media, joining a recent literature that has made progress due to the insight into investor information sharing and beliefs (e.g., Dessaint, Foucault, and Frésard, 2021; Cookson, Fos, and Niessner, 2021). We expect that both measures will continue to enjoy application in other work as the research frontier becomes more interested in learning about how investor beliefs are formed and how investor beliefs help to shape market outcomes.

\section{Data and measurement}

The primary data source for our analysis is Intraday Trade and Quote (TAQ) data for estimating UOB. TAQ data are also used for estimating risk and other uncertainty factors (including volatility-of-mean, volatility-of-volatility, skewness, and kurtosis). We obtain news coverage data from RavenPack Analytics Dow Jones News Wire. We utilize other data: I/B/E/S (IBES) data for earnings and analyst recommendation updates; WRDS's SEC Suite for firms' 8-K filings; and Center for Research in Security Prices (CRSP) data for trading volume, number of shares outstanding, and stock prices. We use the Bloomberg terminal for institutional investor search activity (AIA) and the dates of macroeconomic announcements. A detailed description of all variables is provided in Table B.1.

\section{$2.1 \quad$ Estimating UOB}

To measure UOB, we follow the recent ambiguity literature's (Izhakian and Yermack, 2017; Augustin and Izhakian, 2020; Izhakian et al., 2021) implementation of the expected utility with uncertain probabilities (EUUP, Izhakian, 2017) framework. The primary motivation for using this framework is that it naturally delivers a risk-independent measure of ambiguity, denoted by $\mho^{2}{ }^{4}$ In particular, the degree of ambiguity is measured by the volatility of uncertain probabilities, just as the degree of risk is measured by the volatility of uncertain outcomes. Formally, the measure of ambiguity is defined as:

$$
\mho^{2}[X] \equiv \int \mathrm{E}[\varphi(x)] \operatorname{Var}[\varphi(x)] d x
$$

where $\varphi(\cdot)$ is an uncertain probability density function, and the expectation $\mathrm{E}[\cdot]$ and the variance $\operatorname{Var}[\cdot]$ are taken using the second-order probability measure $\xi$ (i.e., probabilities of probability

\footnotetext{
${ }^{4}$ In the EUUP framework, a decision-maker possesses a set of priors, equipped with second-order beliefs (i.e., probabilities of probability distributions).
} 
distributions) on a set $\mathcal{P}$ of probability measures (Izhakian, 2020).

To estimate the measure of ambiguity in Equation (1), we use intraday stock data from the TAQ database. We compute the degree of ambiguity for each stock each day. To this end, we elicit a set of priors for each stock each day. We assume that the intraday equity return distribution for each time interval during the day in a given day represents a single prior (probability distribution) in the set of priors and the number of priors in the set is assumed to depend on the number of time intrevals in the day. Each prior in the set is elicited from thirty-second observed intraday returns on the firm's equity, over a time interval of 1170 seconds during the trading hours. ${ }^{5}$ Thus, a set of priors consists of 20 realized distributions, at most, over a day. By the principle of insufficient reason (Bernoulli, 1713; de Laplace, 1814), each distribution is assigned an equal weight. The rest of the estimation of Equation (1) follows the methodology in Izhakian and Yermack (2017), Augustin and Izhakian (2020), and Izhakian et al. (2021), which for completeness is detailed in Appendix A. Since the ambiguity measure in Equation (1) captures the volatility (uncertainty) of probabilities, we use it as measure of uncertainty of beliefs, and refer the daily estimation of $\mho^{2}$ as UOB.

\subsubsection{Contrasting with other proxies of uncertainty and dispersion of investor beliefs}

The literature explored different proxies of uncertainty and dispersion of investor beliefs. ${ }^{6}$ However, UOB differs from risk and other uncertainty measures proposed in the literature, and unlike these other measures, it has several properties that make it the ideal measure to use to capture belief uncertainty. In this section, we describe these other proxies and their relation to UOB to clarify our measurement contribution. Further, in our empirical tests, we verify that our measure is not confounded by other proxies used in the literature by introducing them as controls.

First, we control for risk, as the literature shows that risk increases on days of public information arrival. For consistency, we measure the daily risk using the same thirty-second returns that are used to measure the degree of ambiguity. For each stock on each time interval, we compute the variance of thirty-second intraday returns. For each stock in each day, we then measure the degree

\footnotetext{
${ }^{5}$ Our findings are robust to the use of different time intervals, implying a different number of distributions per day.

${ }^{6}$ Antoniou, Harris, and Zhang (2015) and Anderson, Ghysels, and Juergens (2009) proxy for uncertainty (or ambiguity) by disagreement among analyst forecasts about aggregate market returns. Ulrich (2013) uses disagreement in analyst inflation forecasts as a proxy for uncertainty. Cao, Wang, and Zhang (2005), Garlappi, Uppal, and Wang (2006), and Franzoni (2017) use the volatility of mean return as a proxy for uncertainty. Faria and Correia-da Silva (2014), and Baltussen, Van Bekkum, and Van Der Grient (2018) use the volatility of return volatility as a proxy for uncertainty.
} 
of risk as the mean of these values over the day, normalized to daily terms. ${ }^{7}$ Second, we control for daily trading volume, as volume is abnormally high on days with public information. Third, we control for the effective spread estimated using intraday data to account for the degree of asymmetric information on public news days. Fourth, we control for the disagreement of analysts' forecasts $(D A F)$, which is considered to be a measure of dispersion across investors.

Besides these measures, we also control for other probability moments. Sometimes the literature takes the volatility-of-mean or the volatility-of-volatility as proxies for UOB. Note that our measure of UOB, $\mho^{2}$, is broader than volatility-of-mean and the volatility-of-volatility as it accounts for both, as well as for the volatility of all higher moments of the probability distribution (e.g., skewness and kurtosis) through the variance of probabilities. As opposed to the volatility-of-mean and the volatility-of-volatility, the measure $\mho^{2}$ is outcome and risk independent, as it does not depend upon the magnitudes of outcomes, but only upon their probabilities. Furthermore, $\mho^{2}$ solves some major issues that arise from the use of only the volatility-of-mean or the volatility-of-volatility as proxies for uncertainty. For example, two assets could have a constant mean but different degrees of UOB, or two assets could have constant volatility but different degrees of UOB. ${ }^{8}$

Given this background, for our tests, we measure the volatility-of-mean (VOM) as the variance of the time-interval average return over the day, and the volatility-of-volatility $(V O V)$ as the variance of the time-interval variance over the day. In addition, we use the thirty-second intraday returns to estimate the skewness $(S K E W)$ and kurtosis $(K U R T)$ for each stock in each day. Although $V O M$ and $V O V$ have been used in connection with dispersion of beliefs, their analysis delivers a similar conclusion to analyzing RISK. Indeed, unlike UOB, which is risk independent, the correlation between the volatility-of-mean and risk (i.e., volatility of return) is 0.71 , and the correlation between the volatility-of-volatility and risk is 0.57 , implying that these proposed proxies for uncertainty are very closely related to risk.

In our robustness tests, we also control for measures of price discovery including the intraday variance ratio and the ratio of the close-to-open and open-to-close returns to the total close-to-close return.

\footnotetext{
${ }^{7}$ For robustness, we also apply the Scholes and Williams (1977) correction for non-synchronous trading (e.g., French, Schwert, and Stambaugh, 1987). The findings are essentially the same.

${ }^{8}$ For example, the volatility-of-mean will indicate zero uncertainty, even in the case of variation in the variance. Similarly, the volatility-of-volatility will indicate zero uncertainty, even in the case of variation in the mean. In both cases UOB will be strictly positive.
} 


\subsection{Investor disagreement measures}

To measure the daily disagreement for each firm, we employ the measures constructed in Cookson and Niessner (2020), which is based on sentiment-stamped tweets posted to the investor social network StockTwits. Users self-classify individual tweets as bullish (sentiment =1) or bearish (sentiment =-1), and tweets are assigned to individual stocks by their "cashtag," which indicates the stock ticker. ${ }^{9}$ Given a set of tweets about a given firm on a trading day, the disagreement measure $(D I S)$ is the standard deviation of the underlying sentiment.

In addition, we also employ the disagreement measures of within-group disagreement $(D W G)$ and across-group disagreement $(D A G)$. These measures capture whether there tends to dispersion of opinion of investors that share the same investment philosophy $(D W G)$, or if investors of different investment philosophies tend to express different opinions about the same firm at the same time $(D A G)$. Cookson and Niessner (2020) show that $D W G$ captures disagreement that is more likely to be based on differences in information, whereas $D A G$ captures disagreement that resembled model disagreement (or differential interpretation).

\subsection{Firm specific information events}

To explore the relation between public information arrival and investor beliefs, we focus on the following two major firm-specific public information events: earnings announcements $(E A R N)$ and non-earnings 8-K filings $(F 8 K)$. A detailed description of these variables appears in Table B.1.

$E A R N$ is a dummy variable, which receives the value 1 on earnings announcement days and 0 otherwise. Following (Engelberg, Reed, and Ringgenberg, 2012), we shift announcements that occur after market close (i.e., 4pm-midnight) to the next trading day.

The following six major items cover over $96 \%$ of firm 8-K filings: Item 1.01 (entry into a material definitive agreement); Item 2.02 (results of operations and financial condition); Item 5.02 (departure/election of directors or principal officers); Item 5.07 (submission of matters to a vote of security holders); Item 7.01 (Regulation FD disclosure); and Item 8.01 (other events that are not specifically called for by Form 8-K that the firm considers to be of importance to security holders).

\footnotetext{
${ }^{9}$ The majority of tweets are self-classified by users as bullish or bearish. For unclassified tweets, Cookson and Niessner (2020) develop a maximum entropy classifier to assign the remaining messages to a sentiment of bullish or bearish. The measures we use in the paper are the same as those that are posted online here (https://www.tonycookson.com/data-and-programs), which are based on the full sample of tweets - user-classified plus entropy-classified.
} 
Since we analyze earnings announcements separately, we exclude item 2.02 from the 8-K analysis.

We construct a dummy variable for each of the items and an additional dummy variable $(F 8 K)$ that receives the value 1 on days with any of the non-earnings five items and 0 otherwise. ${ }^{10}$

\subsection{Media coverage}

To introduce firm media coverage, which directly reveals the public interest in the firm's event, we augment the set of events with media coverage. The focus in our tests is news events that carry fundamental information (Boudoukh, Feldman, Kogan, and Richardson, 2019). Therefore, we use RavenPack classifications of news events to break specific news events into categories that are informative of the nature of uncertainty of beliefs. For each firm, RavenPack provides detailed information about the articles covering the firms including a relevance score of the article mentioned the firm, the novelty of the article, and a news category (e.g., earnings news, credit rating news, labor issues news). Following the literature, we retain articles with a relevance score of 100 (i.e., the firm is the main subject of the article), and news categories that were found in prior literature as fundamental (Reed, Samadi, and Sokobin, 2018). News that occurs after the market close is shifted to the next trading day.

We construct a news dummy variable $(N E W S)$ that receives a value of 1 if there is at least one news article covering the firm on a given day across the selected categories and 0 otherwise. Similarly, we construct a set of dummy variables for the thirteen analyzed news categories. For follow-on tests, we also use other classifications RavenPack provides, including scheduled vs. nonscheduled news, news during and outside market hours, and the sign of the news.

To contrast the effect of market-level events with firm-specific events, we augment the set of firm-specific events with market-level (or systematic) events. Following Ai and Bansal (2018), we focus on the following five most important macroeconomic announcements: FOMC, Nonfarm Payroll (NFP), Producer Price Index (PPI), the advance estimate for GDP (GDP), and the ISM manufacturing index (ISM). Given the importance of FOMC announcements, we explore FOMC and non-FOMC announcements separately.

\footnotetext{
${ }^{10}$ Following Ben-Rephael, Da, Easton, and Israelsen (2022b), we keep 8-K filings with unique items. Similar to earnings announcements, we shift items that are filed after the market close (but before 5:30 pm) to the next trading day. Based on the SEC rules, filings submitted to EDGAR that after 5:30 pm are assigned the next trading day date. For example, a filing that occurs on $1 / 29 / 2016$ at 8:45 pm is assigned 2/1/2016 as the filing date.
} 


\subsection{Institutional investor attention}

To analyze the effect of investor attention, we use Ben-Rephael et al. (2017) abnormal institutional investor attention measure $(A I A)$. Bloomberg records the number of times terminal users actively search for, or read, news articles on a particular firm, and constructs a firm's attention score as follows. A score of 10 is assigned to active demand for information on a specific firm and a score of 1 for simply reading a news article. The average hourly aggregate score during the previous 8

hours is computed for each firm. An attention score of $0,1,2,3$ or 4 is assigned to each firm if its 8-hour average score is in the lowest $80 \%$ of its hourly average score over the previous 30 days, between $80 \%$ and $90 \%, 90 \%$ and $94 \%, 94 \%$ and $96 \%$, or greater than $96 \%$, respectively. The $A I A$ is a dummy variable that receives the value of 1 if this Bloomberg score is 3 or 4 , and 0 otherwise. Bloomberg's historical attention measures begin on 2/17/2010.

\subsection{Other firm controls}

Other control variables include the natural logarithm of firm size (LnSize), the natural logarithm of firm book-to-market $(\operatorname{LnBM})$, daily stock returns $(R E T)$, cumulative 21-day returns (CumRet), natural logarithm of one plus the number of analysts covering the firm ( LnNumEst), average stock turnover (AveTURNOVER), and the natural logarithm of 1 over the average stock price $\left(\ln \frac{1}{\text { AvePrc }}\right)$. In addition, we control for the rolling averages of turnover, UOB, and other uncertainty measures, estimated over trading days $t-27$ to $t-6$.

\subsection{Summary statistics}

Our sample consists of 6,820,181 daily firm observations from January 2002 to December 2018, over 4,252 trading days with 4,757 unique firms. It consists all common stocks with Share Code 10 and 11 and a daily price greater or equal to $\$ 5$ (Amihud, 2002). The measurement of UOB, for every stock and day requires a minimal number of intraday observations, as detailed in Appendix A. Prior to 2002, there are only a very small number of firms that have sufficient information required to estimate the daily UOB measure. Therefore, our sample starts in January 2002.

Table 1 reports the summary statistics of the main variables of interest. Panel A of Table 1 indicates that the average (median) firm size is 4, 279 (944) million dollars. The average (median) daily turnover is 0.015 (0.011). The average (median) number of analysts covering the firm is 8.2 
(6.7).

[ Table 1 ]

Panel B of Table 1 reports the frequency of firm-specific events, market-wide events, and various news categories (percentage of days the event occurs). As expected earnings announcements occur 4 times a year, having a frequency of $4 / 251=1.6 \%$. FOMC announcements occur around 8 times a year, having a frequency of $3.3 \%$. The frequency of day-stock observations with fundamental news is around $9.3 \%$. Thus, one out of eleven trading days contains information that is relevant to investors. Breaking this frequency across the 13 analyzed categories, earnings announcements frequency is around $2.2 \%(2.2 / 9.3=23.6 \%$ of the analyzed news topics $)$, followed by analyst rating news $(1.8 \%)$, news on products and services (1.7\%), and labor issues news (1.2\%). Out of the $9.3 \%$ news frequency, $66.7 \%(6.2 / 9.3)$ of the news occurs outside regular trading hours. $44.1 \%$ of the analyzed news are scheduled, while $55.9 \%$ are not.

Panel C of Table 1 reports the univariate correlations between UOB and a host risk and various uncertainty measures employed in the literature. Overall, these other measures exhibit a weak correlation with UOB, implying that UOB is not a proxy for one of these alternative factors. For example, the strongest magnitude univariate correlation is with RISK which has a correlation of -0.28 with UOB. Other within-day measures of risk, $V O V$ and $V O M$, also exhibit weak negative correlations to UOB, while $S K E W$ and KURT are broadly unrelated to UOB. Given the high frequency nature of our measure, a natural possibility is that UOB is affected by intraday jumps. However, UOB is only weakly correlated with the number of jumps, the absolute magnitude of the jumps, or jump intensity. Finally, UOB exhibits a weak correlation with the dispersion of analyst forecasts $(D A F)$.

Next, in Table 2, we explore how much of the variation in UOB is explained by other proxies of disagreement, uncertainty and liquidity in a regression framework. Our regression analysis shows that all variables together explain at most $10 \%$ of the variation in UOB. It also provides an important insight about the relation between UOB and VOV and VOM. In contrast to the negative relation observed in Columns 2 and 3 (and Panel C of Table 1), Column 4 reveals that once risk is controlled for, the relation between $\mathrm{UOB}$ and $V O V$ and $V O M$ becomes positive. Thus, to identify the accurate relation between the variation in UOB (variation in probability distribution) and the 
variation in the moments of distribution (variance-of-mean and variance-of-variance), one needs to control for the average level of variance (the risk). Consistent with Panel $\mathrm{C}$ of Table 1, the jump related variables have a little effect on $\mathrm{UOB}$, accounting only for $0.2 \%$ of its variation.

In column 6 onward, the regression specifications include various microstructure features: the effective spread, daily trading volume, and variables related to the high-frequency nature of UOB calculation. We include these microstructure features to examine the degree to which high frequency liquidity factors contribute to variation in UOB. In contrast to this view, we see that these liquidityrelated variables all together, only explain an additional $0.7 \%$ of the variation in UOB.

\section{[ Table 2 ]}

In the last two columns of Table 2, we employ several controls that to address concern about the possibility of a mechanical relation between trading volume and ambiguity. For example, one natural concern is that low trading volume days would feature less populated TAQ data throughout the day, either leading to fewer within-day distributions, or fewer observations per distribution. To evaluate this, columns 7 and 8 control for the number of distributions, as well as the average number of observations per distribution and the standard deviation of observations per distribution. In a similar spirit, column 8 additionally controls for the standard deviation of trading volume across the 20 sub-daily distributions. Although these coefficients are statistically significant correlates with UOB, they together only explain an additional $0.6 \%$ of the variation in UOB.

Finally, a contemporaneous paper relates the firm-day ambiguity measure to participation and trading in options markets, finding a robust negative relation between firm-day ambiguity and trading activity in options (Ben-Rephael et al., 2022a). The fact that firm-day ambiguity (UOB in this paper) bears a similar negative relation to trading activity in the options market alleviates concern about the UOB measure because the link between options trading cannot be mechanically related to the stock trading activities that generate variation in the ambiguity measure.

\section{Belief uncertainty, disagreement and trading}

In this section, we present two sets of empirical findings. First, we present evidence on how belief uncertainty relates to investor disagreement at the daily level. Next, we proceed to analyze how belief uncertainty and disagreement (belief dispersion) jointly relate to daily trading activity. 
These analyses serve to validate the daily $U O B$ measure, as well as show its importance relative to disagreement in explaining daily trading volume.

\subsection{Belief uncertainty and disagreement}

We start by considering how disagreement relates to belief uncertainty. Figure 2 presents the unconditional relationship between disagreement and UOB by presenting the average of disagreement by quintile of UOB. Consistent with the idea that greater uncertainty about beliefs leads to less strident disagreement, we observe that disagreement monotonically decreases as UOB quintile increases. Figure 2 presents this univariate sort for three disagreement measures studied in Cookson and Niessner (2020): overall disagreement, disagreement within group, and disagreement across groups. We observe a monotone and negative relationship between UOB and all three kinds of disagreement.

\section{[ Figure 2 ]}

The negative relation between disagreement and UOB does not reflect other notions of uncertainty. For example, as we present in Figure B.1, the relation between disagreement and RISK is positive, not negative as it is with UOB. Moreover, the negative relation between UOB and disagreement holds while holding constant RISK in a double sort as we present in the appendix (Figure B.2).

Next, we present a series of panel regressions to examine (1) the degree to which the negative relation between UOB and disagreement is robust to controlling for other determinants of disagreement in a panel regression with firm and date fixed effects, and (2) we evaluate the degree to which UOB predicts disagreement for multiple days going forward. Accordingly, we estimate the following regression specification:

$$
\begin{aligned}
& D I S A G R E E_{j, t+i}=\alpha_{j}+\gamma_{t}+\beta_{1} \cdot U O B_{j, t}+\beta_{2} \cdot R I S K_{j, t} \\
& +\beta_{3} \cdot T U R N O V E R_{j, t}+\delta \cdot C O N T R O L S_{j, t}+\epsilon_{j, t} .
\end{aligned}
$$

In this specification, DISAGRE $E_{j, t+i}$ is one of the three measures of disagreement employed in Cookson and Niessner (2020) - overall disagreement (DIS), disagreement within group (DWG), or disagreement across groups $(D A G)$ - measured $i$ days after the focal day $t$. The coefficient of 
interest is $\beta_{1}$, which reflects the (conditional) relationship between disagreement and UOB. All specifications include firm and day fixed effects $\left(\alpha_{j}\right.$ and $\left.\gamma_{t}\right)$, and we control for $R I S K_{j, t}, T U R N O V E R_{j, t}$ and other control variables $\left(C O N T R O L S_{j, t}\right)$ in some specifications. ${ }^{11}$ In the reported regression output, we standardize both UOB and disagreement measures to have a mean of 0 and a standard deviation of 1 to facilitate interpretation and ease relative comparison of coefficient estimates. Standard errors are double clustered by firm and date to account for possible serial correlation of the errors and common shocks.

\section{[ Table 3 ]}

Panel A of Table 3 presents estimates of Equation (2) for overall disagreement (DIS) measured at dates $t, t+1$, and $t+2$. Column 1 presents a specification that only conditions the univariate relationship between UOB and disagreement on firm and date fixed effects. Consistent with our plots of the raw data, we observe a strong negative relationship between UOB and disagreement. Specifically, a standard deviation increase in UOB (standard deviation of 42.3) is associated with a decline of 0.082 standard deviations in disagreement, and is statistically significant at the one percent level.

In columns 2 and 3, we enrich the specification by including controls for RISK, TURNOVER, and CONTROLS $S_{j, t}$, which account for other notions of uncertainty and their persistence. The estimated coefficient on UOB is stable upon the inclusion of these controls. Moreover, these control variables have the expected sign (e.g., RISK and TURNOVER have positive and significant estimated coefficients), and the inclusion of these controls increases the $R^{2}$ meaningfully from $13.9 \%$ to 18.4\%. These estimates and their stability to including the most relevant control variables suggest that the relation between UOB and DIS are unlikely to be driven by an economically meaningful omitted variable (Oster, 2019). By contrast to this coefficient stability for UOB, the coefficient on RISK is quite sensitive to the inclusion of TURNOVER as a control variable, particularly for dates $t+1$ and $t+2$.

In columns 4 through 9, we present analogous specifications for the relation between UOB and

\footnotetext{
${ }^{11}$ These controls include a wide variety of other uncertainty measures (volatility of volatility, volatility of mean, disagreement of analyst forecasts, daily realized skewness and daily realized kurtosis) and the effective spread. To account for persistence in uncertainty, we also include the averages of each uncertainty measure from days $t-27$ to $t-6$. These controls account for the idea that uncertainty and trading activity are often quite persistent at the daily level. Complete variable definitions are provided in Table B.1.
} 
disagreement, but in which disagreement is observed at date $t+1$ and $t+2$. These specifications inform how quickly UOB's relationship to disagreement dissipates. In these specifications, the relation between current UOB and future disagreement persists while dissipating relatively quickly over the next few days. Relative to the contemporaneous estimate of 0.082 , we estimate that a standard deviation increase in UOB is associated with a decrease of 0.053 and 0.032 standard deviations of disagreement at date $t+1$ and $t+2$, respectively. These estimates are also robust to the inclusion of controls for other measures of uncertainty, and their 21-day trailing averages.

Panel B of Table 3 presents analogous specifications relating UOB to disagreement within group $(D W G)$ and disagreement across groups $(D A G)$. For both measures, we estimate that UOB is negatively related to disagreement and that the strength of this relationship dissipates quickly over a few days. Consistent with Cookson and Niessner (2020)'s observation that within-group disagreement reflects mostly informational disagreement, the relationship between UOB and $D W G$ is slightly stronger than the relationship between $\mathrm{UOB}$ and $D A G$.

Overall, these findings validate the intuition that the $U O B$ measure captures uncertainty of beliefs, which reduces investor disagreement.

\subsection{Belief uncertainty and trading}

Next, we consider how belief uncertainty and disagreement jointly explain daily trading activity at the stock-day level. To do this, we estimate regression specifications of the following form:

$$
\begin{aligned}
\text { TURNOVER }_{j, t+i}= & \alpha_{j}+\gamma_{t}+\beta_{1} \cdot U O B_{j, t}+\beta_{2} \cdot D I S_{j, t} \\
& +\beta_{3} \cdot D I S_{j, t} \times U O B_{j, t}+\delta \cdot \text { CONTROL }_{j, t}+\epsilon_{j, t} .
\end{aligned}
$$

In this specification, the dependent variable is $T U R N O V E R_{j, t+i}$, which is the daily stock turnover for stock $j$ on day $t+i$. As in Equation (2), this specification includes firm and date fixed effects, as well as alternative time-varying measures of uncertainty. We also include $D I S_{j, t}$ as an explanatory variable, and in some specifications, we consider the interaction between UOB and $D I S$.

In the specifications without the interaction between UOB and DISAGREE, the coefficient of interest is $\beta_{1}$, which reflects how UOB relates to daily stock turnover while controlling for these other factors that relate to daily trading activity. In the interactive specifications, we are also interested 
in the interaction coefficient $\beta_{3}$, which captures how much the relationship of disagreement to turnover is amplified $\left(\beta_{3}>0\right)$ or dampened $\left(\beta_{3}<0\right)$ in the presence of greater belief uncertainty. To facilitate the interpretations of both main effects and the interaction coefficient, we standardize both UOB and DIS to have a mean of 0 and standard deviation of 1 , prior to interacting them in the regression model. As another benchmark for the interaction coefficient, in some specifications, we also control for the interaction of RISK with DIS. We also standardize TURNOVER in a similar manner.

\section{[ Table 4 ]}

Panel A of Table 4 presents the results from estimating Equation (3) using the overall disagreement measure $(D I S)$.

In the specifications without interactions (columns $1,2,5$ and 7 ), we estimate a negative relation between UOB and turnover, even after holding constant disagreement. A standard deviation increase in UOB is associated with a 0.063 standard deviation decline in total disagreement. This direct link between UOB and trading volume implies roughly one-third the magnitude of a standard deviation increase in disagreement (estimate on DIS is 0.183 in the same specification). Moreover, we obtain a similar estimate on the relation between UOB and turner irrespective of whether we control for other measures of uncertainty. Notably, referring to column 2, RISK has a positive sign while its inclusion does not affect the estimated coefficient on UOB. This specification in column 2 provides another instructive benchmark for our estimated UOB coefficient: a standard deviation increase in RISK is associated with 0.201 standard deviations more turnover. Viewed from this perspective, UOB exhibits a smaller, but still meaningful, estimated magnitude relative to both disagreement and risk's relation to trading.

Next, we consider including the interaction between UOB and DIS. In column 3, the estimated interaction coefficient of -0.064 implies that, for a stock with high belief uncertainty (1 standard deviation above the mean), an increase of one standard deviation in disagreement translates into 0.064 standard deviations of turnover less than if UOB were at the mean. In other words, high belief uncertainty significantly dampens the relationship between disagreement and trading. This dampening of the disagreement-trading relationship in the presence of high belief uncertainty is natural because belief uncertainty naturally reflects less confidence in one's beliefs. Moreover, the 
inclusion of the $R I S K \times D I S$ term in column 4 shows that this dampening is robust to accounting for a similar term for RISK, opposite in sign as the RISK interaction term (RISK amplifies disagreement's relation to trading), and meaningful in comparison to RISK's relationship (more than one-quarter the magnitude of the RISK interaction term).

In Panel B of Table 4, we present a similar specification in which we replace DIS with withingroup disagreement $(D W G)$ and across-group disagreement $(D A G)$. The interactive specifications include two interactions with $\mathrm{UOB}$, one for each measure, in an effort to shed light into whether the patterns we see in the overall disagreement are driven by within-group versus across-group differences of opinion. The results in Panel B highlight that most of the overall relationship between disagreement and trading volume is due to disagreement within groups, not disagreement across groups. This finding is consistent with Cookson and Niessner (2020)'s finding that informational disagreement is more tightly related to trading than model disagreement. Consistent with an informational view of the UOB measure, almost all of the interaction between UOB and disagreement in driving trading volume is due to within-group (informational) differences. This finding is consistent with the idea that variation in UOB primarily reflects the impact of information.

[ Figure 3 ]

The tabular results in Table 4 present the trading outcomes over the first couple of days. In the longer horizon, the relationship between disagreement, uncertainty of beliefs, and trading dissipates. Figure 3 presents this dynamic relationship, expressed as the impact of a standard deviation increase in disagreement on trading at different horizons from $0,1,2,3,5$, and 10 days forward.

This figure shows that the main facts from the tables extend beyond the first two days as the impact of disagreement dissipates to zero. Notably, firm-days with high UOB (1 standard deviation above the mean of UOB) exhibit a much weaker relationship between disagreement and trading as is indicated by the solid blue line, whereas low UOB (1 standard deviation below the mean of UOB) exhibits a much stronger relation between disagreement and trading as is indicated by the dashed black line. Moreover, very little trading activity is explained by across-group disagreement in comparison to (informational) within-group disagreement. 


\section{Results around firm news events}

Building on the results from the previous section that connect belief uncertainty to disagreement and trading volume, this section considers the impact of identifiable firm-specific news events on belief uncertainty. We begin the section by showing the heterogeneous response of belief uncertainty to firm news events, such as earnings announcements and 8-K disclosures. After showing this heterogeneity and evaluating several channels behind it, we connect these changes in belief uncertainty to changes in disagreement and trading around these events.

\subsection{Heterogeneity across news events}

In this section, we consider a wide variety of firm news events and evaluate their heterogeneous impact on belief uncertainty. Specifically, we consider the impact of earnings announcements, firm 8-K disclosures of different types, and fundamental news coverage of different types. We adopt an event window approach toward evaluating the impact of the firm news event on belief uncertainty.

Throughout this section, we report estimates from specifications of the following form:

$$
U O B_{j, t+i}=\alpha_{j}+\gamma_{t}+\beta_{i} \cdot E V E N T_{j, t}+\gamma \cdot C O N T R O L S_{j, t}+\epsilon_{j, t}
$$

where the dependent variable is $\mathrm{UOB}$ for firm $j$ on trading date $t+i$, where $i$ denotes the lead (or lag) relative to the event date. This specification denotes an event $\left(E V E N T_{j, t}\right)$ that occurs on trading date $t$ for firm $j$. Based on varying $i$ from -5 to +20 , we present the estimated $\beta_{i}$ coefficients versus the lead (lag) to convey the dynamics of how UOB evolves around the event. The specification accounts for firm and date fixed effects $\left(\alpha_{j}\right.$ and $\left.\gamma_{t}\right)$, and includes controls for a wide variety of uncertainty proxies in addition to their 21-day trailing averages as in Equation (2). ${ }^{12}$

\subsubsection{Earnings news versus 8-K disclosures}

In this section, we contrast how belief uncertainty evolves around earnings announcements versus firm 8-K disclosures.

Separately for earnings announcements and firm 8-K events, we estimate the event specification in Equation (4). Table 5 presents the estimated $\beta_{i}$ coefficients for lags $i \in\{-1,0,1,2,3,5\}$ relative

\footnotetext{
${ }^{12}$ In these specifications, we also include controls for the log of firm size ( $\left.L n S i z e\right), \log$ book-to-market ratio $(L n B M)$, cumulative stock returns (CumRet), log one plus the number of analysts estimates (LnNumEst), institutional holdings (InstHold), average turnover from day $t-27$ to $t-6$ (AveTURNOVER), log one over average price $\left(\ln \frac{1}{\text { AvePrc }}\right)$, return $(R E T)$, and stock turnover (TURNOVER), which are commonly controlled in analyses of earnings announcements.
} 
to the earnings announcement date (Panel A) or the firm 8-K disclosure date (Panel B). Figure 4 presents the estimates and $95 \%$ confidence intervals for each of the $\beta_{i}$ coefficients in the wider window from $i=-5$ to $i=+20$.

\section{[ Table 5 ]}

In Panel A of Table 5, we see that UOB declines significantly around firm earnings announcements. Relative to its baseline level, we estimate that UOB is 0.199 standard deviations lower on the earnings announcement date (date $t$ ). One day prior to the earnings announcement, there is a somewhat smaller decline in UOB relative to the baseline, which indicates some anticipation or leakage of information prior to the announcement date. On the days following the earnings announcement, UOB returns to a normal level quickly and completely, exhibiting a normal level of UOB by date $t+5$. Panel A of Figure 4 portays this same narrative, but over a longer event window.

[ Figure 4 ]

As we see in Panel B of Table 5, the dynamics of UOB around firm 8-K disclosures are quite different than earnings announcements. Although we observe a significant dip in UOB on the 8-K disclosure day, our estimated $\beta_{i}$ coefficients for subsequent dates are positive and significant, reflecting a persistent increase in belief uncertainty in the event window. As we portray in the wider event window in Panel B of Figure 4, this increase in UOB remains significant until at least date $t+10$, and the estimate is positive (though moderately statistically insignificant) at date $t+20$.

In Table B.9 in the appendix, we perform a similar analysis of the dynamics of $R I S K, V O V$, and $V O M$ around earnings announcement days. These results provide a useful contrast with our main analysis of the dyanmics of UOB. For example, RISK is greater on the earnings announcement day (and the day prior to the earnings announcement), but then is persistently lower in the post earnings announcement period. $V O V$ and $V O M$ follow a similar pattern. These results qualitatively differ from the sharp decline for UOB, followed by a quick recovery to normal levels, consistent with the broad theme that UOB is distinct from risk.

This contrasting pattern for how belief uncertainty evolves around earnings announcements versus firm 8-K disclosures highlights the fact that different corporate events contain qualitatively 
different information. For instance, our estimates convey that earnings announcements contain mostly clarifying information, which reduces belief uncertainty. By contrast, firm 8-K disclosures often contain voluntary or opaque information that increases belief uncertainty. As our earlier results show that belief uncertainty shapes disagreement and trading outcomes, these differences across events imply important changes to disagreement and trading around the arrival of public information.

\subsubsection{Heterogeneity across earnings announcements}

To help understanding the broad differences between the UOB patterns around earnings announcements versus 8 -K disclosures, we now turn to examining heterogeneity within each news type.

In this section, we analyze an aspect of earnings disclosures that shapes the precision of investor belief updates. Namely, we analyze the degree to which firm earnings guidance shapes the UOB reaction to the earnings announcement itself. To this end, we introduce an indicator variable $E G$ that equals one if the firm issued earnings guidance in the 90 days up to and including the earnings announcement, and otherwise zero. Then, we interact this indicator with the $E A R N$ event in a specification as in Equation (4).

Panel A of Table 6 presents the estimates from this extended specification. On average, we observe that issuing earnings guidance tends to relate to a larger reduction in UOB around earnings announcements, significantly reducing UOB on the earnings day but with large and statistically insignificant coefficients for other days. On the earnings announcement day itself, having issued earnings guidance is associated with a more than doubling $(-0.365$ versus -0.143$)$ of the reduction in UOB.

Panel B of Table 6 delves deeper into this underlying relationship. Notably, some earnings guidance offer a narrow range of earnings, whereas other earnings guidance disclosures give analysts a wider range of earnings to consider. In Panel $\mathrm{B}$, we therefore split the $E G$ indicator into two: one for high dispersion earnings guidance and the other for low dispersion earnings guidance. This split delivers further evidence that precise earnings guidance, in particular, reduces UOB around the earnings announcement. On the day of the earnings announcement, we observe that low $E G$ dispersion events see $-0.142-0.362=-0.504$ lower UOB, whereas events without earnings guidance see only a reduction of -0.142 . By contrast, high dispersion earnings guidance is associated with 
only a reduction of -0.062 , which is not statistically different from zero. ${ }^{13}$

[ Table 6 ]

\subsubsection{Heterogeneity within 8-K disclosures}

Although the contrast between earnings news events and 8-K disclosures is instructive, it is natural to interpret differential reaction of UOB to these events as a difference in the amount of the information, not just its nature. Consistent with this idea, the magnitude of the reaction to earnings announcements (around a 0.2 standard deviation decline in UOB) is much greater than the reaction to 8-K filings (around 0.01 a standard deviation increase in UOB).

To shed light into the heterogeneous response to firm-level news events while focusing on similar amounts of information disclosed, we next consider the heterogeneous reaction of UOB to different kinds of 8-K disclosures. For example, a firm files an 8-K under Item 7.01 when it comes into possession material, nonpublic information that is relevant to shareholders. In this respect Item 7.01 disclosures are like earnings announcements in their content, but do not adhere to a quarterly schedule. By contrast, firms must also file an $8-\mathrm{K}$ when it makes a material definitive agreement that can change a firm's operations (Item 1.01), or when the firm makes a voluntary disclosure (Item 8.01). From the standpoint of investors, these disclosures are information that admits a wider scope of possibilities than mere earnings information.

For these different 8-K firm disclosures, we repeat the analysis of the prior section by estimating the lead-lag specification in Equation (4). For each sub-event, Table 7 presents the estimated $\beta_{i}$ coefficients for lags $i \in\{-1,0,1,2,3,5\}$. Figure 4 presents the estimates and $95 \%$ confidence intervals for each of the $\beta_{i}$ coefficients in the wider window from $i=-5$ to $i=+20$.

\section{[ Table 7 ]}

In Panel A of Table 7, we see that UOB declines significantly around Regulation FD disclosures, similar to earnings announcements. However, relative to earnings announcements, UOB reverts to its baseline level more quickly, by date $t+1$. Panel A of Figure 5 displays the evolution of UOB around Regulation FD disclosures for a wider event window. Consistent with earnings information

\footnotetext{
${ }^{13}$ To construct the estimates for low versus high $E G$ dispersion, add the coefficient estimate from the interaction to the main effect. The $\mathrm{F}$ test that the main effect plus the $E G$ interaction equals zero delivers a $p$-value of 0.437 .
} 
that is clarifying for investors, Regulation FD disclosures reduce UOB upon the announcement, while quickly reverting to zero change from before.

\section{[ Figure 5 ]}

By contrast, when we examine 8-K disclosures that are material changes in firm operations or voluntary disclosures, UOB increases persistently after the release of the information. Panel B (of both Table 7 and Figure 5) reports the coefficient estimates in the event window around the disclosures of material changes in firm operations via Item 1.01 disclosures. These increases are persistent over the whole event window, and confirm the intuition that the information in these disclosures takes longer to incorporate into prices. We see a similar pattern, with slightly larger magnitudes, for voluntary disclosures detailed in Item 8.01 disclosures. ${ }^{14}$

Overall, the evidence in this section shows that there is important heterogeneity within different kinds of 8-K firm disclosures. As in the comparison to earnings announcements, 8-K disclosures that are more clarifying (Regulation FD disclosures) tend to reduce belief uncertainty. However, disclosures that connote material changes to operations or disclosures that are voluntary tend to increase belief uncertainty persistently for up to 20 days after the disclosure event.

\subsubsection{Heterogeneity across media news events}

Next, we consider heterogeneity in the response of belief uncertainty to a broader class of firm news events - those drawn from traditional media coverage. Specifically, we refine the news classification into categories using media coverage captured by RavenPack's news category classification.

Our objective is similar to the previous section on 8-K filings: we aim to highlight the heterogeneous response of belief uncertainty to firm news events, and in so doing, provide insight into why belief uncertainty responds differently to different firm news events. To do this, we consider four categories of fundamental news: (1) all fundamental news events, (2) earnings news events, (3) M\&A target firm news events, and (4) credit watch news events.

Connecting to earlier results, we expect earnings news to be similar to the earnings announcement events in Section 4.1.1. By contrast, credit watch and target firm events are more likely to

\footnotetext{
${ }^{14}$ In the appendix Figure B.3, we report analogous coefficient estimates for other 8-K categories that neither increase nor decrease belief uncertainty. These Item 5.02 and Item 5.07 disclosures have less informational impact than the ones reported in the main text.
} 
open up possibilities that investors had not fully considered prior to the arrival of news, thereby raising investor belief uncertainty.

Focusing on these RavenPack news events, we perform an analogous exercise to that in the prior sections, estimating the lead-lag specification in Equation (4). To conserve space, we do not report the estimates in tabular form, but present the estimated $\beta_{i}$ and $95 \%$ confidence intervals at each lag in the wider window from $i=-5$ to $i=+20$. Figure 6 reports these estimates in four panels (one for each type of news event).

\section{[ Figure 6 ]}

Panel A presents the event window changes in UOB around all fundamental news events as classified by RavenPack. Like earnings news, fundamental news events, on average, exhibit a dip downward in UOB, which indicates that fundamental news provides information that clarifies and reduces the belief uncertainty of investors.

The remaining panels of Figure 6 consider useful subsets of fundamental events. Mirroring our previous evidence on UOB around earnings announcements, Panel B presents the analogous plot for earnings news events covered in RavenPack. Using on this measure from news coverage, earnings news is clarifying information that reduces belief uncertainty of investors, confirming our event-level analysis in Section 4.1.1.

By contrast to these two categories of clarifying news, news that a firm is the target of an acquisition tends to increase UOB. Panel $\mathrm{C}$ presents the event window evidence around these target firm events. We estimate a distinct increase in UOB around the announcement that a firm is a target in an acquisition. The finding that UOB increases around these events is sensible, given literature on merger announcements, withdrawals, and the uncertainty surrounding the. ${ }^{15}$ The announcement that a firm is targeted in a merger raises many long-term prospects that shareholders did not consider before. Beyond successful acquisitions, the announcement of a merger is followed by an uncertain interim period during which the terms of the merger could be adjusted, or the merger could even be withdrawn. These expanded possibilities

Similar to the announcement of merger targets, the announcement of a credit watch about a firm is also associated with an increased UOB in the subsequent twenty trading days. Firm credit

\footnotetext{
${ }^{15}$ Herron and Izhakian (2019) find that firms with high uncertainty of probabilities (ambiguity) seek to acquire firms with low ambiguity and after the announcement the acquirer ambiguity declines but the target ambiguity inclines.
} 
conditions affect the cost of capital and the firm's debt capacity, thereby increasing the levels of UOB. They also present a form of tension between different stakeholders at the firm; in particular, between debt holders and equity holders. Naturally, such a tension increases UOB, as does the possibility that credit ratings could deteriorate in the near future.

Overall, these findings highlight the substantial heterogeneity in the response of UOB to firm news events. Irrespective of whether we base our conclusions on filings-based measures (e.g., earnings announcements or $8-\mathrm{Ks}$ ) or news-based measures, we find a common theme to our results: Opaque news events tend to increase UOB, whereas clarifying news events like earnings announcements tend to increase it.

\subsection{Belief uncertainty, disagreement and trading around notable news events}

In the prior section, we saw substantial heterogeneity in the impact of news arrival on belief uncertainty. Clarifying news events reduce belief uncertainty, whereas opaque news and voluntary disclosures increase it. Given these findings, belief uncertainty provides useful insight into how disagreement and trading evolve around the arrival of news. For example, consider earnings announcements, which abruptly and significantly reduce belief uncertainty. Taking the results from Section 3 at face value, this decline in belief uncertainty predicts more disagreement and more trading, as well as a strengthening in the relationship between disagreement and trading.

This offers a novel explanation for high trading volume and disagreement around earnings announcements, which contrasts with classic explanations for why disagreement and trading increase around the arrival of news. For example, the existing literature focuses on explanations of disagreement and trading based on differential interpretation of public information or gradual percolation of the information through the set of investors (e.g., see Kandel and Pearson (1995) and Hong and Stein (1999)). By contrast, the rise in disagreement and trading in our setting is due to the arrival of clarifying information, which strengthens disagreement because it reduces belief uncertainty. According to this view, trading increases both because disagreement increases and because belief uncertainty decreases.

To close the empirical loop on this argument, we re-estimate the specifications for disagreement and turnover as a function of $\mathrm{UOB}$, but now, we restrict to earnings announcement days and 8-K disclosure days. Our aim is to understand if UOB has similar impacts on disagreement and trading 
around these news events.

First, consider the relation to UOB and disagreement around earnings and 8-K disclosure days. Panel A of Table 8 reports the results from estimating Equation (2) for disagreement measured as of date $t$. When we examine the coefficient estimate across specifications, we see that $U O B$ has a robustly negative relationship to $D I S$, irrespective of whether the event is an earnings announcement or an 8-K disclosure. The magnitude of the relation between UOB and DIS is somewhat stronger for 8-K disclosure days, but for either news event, the inclusion of control variables does not affect the estimated magnitudes in a meaningful way.

\section{[ Table 8 ]}

Next, we consider how UOB and DIS jointly explain stock turnover around earnings announcements and 8-K disclosures. Panel $\mathrm{B}$ of Table 8 estimates the specification in (3) to consider this joint relationship to trading. For both categories of events, the results align perfectly with what we observed in the broad sample: 1) greater belief uncertainty is negatively related to trading, 2) greater disagreement is positively related to trading activity, and 3) in the presence of high belief uncertainty, the impact of disagreement on trading is dampened. In either case, belief uncertainty explains a significant amount of trading relative to investor disagreement, with the main effect for belief uncertainty equal to one-quarter to one-half of the disagreement coefficient, and the interactive effect equal to one-third to one-half of the disagreement coefficient.

In Figure B.4, we plot how disagreement evolves in an event window around earnings announcements versus firm 8-K filings. This evidence is consistent with the heterogeneity in patterns from UOB translating into similar (but opposing in sign) changes to disagreement around firm news events. Notably, we see a spike in disagreement around the earnings announcement day that dissipates quickly over time. We also see that - after an initial spike in disagreement around the 8-K disclosure date - disagreement in the period after the 8 - $\mathrm{K}$ disclosure is persistently lower while slowly converging to a normal level.

Wrapping up, we note that the heterogeneous response of UOB to the arrival of news not only provides a novel explanation for the evolution of disagreement and trading around public news arrival, but it also provides predictions for how disagreement and trading respond based on the nature of the news: Clearer news revelations ought to generate more trading and disagreement, 
while opaque news and voluntary disclosures generate less.

\section{$5 \quad$ Extensions and robustness tests}

We conduct five additional analyses: the interaction with institutional attention, cross-sectional firm size; news release timing; subperiod analysis; and additional robustness tests. To converse space, we briefly discuss the findings and report part of the analysis in the Online Appendix.

\subsection{Institutional attention}

New information arrival does not guarantee that investors pay attention and reflect information into prices (Hirshleifer, Lim, and Teoh, 2009; DellaVigna and Pollet, 2009). Exploring the effect of institutional investor attention, Ben-Rephael et al. (2017) find that institutional investors search (i.e., actively demanding information), measured by $A I A$, has important implications for incorporating information into stock prices.

Through the lens of gradual information diffusion, the effect of information arrival on UOB should be stronger when investors are paying attention. In particular, the effect of $N E W S$ should be stronger when interacted with $A I A$, since an abnormal search by institutional investors can identify news that is more salient about the firm. In addition, $A I A$ should have a direct effect on UOB, since information processing and learning by institutional investors may alter their beliefs and their uncertainty bout these beliefs. To test these conjectures, we use the regression specification that takes the following form:

$$
\begin{aligned}
U O B_{j, t+i}= & \alpha_{j}+\gamma_{t}+\beta_{1} \cdot N E W S_{j, t}+\beta_{2} \cdot A I A_{j, t}+\beta_{3} \cdot N E W S \times A I A_{j, t}+ \\
& \gamma \cdot \operatorname{CONTROLS}_{j, t}+\epsilon_{j, t}
\end{aligned}
$$

where $i=-5, \ldots, 20 ; t$ identifies the trading day; $j$ identifies the firm; $N E W S$ is the news coverage dummy; $A I A$ is a dummy variable that captures abnormal search by institutional investors; $C O N$ TROLS is the set of controls variables used in Equation (4); $\alpha_{j}$ is firm fixed effects; and $\gamma_{t}$ is date fixed effects.

Table 9 reports the findings of the regression test in Equation (5). The findings are consistent with our conjectures and the literature on limited investor attention, indicating that institutional search of information has a substantial negative relation with UOB. The direct association of $A I A$ with UOB is a reduction in UOB over the subsequent twenty trading days, with about $21.7 \%$ 
reduction relative to the sample mean on trading day $t$ and $3.5 \%$ reduction on trading day $t+20$. The interaction of $A I A$ with $N E W S$ indicates that, on trading day $t$, the direct association between $N E W S$ with $A I A$ and UOB is more than 4 time stronger than that of $N E W S$ alone (a coefficient estimate of -8.13 relative to a coefficient of -1.84 ). Although we cannot show causality without clear identification, our findings are consistent with the literature on investor attention and gradual information diffusion. They show that when investors are paying attention, the effect of information arrival on beliefs is stronger, consistent with quicker incorporation of information into beliefs.

\section{[ Table 9 ]}

\subsection{Cross-sectional firm size}

We repeat the analysis conducted in Table 5 based on firm size (i.e., market cap). Firm size is a good proxy for the information environment (Cohen and Lou, 2012), and may reflect on the relation between information arrival and UOB. To explore this conjecture, we re-estimate the event specification for the set of earnings announcements in a specification like Equation (4), but we additionally interact lead-lag indicator variable with dummy variables for the size tercile (SMALL, MEDIUM, LARGE)

Table 10 reports the findings from estimating this specification. To infer the economic significance of $E A R N$ on UOB, we look at the reduction in UOB relative to the relevant UOB's tercile average. The averages UOB of subsamples SMALL, MEDIUM, and LARGE are 35.3, 54.05, and 98.87 respectively. ${ }^{16}$ The findings indicate that the negative relation between $E A R N$ and UOB is driven by large firms (MEDIUM and LARGE). In particular, $E A R N$ is associated with about $13.4 \%$ and $47 \%$ reduction in UOB relative to the sub-sample mean, respectively. In contrast, we find that for small firms (SMALL), EARN is associated with an increase of $14 \%$ in UOB.

These findings are consistent with the fact that larger firms have greater analyst and media coverage, which facilitates the dissemination of firm information to market participants. As a result of this greater information processing, investors have lower uncertainty in beliefs, since investors can learn more about the firm. In contrast, for smaller firms information arrival seem to increase investor belief uncertainty. These findings are consistent with larger firms resolving more uncertainty about

\footnotetext{
${ }^{16}$ Larger firms have a higher level of UOB than smaller firms, since larger firms are more complex, affecting investors' ability to asset information (?). Moreover, there is higher uncertainty about the growth path of mature firms.
} 
earnings (Patton and Verardo, 2012; Savor and Wilson, 2016). The stark differences between large and small firms may shed light on the mixed results found in the literature regarding convergence of beliefs. Our findings suggest that information environment, captured by firm size, is an important determinant of beliefs adjustment.

\section{[ Table 10 ]}

\subsection{Trading volume and volatility around earning announcement days}

The positive relation between trading volume and volatility is well documented (Karpoff, 1987; Gallant, Rossi, and Tauchen, 1992). Given it importance, we explore whether this relation is subject to UOB around earnings announcement days, where the correlation between trading volume and volatility is heightened. ${ }^{17}$ To this end, we estimate the daily correlation between volatility and trading volume using thirty second return, based on 20 intraday time intervals.

We regress $C O R R(T R D V O L, V A R)$ on UOB and its interaction with firm event dummies. The regression specification takes the following form:

$$
\operatorname{CORR}(T R D V O L, V A R)_{j, t+i}=\alpha_{j}+\gamma_{t}+\beta_{1} \cdot U O B_{j, t}+\delta \cdot C O N T R O L S_{j, t} \epsilon_{j, t}
$$

where $i=0, \ldots, 5 ; t$ identifies the earnings announcement day; $j$ identifies the firms; CONTROLS is the set of controls variables used in Equation $(4) ; \alpha_{j}$ is firm fixed effects; and $\gamma_{t}$ is date fixed effects.

Table B.4 reports the findings of the regression test in Equation (6). Consistent with previous literature, there is a positive and significant increase in the correlation between trading volume and volatility on earnings announcements days (Karpoff, 1987; Gallant et al., 1992). Strikingly, this well documented relation depends on the level of UOB, where the effect lasts up to day $t+2$. Overall, these findings suggest that belief uncertainty may be an important driver of the relation between volatility and trading volume.

\subsection{Market-wide information and firm-level belief uncertainty}

Having established the relation between firm-level public information arrival and UOB, it is natural to expect that belief uncertainty should relate to the disclosure of market-wide news as well. We estimate the relation between market-wide information (macroeconomic announcements) arrival and

\footnotetext{
${ }^{17}$ We thank Snehal Banerjee for this suggestion.
} 
firm-level UOB, with a focus on major macroeconomic announcements. This could be an important mechanism driving co-variation in $U O B$ across firms because investors naturally incorporate relevant market-wide information into their stock valuation. For example, Peng and Xiong (2006) argue that limited investor attention leads to category-learning behavior, where investors tend to process more market- and sector-wide information than firm-specific information.

To explore the relation between market-wide information and firm-specific UOB, we apply panel regressions from day $t$ to $t+3$, similar to Equation (4). However, we cannot include macroeconomic announcements together with date fixed effects. Therefore, to control for effects that are driven by the day of the week (DellaVigna and Pollet, 2009), we replace the date fixed effects with the day-of-the-week fixed effects. The regression specification takes the following form:

$$
U O B_{j, t+i}=\alpha_{j}+\gamma_{d o w}+\beta_{1} \cdot M A C R O_{t}+\gamma \cdot C O N T R O L S_{j, t}+\epsilon_{j, t}
$$

where $i=0, \ldots, 3 ; t$ identifies the trading day; $j$ identifies the firm; $M A C R O_{t}$ refers to either FOMC announcements, or non-FOMC announcements; CONTROLS is the set of controls variables used in Equation (4); $\alpha_{j}$ is firm fixed effects; and $\gamma_{\text {dow }}$ is day-of-the-week fixed effects.

Table B.5 reports the findings of the regression test in Equation (7). For brevity, control variables are not reported. Consistent with our firm-level news events, we find that macroeconomic announcements are associated with a reduction in UOB, revealing that investors also learn about firms' UOB from these announcements. In particular, on trading day- $t F O M C$ announcements are associated with a reduction in $\mathrm{UOB}$ of $11.5 \%$ relative to the sample mean, which is about $1 / 3$ the effect of earnings announcements. Consistent with the literature (e.g., Savor and Wilson, 2013), the relation between FOMC announcements and UOB is stronger than that of other MACRO_OTHER. The effect of MACRO_OTHER on UOB is about $1 / 5$ the effect of earnings announcements. Overall, the findings show that systematic information events also matter at the firm level and result in a reduction in UOB.

\subsection{News release timing}

In this section, we evaluate whether the timing of news release - during versus after trading hours - matters for how belief uncertainty. We expect the disclosures of news after hours to affect $U O B$ more strongly than than news released during trading hours. To the extent that there is strategic disclosure of bad news events after hours, we might also expect that these disclosures contain 
more information. Even in terms of timing within the day, there are reasons to expect after hours disclosures to have a bigger impact. ${ }^{18}$ To explore this idea, we split the news based on news that released before the market the opens (BMO, from after market close on $t-1$ to pre-open on trading day $t$ ) and news that released during regular trading hours (DHM).

Table B.6 reports the findings. Consistent with our conjecture, news released before market open have a stronger effect on UOB relative to news released during market hours. For example, trading day $t$ response is $80 \%$ stronger for $E A R N$ if the news is released before the market opens.

\section{Conclusion}

Using a novel measure to investors' uncertainty of beliefs (UOB), we provide empirical evidence on a new channel through which new information arrival affects disagreement and trading. This belief uncertainty measure is distinct from risk and other uncertainty measures, as it measures variations in probabilities distinct from variations in outcomes. Thereby, it allows a direct exploration of the implications of new information arrival for investor beliefs.

Far from being a sideshow, we find that belief uncertainty has a first order impact on disagreement and trading outcomes. In the presence of greater belief uncertainty, investors disagree less with one another and less likely to trade. We also find that belief uncertainty has meaningful impacts on trading in the presence of disagreement: the relationship between investor disagreement and trading is three times as strong if belief uncertainty is low than if belief uncertainty is high.

Digging deeper, this measure of belief uncertainty sheds novel light on the information content of firm-specific news events. There is substantial heterogeneity in how belief uncertainty responds to the arrival of firm-specific news, and this heterogeneity reflects the degree to which the information is clarifying versus opaque. For example, we see that the arrival of news leads belief uncertainty to increase for unscheduled events, opaque news, and voluntary disclosures. By contrast, clarifying events like scheduled earnings announcements lead belief uncertainty to decline. Because belief uncertainty exhibits a tight link to disagreement and trading outcomes, our findings provide a novel rationale for why different events exhibit disparate trading and disagreement outcomes.

\footnotetext{
${ }^{18}$ The timing of the news release is important for two main reasons. First, if news is released toward the end of the trading day, it may create an error in measurement affecting our conclusions. Second, an important aspect of attention and information processing is the ability to process information in a timely manner. Some news is released before the market opens and some during market hours. One would expect a stronger reaction to news released before the market opens relative to news that is released during trading hours.
} 
Our paper directly contributes to the literature on investor disagreement. It reveals that different types of news events may have different implications for convergence of beliefs. Some news events result in divergence of beliefs (higher disagreement), while some other news events results in convergence in beliefs (lower disagreement). This paper introduces an important link between information arrival and disagreement, which depends on investors' uncertainty of beliefs. It paves the way for further empirical research of the implication of uncertainty of beliefs (ambiguity) for financial decision made by individuals and by groups. It also motivates future theoretical research of learning and decision processes in financial markets in response to information arrival. 


\section{References}

Ai, H., Bansal, R., 2018. Risk preferences and the macroeconomic announcement premium. Econometrica $86,1383-1430$.

Amihud, Y., 2002. Illiquidity and stock returns: cross-section and time-series effects. Journal of Financial Markets 5, 31-56.

Anderson, E. W., Ghysels, E., Juergens, J. L., 2009. The impact of risk and uncertainty on expected returns. Journal of Financial Economics 94, 233-263.

Antoniou, C., Harris, R. D., Zhang, R., 2015. Ambiguity aversion and stock market participation: An empirical analysis. Journal of Banking \& Finance 58, 57-70.

Augustin, P., Izhakian, Y., 2020. Ambiguity, volatility, and credit risk. The Review of Financial Studies 33, $1618-1672$

Baltussen, G., Van Bekkum, S., Van Der Grient, B., 2018. Unknown unknowns: uncertainty about risk and stock returns. Journal of Financial and Quantitative Analysis 53, 1615-1651.

Banerjee, S., Kremer, I., 2010. Disagreement and learning: Dynamic patterns of trade. The Journal of Finance 65, 1269-1302.

Barberis, N., Shleifer, A., Vishny, R., 1998. A model of investor sentiment. Journal of financial economics 49, 307-343.

Bayes, T., Price, R., Canton, J., 1763. An essay towards solving a problem in the doctrine of chances. C. Davis, Printer to the Royal Society of London London, U. K.

Ben-David, I., Fermand, E., Kuhnen, C. M., Li, G., 2018. Expectations uncertainty and household economic behavior. Tech. rep., National Bureau of Economic Research.

Ben-Rephael, A., Cookson, J. A., Izhakian, Y., 2022a. Trading, ambiguity and information in the options market. SSRN eLibrary 4180712.

Ben-Rephael, A., Da, Z., Easton, P. D., Israelsen, R. D., 2022b. Who pays attention to sec form 8-k? The Accounting Review, forthcoming .

Ben-Rephael, A., Da, Z., Israelsen, R. D., 2017. It depends on where you search: Institutional investor attention and underreaction to news. The Review of Financial Studies 30, 3009-3047.

Bernoulli, J., 1713. Ars Conjectandi (The Art of Conjecturing).

Boehmer, E., Jones, C. M., Zhang, X., Zhang, X., 2021. Tracking retail investor activity. The Journal of Finance 76, 2249-2305.

Boudoukh, J., Feldman, R., Kogan, S., Richardson, M., 2019. Information, trading, and volatility: Evidence from firm-specific news. The Review of Financial Studies 32, 992-1033.

Brenner, M., Izhakian, Y., 2018. Asset prices and ambiguity: Empirical evidence. Journal of Financial Economics 130, 503-531.

Cao, H. H., Wang, T., Zhang, H. H., 2005. Model uncertainty, limited market participation, and asset prices. The Review of Financial Studies 18, 1219-1251.

Carlin, B. I., Longstaff, F. A., Matoba, K., 2014. Disagreement and asset prices. Journal of Financial Economics 114, 226-238.

Charles, C., Frydman, C., Kilic, M., 2021. Insensitive investors. Available at SSRN .

Cohen, L., Lou, D., 2012. Complicated firms. Journal of financial economics 104, 383-400.

Cookson, J. A., Engelberg, J., Mullins, W., 2022. Echo chambers. Review of Financial Studies, Forthcoming

Cookson, J. A., Engelberg, J. E., Mullins, W., 2020. Does partisanship shape investor beliefs? evidence from the covid-19 pandemic. The Review of Asset Pricing Studies 10, 863-893.

Cookson, J. A., Fos, V., Niessner, M., 2021. Does disagreement facilitate informed trading? Evidence from Activist Investors (April 12, 2021). 
Cookson, J. A., Niessner, M., 2020. Why don't we agree? evidence from a social network of investors. The Journal of Finance $75,173-228$.

Daniel, K., Hirshleifer, D., Subrahmanyam, A., 1998. Investor psychology and security market under-and overreactions. the Journal of Finance 53, 1839-1885.

de Laplace, P. S., 1814. Théorie analytique des probabilitiés.

DellaVigna, S., Pollet, J. M., 2009. Investor inattention and friday earnings announcements. The Journal of Finance 64, 709-749.

Dessaint, O., Foucault, T., Frésard, L., 2021. Does alternative data improve financial forecasting? the horizon effect .

Diether, K. B., Malloy, C. J., Scherbina, A., 2002. Differences of opinion and the cross section of stock returns. The Journal of Finance 57, 2113-2141.

Engelberg, J. E., Reed, A. V., Ringgenberg, M. C., 2012. How are shorts informed?: Short sellers, news, and information processing. Journal of Financial Economics 105, 260-278.

Epstein, L. G., Schneider, M., 2007. Learning under ambiguity. The Review of Economic Studies 74, 12751303.

Faria, G., Correia-da Silva, J., 2014. A closed-form solution for options with ambiguity about stochastic volatility. Review of Derivatives Research 17, 125-159.

Fedyk, A., 2021. Disagreement after news: Gradual information diffusion or differences of opinion? The Review of Asset Pricing Studies 11, 465-501.

Franzoni, L. A., 2017. Liability law under scientific uncertainty. American Law and Economics Review 19, $327-360$.

French, K. R., Schwert, G. W., Stambaugh, R. F., 1987. Expected stock returns and volatility. Journal of Financial Economics 19, 3-29.

Gallant, A. R., Rossi, P. E., Tauchen, G., 1992. Stock prices and volume. The Review of Financial Studies $5,199-242$.

Garlappi, L., Giammarino, R., Lazrak, A., 2017. Ambiguity and the corporation: Group disagreement and underinvestment. Journal of Financial Economics 125, 417-433.

Garlappi, L., Uppal, R., Wang, T., 2006. Portfolio selection with parameter and model uncertainty: A multi-prior approach. The Review of Financial Studies 20, 41-81.

Giglio, S., Maggiori, M., Stroebel, J., Utkus, S., 2021. Five facts about beliefs and portfolios. American Economic Review 111, 1481-1522.

Gilboa, I., Schmeidler, D., 1989. Maxmin expected utility with non-unique prior. Journal of Mathematical Economics 18, 141-153.

Harris, M., Raviv, A., 1993. Differences of opinion make a horse race. The Review of Financial Studies 6 , 473-506.

He, H., Wang, J., 1995. Differential information and dynamic behavior of stock trading volume. The Review of Financial Studies 8, 919-972.

Herron, R., Izhakian, Y., 2019. Mergers and ambiguity: The role of ambiguity. SSRN eLibrary 3100611.

Hirshleifer, D., Lim, S. S., Teoh, S. H., 2009. Driven to distraction: Extraneous events and underreaction to earnings news. The Journal of Finance 64, 2289-2325.

Hong, H., Stein, J. C., 1999. A unified theory of underreaction, momentum trading, and overreaction in asset markets. The Journal of finance 54, 2143-2184.

Hong, H., Stein, J. C., 2007. Disagreement and the stock market. Journal of Economic perspectives 21, 109-128.

Izhakian, Y., 2017. Expected utility with uncertain probabilities theory. Journal of Mathematical Economics 69, 91-103. 
Izhakian, Y., 2020. A theoretical foundation of ambiguity measurement. Journal of Economic Theory 187, 105001.

Izhakian, Y., Yermack, D., 2017. Risk, ambiguity, and the exercise of employee stock options. Journal of Financial Economics 124, 65-85.

Izhakian, Y., Yermack, D., Zender, J., 2021. Ambiguity and the trade off theory of capital structure. Management Science 68, 1526-5501.

Izhakian, Y. Y., Izhakian, Z., 2020. A continuous-time, forward-looking, implied ambiguity index. Zur, A Continuous-Time, Forward-Looking, Implied Ambiguity Index (May 17, 2020) .

Jaynes, E. T., 1957. Information theory and statistical mechanics. Physical review 106, 620.

Jegadeesh, N., Kim, W., 2009. Do analysts herd? an analysis of recommendations and market reactions. The Review of Financial Studies 23, 901-937.

Kandel, E., Pearson, N. D., 1995. Differential interpretation of public signals and trade in speculative markets. Journal of Political Economy 103, 831-872.

Karpoff, J. M., 1987. The relation between price changes and trading volume: A survey. Journal of Financial and quantitative Analysis 22, 109-126.

Kendall, M., Stuart, A., 2010. The advanced theory of statistics. vol. 1: Distribution theory. London: Griffin, 2010, 6th ed. 1.

Kim, O., Verrecchia, R. E., 1991. Trading volume and price reactions to public announcements. Journal of accounting research $29,302-321$.

Kim, O., Verrecchia, R. E., 1994. Market liquidity and volume around earnings announcements. Journal of accounting and economics 17, 41-67.

Lee, S. S., Mykland, P. A., 2008. Jumps in financial markets: A new nonparametric test and jump dynamics. The Review of Financial Studies 21, 2535-2563.

Loh, R. K., Stulz, R. M., 2010. When are analyst recommendation changes influential? The review of financial studies 24, 593-627.

Meeuwis, M., Parker, J. A., Schoar, A., Simester, D. I., 2021. Belief disagreement and portfolio choice. Journal of Finance, Forthcoming .

Oster, E., 2019. Unobservable selection and coefficient stability: Theory and evidence. Journal of Business \& Economic Statistics 37, 187-204.

Patton, A. J., Verardo, M., 2012. Does beta move with news? firm-specific information flows and learning about profitability. The Review of Financial Studies 25, 2789-2839.

Peng, L., Xiong, W., 2006. Investor attention, overconfidence and category learning. Journal of Financial Economics 80, 563-602.

Reed, A. V., Samadi, M., Sokobin, J. S., 2018. Shorting in broad daylight: Short sales and venue choice .

Savor, P., Wilson, M., 2013. How much do investors care about macroeconomic risk? evidence from scheduled economic announcements. Journal of Financial and Quantitative Analysis 48, 343-375.

Savor, P., Wilson, M., 2016. Earnings announcements and systematic risk. The Journal of Finance 71, 83-138.

Scholes, M., Williams, J., 1977. Estimating betas from nonsynchronous data. Journal of Financial Economics $5,309-327$.

Tetlock, P. C., 2010. Does public financial news resolve asymmetric information? The Review of Financial Studies 23, 3520-3557.

Ulrich, M., 2013. Inflation ambiguity and the term structure of u.s. government bonds. Journal of Monetary Economics 60, 295-309.

Xiong, W., 2013. Bubbles, crises, and heterogeneous beliefs. Tech. rep., National Bureau of Economic Research. 


\section{A Appendix}

\section{Estimating Equity Ambiguity}

The measure of ambiguity, denoted by $\mho^{2}$ and defined by Equation (1), represents an expected probability-weighted average of the variances of probabilities. We follow the recent literature (e.g., Brenner and Izhakian, 2018; Augustin and Izhakian, 2020; Izhakian et al., 2021) and estimate the monthly degree of ambiguity for each firm's equity using intraday stock return data from TAQ. To estimate ambiguity as implemented in Equation (8) below, the expectation of and the variation in return probabilities across the set of possible prior probability distributions, $\mathcal{P}$, must be measured.

We assume that the intraday equity return distribution for each time interval during the day in a given day represents a single prior distribution, $\mathrm{P}$, in the set of possible distributions, $\mathcal{P}$, and the number of priors in the set is assumed to depend on the number of time intrevals in the month. Each prior (distribution) in the set is represented by the thirty-second observed intraday returns on the firm's equity, in a time interval of 1170 seconds during the trading hours. ${ }^{19}$ Thus, the set of priors consists of 20 realized distributions, at most, over a day. For practical implementation reasons, we discretize return distributions into $n$ bins $B_{\ell}=\left(r_{\ell-1}, r_{\ell}\right]$ of equal size, such that each distribution is represented by a histogram, as demonstrated in Figure 1. The height of the bar for each bin is the frequency of intraday returns observed in that bin and, thus, represents the probability of the returns in that bin. Equipped with these 20 return histograms, we compute the expected probability in a particular bin across the return distributions, $\mathrm{E}\left[\mathrm{P}\left(B_{\ell}\right)\right]$, as well as the variance of these probabilities, $\operatorname{Var}\left[\mathrm{P}\left(B_{\ell}\right)\right]$. To this end, an equal likelihood is assigned to each histogram. ${ }^{20}$ We use these equally likely histograms to compute the daily degree of ambiguity of stock $j$ as follows

$$
\mho^{2}\left[r_{j}\right] \equiv \frac{1}{\sqrt{w(1-w)}} \sum_{\ell=1}^{n} \mathrm{E}\left[\mathrm{P}_{j}\left(B_{\ell}\right)\right] \operatorname{Var}\left[\mathrm{P}_{j}\left(B_{\ell}\right)\right] .
$$

To minimize the impact of bin size on the scale of ambiguity, we apply a variation of Sheppard's

\footnotetext{
${ }^{19}$ Our findings are robust to the use of different time intervals, implying a different number of distributions per day.

${ }^{20}$ Equal weighting is consistent with the principle of insufficient reason, which states that given $n$ possibilities that are indistinguishable except for their names, each possibility should be assigned a probability equal to $\frac{1}{n}$ (Bernoulli, 1713; de Laplace, 1814); with the idea of the simplest non-informative prior in Bayesian probability (Bayes, Price, and Canton, 1763), which assigns equal probabilities to all possibilities; and with the principle of maximum entropy (Jaynes, 1957), which states that the probability distribution which best describes the current state of knowledge is the one with the largest entropy.
} 
correction and scale the probability weighted-average variance of probabilities to the size of the bins by $\frac{1}{\sqrt{w(1-w)}}$, where $w=r_{\ell-1}-r_{\ell}$.

\section{[ Figure 1 ]}

In our implementation, we sample thirty-second stock returns from 9:30 to 16:00. Thus, we obtain intradaily histograms of up to 39 intraday returns. If we observe no trade in a specific time interval for a given stock, we compute returns based on the volume-weighted average of the nearest trading prices. We ignore returns between closing and next-day opening prices to eliminate the impact of overnight price changes and dividend distributions. We drop all time intervals with fewer than 10 thirty-second returns, and then we drop days with fewer than 10 intraday return distributions. $^{21}$ In addition, we drop extreme returns ( $\pm 5 \% \log$ returns over thirty seconds), as many such returns are due to improper orders that are often later canceled by the stock exchange. We normalize the intraday thirty-second rates of return to daily returns. ${ }^{22}$

For the bin formation, we divide the range of normalized returns into 1,002 intervals. We form a grid of 1,000 bins, from $-100 \%$ to $+100 \%$, each of width $0.2 \%$, in addition to the left and right tails, defined as $(-\infty,-100 \%]$ and $[+100 \%,+\infty)$, respectively. We compute the mean and the variance of probabilities for each bin, assigning an equal likelihood to each distribution (i.e., all histograms are equally likely). ${ }^{23}$ Some bins may not be populated with return realizations. Therefore, we assume a normal return distribution and use its moments to extrapolate return probabilities. That is, $\mathrm{P}_{j}\left(B_{\ell}\right)=\Phi\left(r_{\ell} ; \mu_{j}, \sigma_{j}\right)-\Phi\left(r_{\ell-1} ; \mu_{j}, \sigma_{j}\right)$, where $\Phi(\cdot)$ denotes the cumulative normal probability distribution, characterized by its mean $\mu_{j}$ and variance $\sigma_{j}^{2}$ of returns. ${ }^{24}$

\footnotetext{
${ }^{21}$ For robustness, we run all the regression tests excluding all time intervals with fewer than 15 thirty-second returns and all days with fewer than 15 intraday return distributions. The findings are essentially the same.

${ }^{22}$ Our findings are robust to the inclusion of extreme price changes, as well as to a cutoff at a level of $1 \%$ in terms of $\log$ returns.

${ }^{23}$ The assignment of equal likelihoods is equivalent to assuming that the daily ratios $\frac{\mu}{\sigma}$ are Student- $t$ distributed. When $\frac{\mu}{\sigma}$ is Student- $t$ distributed, cumulative probabilities are uniformly distributed (Kendall and Stuart, 2010, Proposition 1.27, p. 21).

${ }^{24}$ As in French et al. (1987), Brenner and Izhakian (2018) and Augustin and Izhakian (2020) apply the Scholes and Williams (1977) adjustment for non-synchronous trading to estimate the variance of returns. Scholes and Williams (1977) suggest adjusting the volatility of returns for non-synchronous trading as $\sigma_{t}^{2}=\frac{1}{N_{t}} \sum_{\ell=1}^{N_{t}}\left(r_{t, \ell}-\mathrm{E}\left[r_{t, \ell}\right]\right)^{2}+$ $2 \frac{1}{N_{t}-1} \sum_{\ell=2}^{N_{t}}\left(r_{t, \ell}-\mathrm{E}\left[r_{t, \ell}\right]\right)\left(r_{t, \ell-1}-\mathrm{E}\left[r_{t, \ell-1}\right]\right)$. This adjustment mitigates microstructure effects caused by bid-ask bounce. For robustness, we run all regression tests in which ambiguity is computed using this adjusted volatility of returns. The findings are essentially the same.
} 
An important characteristic of the measure of ambiguity implied by EUUP is that it is outcome independent (up to a state space partition), which allows for a risk-independent examination of the impacts of ambiguity on financial decisions. Specifically, the measure of ambiguity $\mho^{2}$ captures the variation in the frequencies (probabilities) of the outcomes, without incorporating the magnitudes of the outcomes. In contrast, the measure of risk captures the variation in the magnitudes of the outcomes without incorporating the variation in the frequencies with which the outcomes are observed. Thus, the measure of ambiguity is risk independent, just as standard measures of risk are ambiguity independent, implying that these two measures capture distinct aspects of uncertainty.

Other proxies for ambiguity in the literature include the volatility of mean returns (Franzoni, 2017), the volatility of volatility of returns (Faria and Correia-da Silva, 2014), or the disagreement of analysts' forecasts (Anderson et al., 2009). These measures are sensitive to changes in the set of outcomes (i.e., are outcome dependent), so they are risk dependent and, therefore, less useful for this study. For similar reasons, skewness and kurtosis (as well as other higher moments of the return distribution) are also different from $\mho^{2}$, as the former are outcome dependent and the latter is outcome independent. Time-varying mean, time-varying volatility, and jumps (return shocks) are outcome dependent as well.

Figure 1 also demonstrates that ambiguity is independent of outcomes and, therefore, independent of risk. Consider, for example, an extreme return (i.e., a stock price jump or a shock). If the partition of the state space remains unchanged, one of the bins will be associated with a higher return, but the probability of that particular bin, or any other bin, remains unchanged. Therefore, ambiguity remains unchanged. ${ }^{25}$ If, on the other hand, the partition of the state space changes, then one additional bin may be added to the histogram, thereby characterizing a new event. This new bin may also affect the population of other bins, and therefore, affect ambiguity. However, both the expected probability of experiencing a return in this new bin and the probability variance associated with it, are small. Thus, such an extreme return would have a negligible impact on ambiguity, since the effect on ambiguity is by the product of the expected probability and the variance of probability, which is even smaller.

\footnotetext{
${ }^{25}$ To illustrate, consider a rate of return on an investment that is determined by a coin toss with unknown probabilities, where heads yields a $2 \%$ return and tails a $1 \%$ return. Even if after 10 coin tosses the rate of return for heads changes to $10 \%$ (i.e., a jump), ambiguity remains unchanged, since no new information about probabilities has been obtained.
} 
Brenner and Izhakian (2018) study the implications of the aggregate market ambiguity and suggest that, in their sample, $\mho^{2}$ does not capture other well-known uncertainty factors including skewness, kurtosis, the volatility-of-mean, the volatility-of-volatility, volatility jumps, unexpected volatility, downside risk, mixed data sampling measure of volatility forecasts (MIDAS), investor sentiment, and several others. Augustin and Izhakian (2020) study the implications of firm ambiguity for the spread of credit default swaps and suggest that, in their sample, $\mho^{2}$ also does not capture these factors at the firm level. ${ }^{26}$ To further mitigate the concerns that $\mho^{2}$ captures other well-known uncertainty factors or market-microstructure effects, in the Online Appendix, we examine the explanatory power of $\mho^{2}$ relative to these uncertainty factors at the daily firm level.

\footnotetext{
${ }^{26}$ In a battery of robustness tests, Augustin and Izhakian (2020) also mitigate concerns that the measure of ambiguity $\mho^{2}$ is sensitive to the selection of the time interval of intraday rate of returns, the bin size, and the type of parametric probability distribution used to extrapolate bins' probabilities.
} 
Figure 1: Ambiguity (UOB) Measurement

This figure illustrates how we compute the ambiguity measure for each firm-day based on intraday stock-returns sampled at thirty-second intervals from 9:30 to 16:00. For each firm-day, these samples create 20 daily histograms of up to 39 intraday returns. For each daily histogram, we discretize the time-segment return distribution into $n$ bins of equal size $B_{j}=\left(r_{j}, r_{j-1}\right]$. The height of each daily histogram bin is the fraction of daily intraday returns observed in that bin and represents the probability of that bin's outcome. For simplicity, this figure shows three histograms with six bins. Across the daily return distributions, we compute the expected probability of returns in a bin as $\mathrm{E}\left[\mathrm{P}_{i}\left(B_{j}\right)\right]$ and the variance of probabilities as $\operatorname{Var}\left[\mathrm{P}_{i}\left(B_{j}\right)\right]$. Finally, we compute firm-month ambiguity as $\mho^{2}\left[X_{i}\right] \equiv 1 / \sqrt{w(1-w)} \sum_{j=1}^{n} \mathrm{E}\left[\mathrm{P}_{i}\left(B_{j}\right)\right] \operatorname{Var}\left[\mathrm{P}_{i}\left(B_{j}\right)\right]$, where we scale the weighted-average variance of probabilities by the bin size $w=r_{i, j}-r_{i, j-1}$.

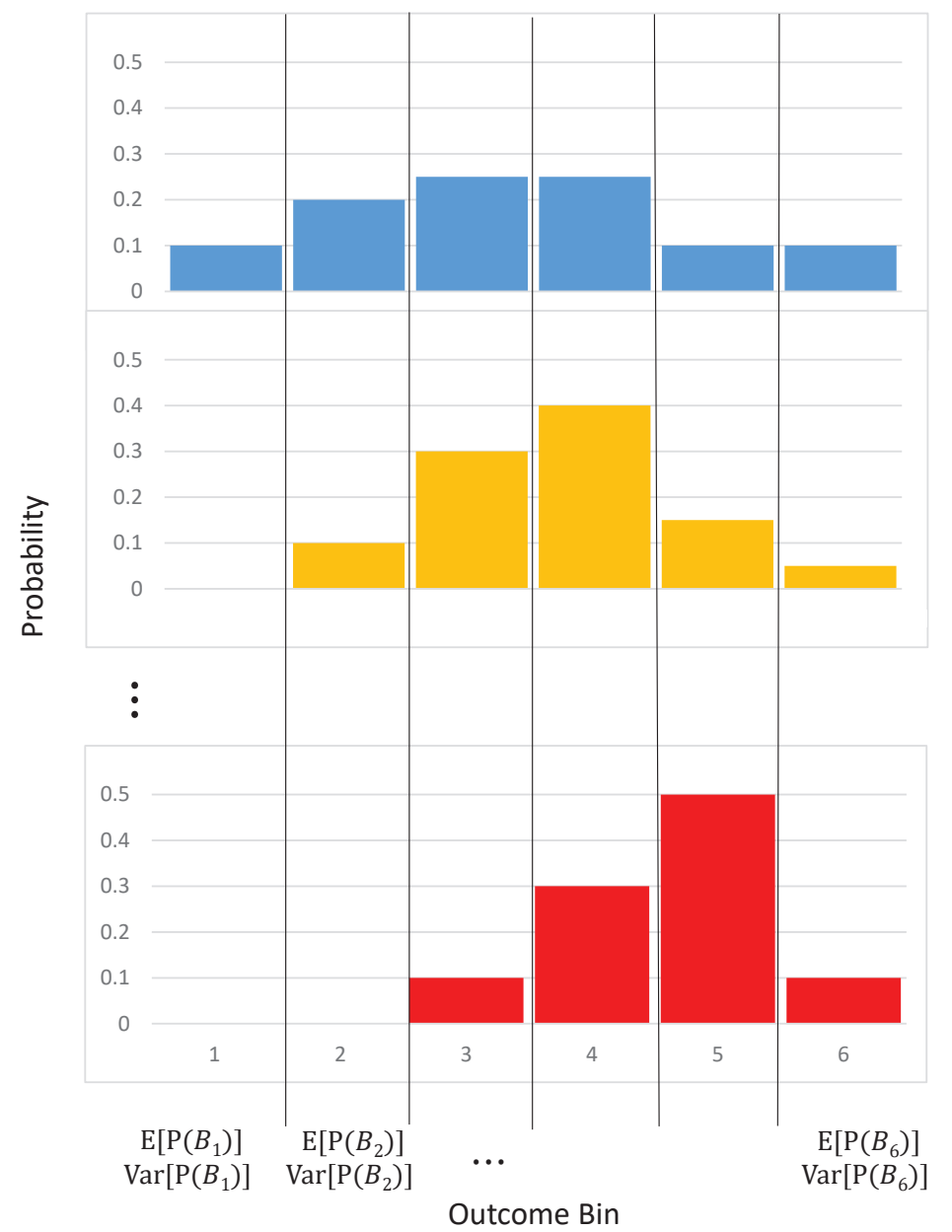


Figure 2: Investor Disagreement measures conditional on the Uncertainty of Beliefs (UOB)

This figure plots averages of different investor Disagreement measures on day $t$ of portfolio sorts on within firm percentage changes in UOB, measured on day $t$. $D I S$ is the investor total disagreement measure. $D W G$ is the "within group" investor disagreement measure, and $D A G$ is the "across group" investor disagreement measure. The percentage change in UOB is calculated relative to its 21-day trailing averages from day $t-27$ to $t-6$. All variables are defined in Table B.1. The sample period is from January 2002 to December 2018.

\section{Panel A: Total Disagreement $(D I S)$}

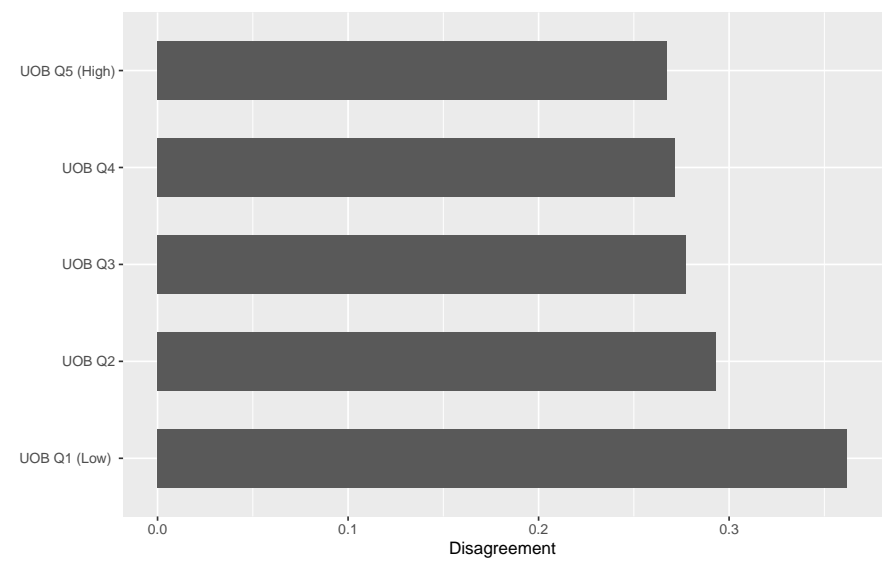

Panel B: Within Group Disagreement $(D W G)$

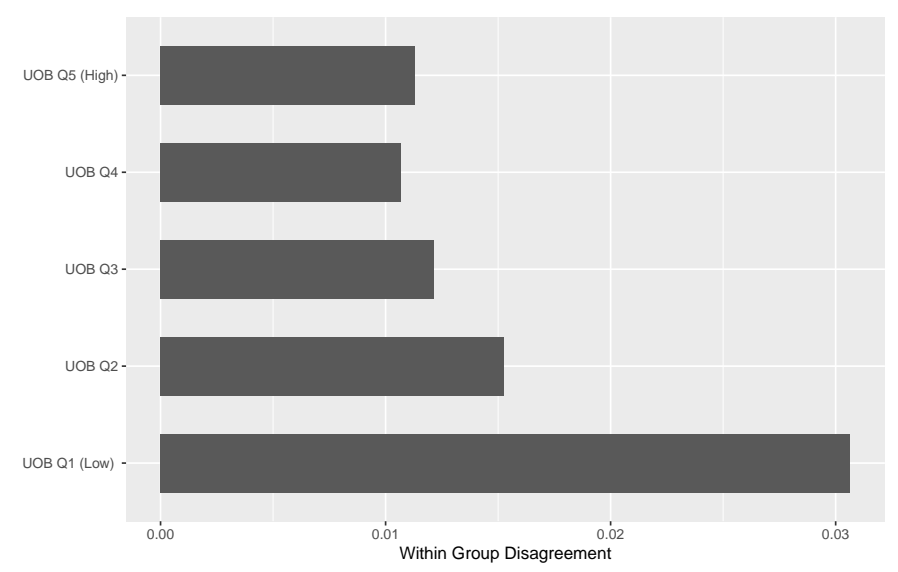

Panel C: Across Group Disagreement $(D A G)$

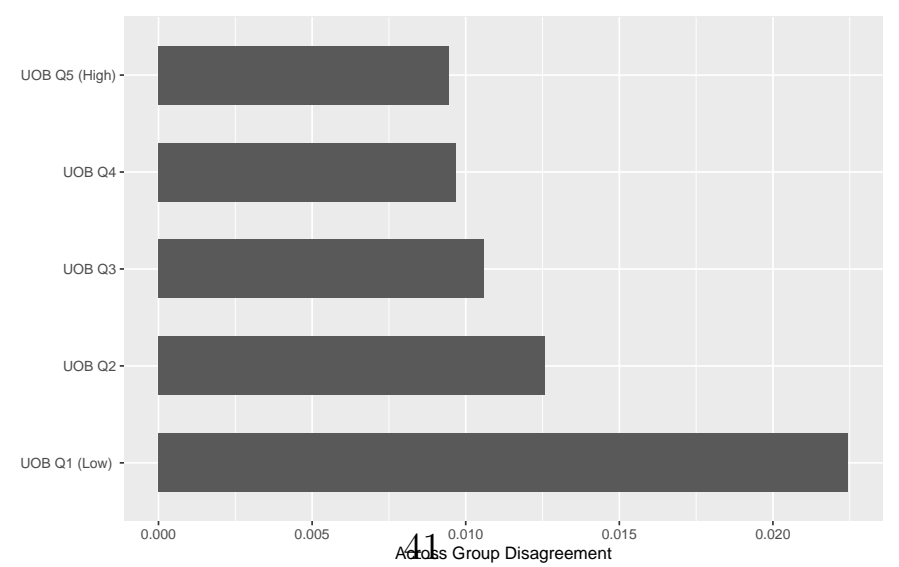


Figure 3: The effect of Disagreement measures on TURNOVER conditional on Uncertainty of Beliefs (UOB)

This figure plots the effect of investor Disagreement on Turnover, conditioning on the levels of UOB, based upon the coefficient estimates from table 4. In Panel A, high (low) is constructed based on coefficient of DIS(Z) plus (minus) the interaction coefficient of $D I S(Z)$ with $U O B(Z)$. In a similar manner, Panel B (C) in based on $D W G(D A G)$.

Panel A: Total Disagreement $(D I S)$

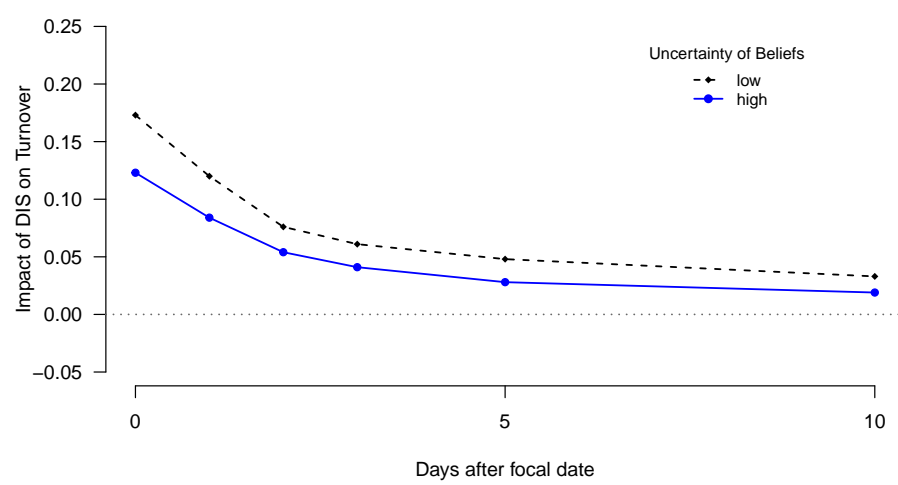

Panel B: Within Group Disagreement $(D W G)$

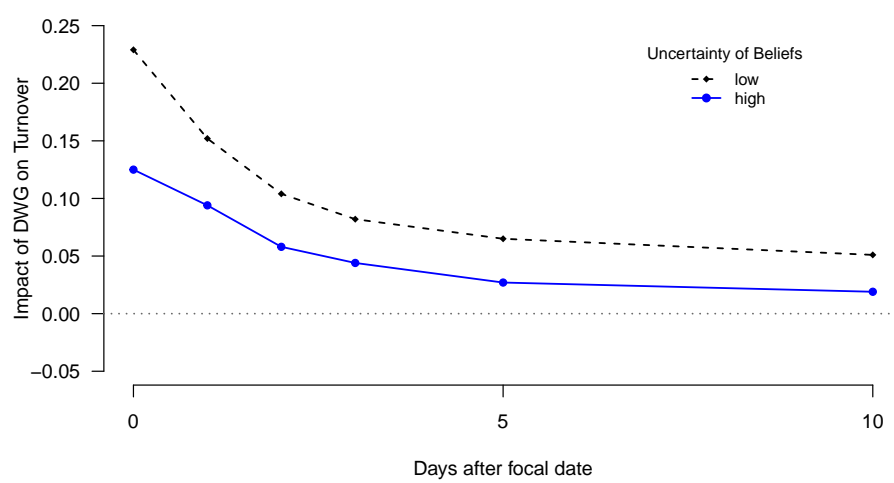

Panel C: Across Group Disagreement $(D A G)$

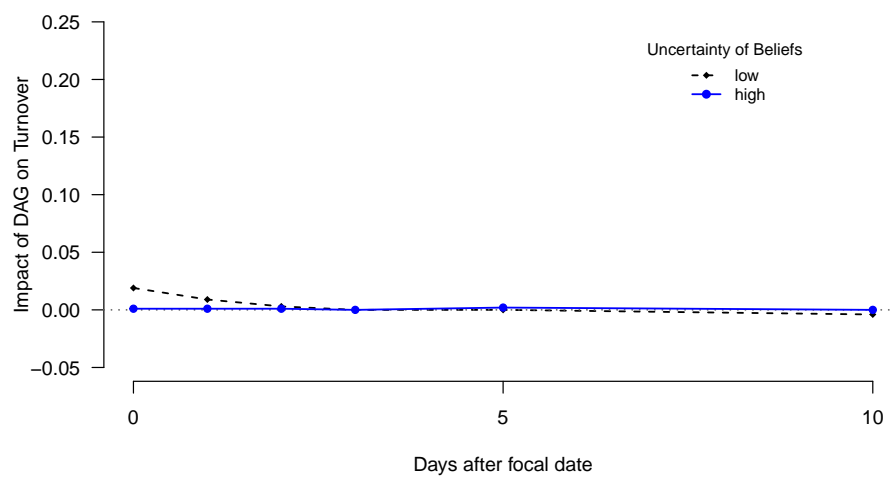


Figure 4: Uncertainty of Beliefs (UOB) around Major Firm Specific Events

This figure plots the coefficient estimates from Table 5 of the effect of earnings announcements (Panel A) and firm 8-K filings (Panel B) on UOB.

Panel A: Earnings Announcements

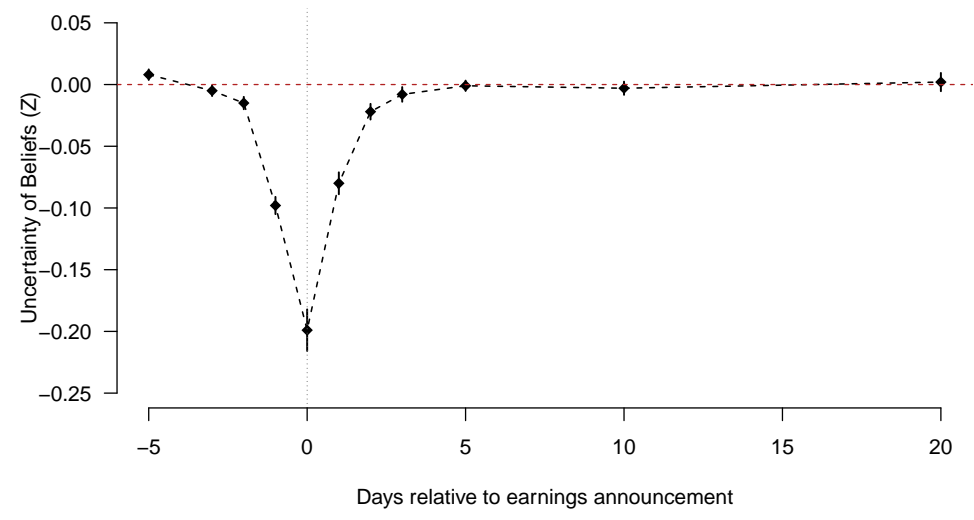

Panel B: Firm 8-K Filings

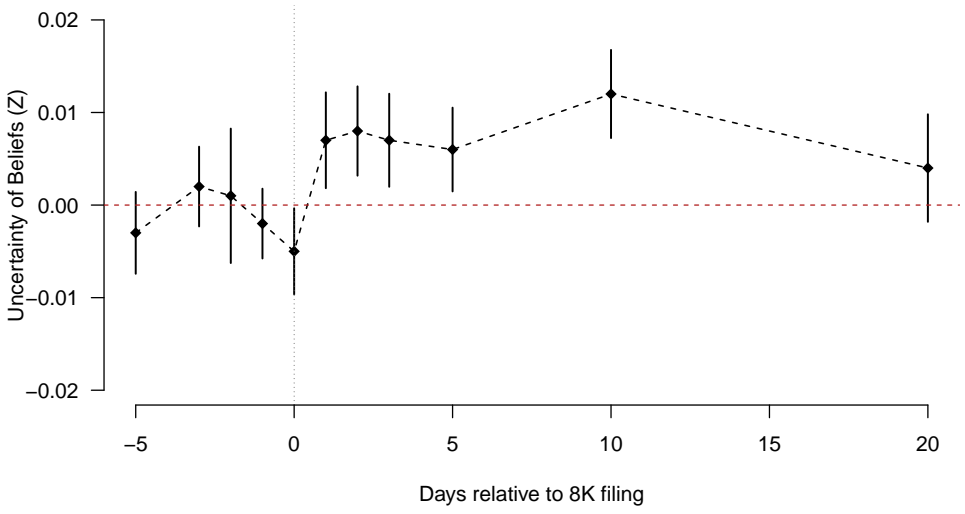


Figure 5: Uncertainty of Beliefs (UOB) around 8-K filing days

This Figure consider 8-K filings with material changes in firm operations and voluntary disclosure. It plots the coefficient estimates from Table 7 of the effect of 8 -K item types on UOB.

Panel A: Regulation FD disclosure

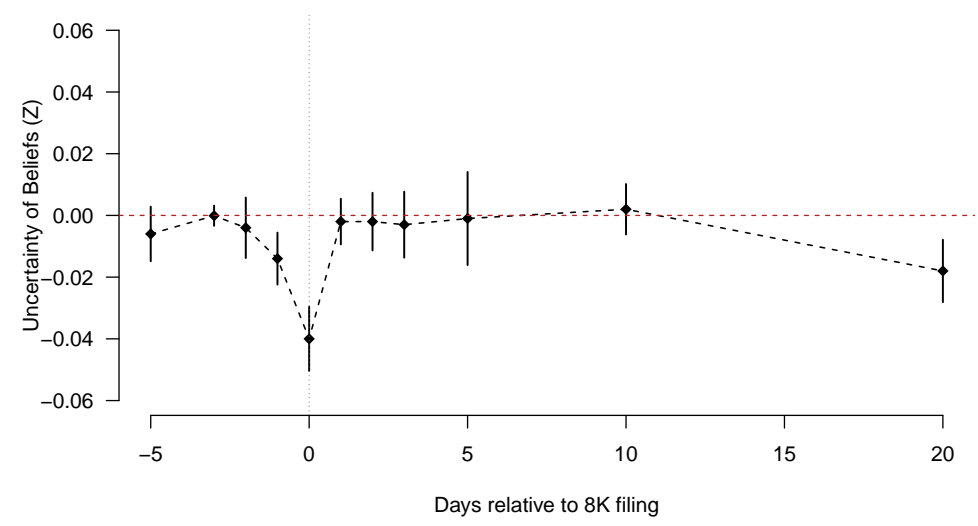

Panel B: Material Changes in Firm Operations

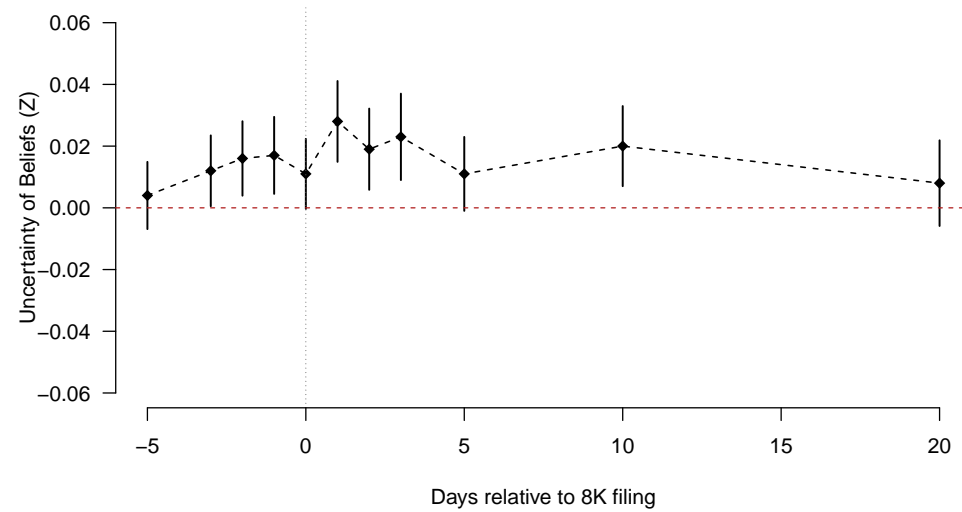

Panel C: Voluntary Disclosure

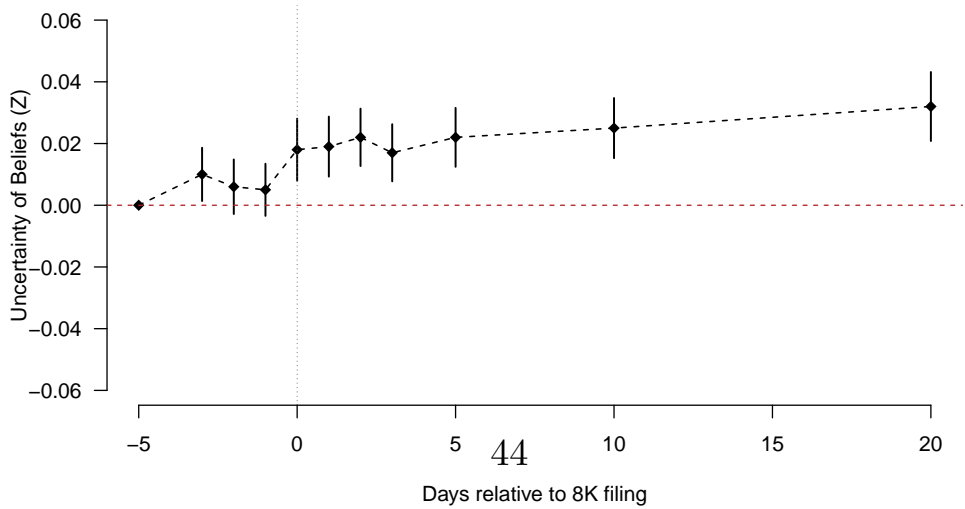


Figure 6: Uncertainty of Beliefs (UOB) around fundamental news events

This figure plots the effect of various news events on UOB. It is based upon the coefficient estimates of regression tests similar to those reported in Figure 4. Panel A focuses on all news events. Panel B focuses on earnings news events. Panel $\mathrm{C}$ focuses on target firm news events (under the category of M\&A news). Panel D focuses on credit watch news events (under the category of credit rating news).

Panel A: UOB around all fundamental news events

Panel B: UOB around earnings news events

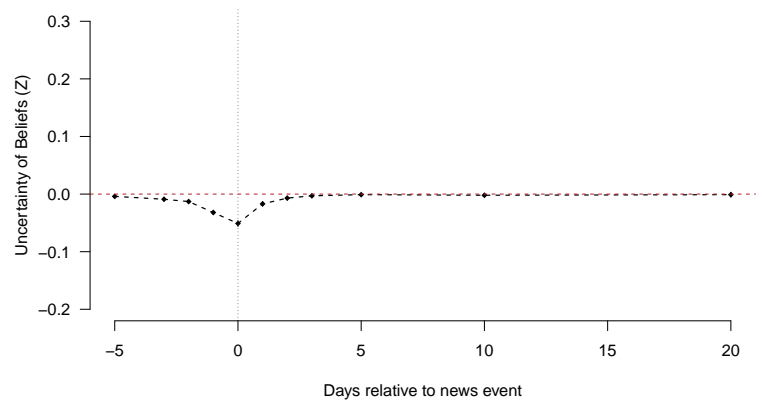

Panel C: UOB around target Firm news events

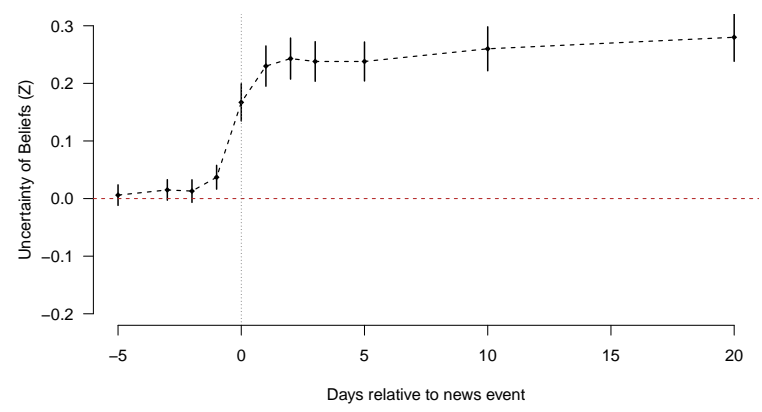

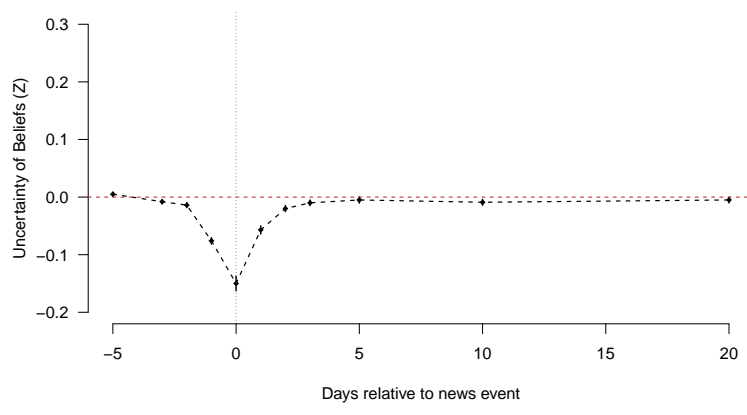

Panel D: UOB around credit watch news events

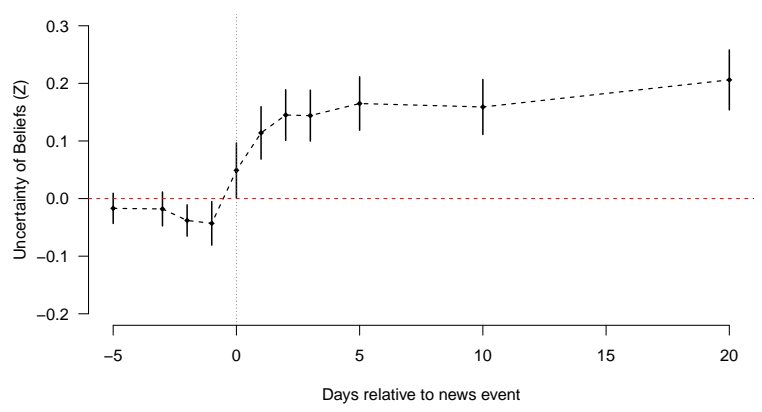


Table 1: Summary statistics

This table reports the summary statistics of the uncertainty of belief (UOB) measure and other selected variables. The sample period is from January 2002 to December 2018. Panel A reports the cross-sectional statistics of the firms' time series averages. For ease of presentation, UOB and RISK are multiplied by 10000; VOV is multiplied by 1 million; and VOM and CumRet are multiplied by 100. Panel B reports the sample frequency (in percent) of various information events and news coverage variables. Panel C reports the univariate correlation of UOB and various risk and uncertainty proxies. All variables are defined in Table B.1.

Panel A: Main Variables

\begin{tabular}{lccccccc}
\hline \hline & & & & & & \\
& Avg. & Std. Dev. & $5 \%$ & $25 \%$ & Median & $75 \%$ & $95 \%$ \\
\hline UOB & 45.830 & 42.312 & 11.150 & 19.828 & 30.519 & 56.413 & 133.215 \\
RISK & 15.638 & 10.125 & 2.959 & 7.500 & 14.031 & 21.505 & 35.333 \\
VOV & 2.687 & 2.328 & 0.178 & 0.796 & 2.106 & 3.989 & 7.251 \\
VOM & 2.926 & 1.758 & 0.615 & 1.525 & 2.674 & 4.005 & 6.224 \\
DAF & 0.100 & 0.741 & 0.003 & 0.014 & 0.025 & 0.052 & 0.203 \\
SKEW & -0.002 & 0.029 & -0.040 & -0.013 & -0.003 & 0.008 & 0.036 \\
KURT & 4.720 & 0.527 & 3.849 & 4.386 & 4.722 & 5.051 & 5.601 \\
Size in Millions & 4279.471 & 16138.402 & 163.968 & 428.018 & 944.397 & 2535.547 & 15555.723 \\
Book-to-Market & 0.538 & 0.547 & 0.110 & 0.268 & 0.453 & 0.683 & 1.199 \\
Number of Analysts & 8.154 & 5.760 & 1.364 & 4.067 & 6.696 & 10.787 & 19.666 \\
InstHold & 0.625 & 0.204 & 0.231 & 0.505 & 0.667 & 0.787 & 0.883 \\
TURNOVER & 0.015 & 0.065 & 0.005 & 0.008 & 0.011 & 0.016 & 0.030 \\
ES & 0.004 & 0.007 & 0.001 & 0.002 & 0.002 & 0.004 & 0.010 \\
1 & 0.066 & 0.047 & 0.017 & 0.031 & 0.052 & 0.090 & 0.161 \\
CumRet & 2.658 & 24.193 & -4.409 & 0.467 & 1.279 & 2.501 & 10.308 \\
\hline \hline
\end{tabular}

Panel B: Frequency of events and news categories

\begin{tabular}{lc}
\hline \hline & Mean \\
\hline$E A R N$ & 1.614 \\
REC & 0.622 \\
F8K & 1.505 \\
ITEM 1.01 & 0.176 \\
ITEM 5.02 & 0.368 \\
ITEM 5.07 & 0.076 \\
ITEM 7.01 & 0.339 \\
ITEM 8.01 & 0.445 \\
MACRO_FOMC & 3.261 \\
MACRO_OTHER & 11.604 \\
NEWS & 9.310 \\
EARNINGS & 2.240 \\
ANALRATE & 1.772 \\
PRODSERV & 1.744 \\
LABOR & 1.159 \\
$M E A$ & 0.701 \\
EQUITYACT & 0.743 \\
MKTG & 0.628 \\
CREDRATE & 0.538 \\
DIV & 0.605 \\
ASSETS & 0.275 \\
PARTNER & 0.303 \\
CREDIT & 0.216 \\
LEGAL & 0.186 \\
\hline \hline
\end{tabular}


Panel C: UOB, RISK, and other uncertainty measures

\begin{tabular}{|c|c|c|c|c|c|c|c|c|c|c|}
\hline & (1) & $(2)$ & $(3)$ & (4) & (5) & (6) & $(7)$ & $(8)$ & $(9)$ & $(10)$ \\
\hline (1) $U O B$ & 1.00 & & & & & & & & & \\
\hline (2) $R I S K$ & -0.28 & 1.00 & & & & & & & & \\
\hline (3) $\mathrm{VOV}$ & -0.08 & 0.57 & 1.00 & & & & & & & \\
\hline (4) $V O M$ & -0.18 & 0.71 & 0.40 & 1.00 & & & & & & \\
\hline (5) $S K E W$ & -0.01 & 0.01 & 0.00 & 0.00 & 1.00 & & & & & \\
\hline (6) $K U R T$ & 0.16 & -0.40 & -0.18 & -0.29 & -0.00 & 1.00 & & & & \\
\hline (7) \# Jumps & 0.06 & -0.04 & 0.06 & 0.02 & 0.00 & 0.13 & 1.00 & & & \\
\hline (8) Ave \# Jumps & 0.06 & -0.03 & 0.07 & 0.02 & 0.00 & 0.13 & 0.99 & 1.00 & & \\
\hline (9) Jump Intensity & -0.00 & 0.01 & 0.00 & 0.01 & 0.06 & -0.01 & 0.02 & 0.02 & 1.00 & \\
\hline (10) $D A F$ & -0.01 & 0.02 & -0.00 & 0.01 & -0.00 & -0.03 & -0.01 & -0.01 & -0.00 & 1.00 \\
\hline
\end{tabular}


Table 2: The relation between Uncertainty of Beliefs (UOB) and other proxies for uncertainty and dispersion of investor beliefs

This table reports findings of daily panel regressions of UOB on other uncertainty proxies, all measured on day $t$. All variables are defined in Table B.1. To account for firm fixed effect, all variables are demeaned. Consequently, the $\operatorname{Adj} R^{2}$ reports the variance explained by the independent variables, excluding the part explained by firm fixed effects. Standard errors are double clustered by firm and date and are reported in parentheses below the coefficient estimates. Statistical significance at the $10 \%, 5 \%$, and $1 \%$ level is indicated with $*, * *$, and ${ }^{* * *}$, respectively.

\begin{tabular}{|c|c|c|c|c|c|c|c|c|}
\hline & $\begin{array}{c}(1) \\
\mathrm{t}\end{array}$ & $\begin{array}{c}(2) \\
\mathrm{t}\end{array}$ & $\begin{array}{c}(3) \\
\mathrm{t}\end{array}$ & $\begin{array}{c}(4) \\
\mathrm{t}\end{array}$ & $\begin{array}{c}(5) \\
\mathrm{t}\end{array}$ & $\begin{array}{c}(6) \\
t\end{array}$ & $\begin{array}{c}(7) \\
\mathrm{t}\end{array}$ & $\begin{array}{c}(8) \\
\mathrm{t}\end{array}$ \\
\hline RISK & $\begin{array}{c}-2.979^{* * *} \\
(0.059)\end{array}$ & $\begin{array}{c}-3.961^{* * *} \\
(0.067)\end{array}$ & $\begin{array}{c}-3.961^{* * *} \\
(0.067)\end{array}$ & $\begin{array}{c}-3.735^{* * *} \\
(0.076)\end{array}$ & $\begin{array}{c}-3.687^{* * *} \\
(0.075)\end{array}$ & $\begin{array}{c}-3.648^{* * *} \\
(0.074)\end{array}$ & $\begin{array}{c}-3.615^{* * *} \\
(0.072)\end{array}$ & $\begin{array}{c}-3.373^{* * *} \\
(0.069)\end{array}$ \\
\hline VOV & & $\begin{array}{c}4.052^{* * *} \\
(0.093)\end{array}$ & $\begin{array}{c}4.053^{* * *} \\
(0.093)\end{array}$ & $\begin{array}{c}3.922^{* * *} \\
(0.098)\end{array}$ & $\begin{array}{c}3.738^{* * *} \\
(0.096)\end{array}$ & $\begin{array}{c}3.709^{* * *} \\
(0.093)\end{array}$ & $\begin{array}{c}3.396^{* * *} \\
(0.092)\end{array}$ & $\begin{array}{c}3.007^{* * *} \\
(0.081)\end{array}$ \\
\hline$V O M$ & & $\begin{array}{c}1.615^{* * *} \\
(0.112)\end{array}$ & $\begin{array}{c}1.615^{* * *} \\
(0.112)\end{array}$ & $\begin{array}{c}1.657^{* * *} \\
(0.113)\end{array}$ & $\begin{array}{c}1.498^{* * *} \\
(0.115)\end{array}$ & $\begin{array}{c}1.592^{* * *} \\
(0.114)\end{array}$ & $\begin{array}{c}1.484^{* * *} \\
(0.117)\end{array}$ & $\begin{array}{c}1.538^{* * *} \\
(0.124)\end{array}$ \\
\hline$D A F$ & & & $\begin{array}{c}0.185 \\
(0.349)\end{array}$ & $\begin{array}{c}0.427 \\
(0.364)\end{array}$ & $\begin{array}{c}0.450 \\
(0.362)\end{array}$ & $\begin{array}{c}0.407 \\
(0.364)\end{array}$ & $\begin{array}{c}0.537 \\
(0.361)\end{array}$ & $\begin{array}{c}0.424 \\
(0.386)\end{array}$ \\
\hline$S K E W$ & & & & $\begin{array}{c}-1.997^{* * *} \\
(0.211)\end{array}$ & $\begin{array}{c}-2.009^{* * *} \\
(0.210)\end{array}$ & $\begin{array}{c}-2.001^{* * *} \\
(0.209)\end{array}$ & $\begin{array}{c}-2.115^{* * *} \\
(0.208)\end{array}$ & $\begin{array}{c}-2.070^{* * *} \\
(0.212)\end{array}$ \\
\hline KURT & & & & $\begin{array}{c}4.097^{* * *} \\
(0.374)\end{array}$ & $\begin{array}{c}3.677^{* * *} \\
(0.374)\end{array}$ & $\begin{array}{c}3.991^{* * *} \\
(0.366)\end{array}$ & $\begin{array}{c}4.355^{* * *} \\
(0.308)\end{array}$ & $\begin{array}{c}7.020^{* * *} \\
(0.263)\end{array}$ \\
\hline \# Jumps & & & & & $\begin{array}{c}-4.774^{* * *} \\
(1.557)\end{array}$ & $\begin{array}{c}-5.057^{* * *} \\
(1.568)\end{array}$ & $\begin{array}{c}5.507^{* * *} \\
(1.284)\end{array}$ & $\begin{array}{c}4.155^{* * *} \\
(1.253)\end{array}$ \\
\hline Ave \# Jumps & & & & & $\begin{array}{c}541.502^{* * *} \\
(118.138)\end{array}$ & $\begin{array}{c}567.961^{* * *} \\
(118.954)\end{array}$ & $\begin{array}{c}-246.226^{* *} \\
(96.901)\end{array}$ & $\begin{array}{l}-150.138 \\
(94.541)\end{array}$ \\
\hline Jump Intensity & & & & & $\begin{array}{l}-481.115 \\
(417.869)\end{array}$ & $\begin{array}{l}-480.778 \\
(415.409)\end{array}$ & $\begin{array}{l}-312.696 \\
(414.724)\end{array}$ & $\begin{array}{l}-402.030 \\
(446.239)\end{array}$ \\
\hline TURNOVER & & & & & & $\begin{array}{c}-33.813^{* * *} \\
(11.025)\end{array}$ & $\begin{array}{l}-14.228 \\
(13.578)\end{array}$ & $\begin{array}{c}-29.839^{* *} \\
(14.499)\end{array}$ \\
\hline$E S$ & & & & & & $\begin{array}{c}-135.501^{* * *} \\
(24.164)\end{array}$ & $\begin{array}{c}-142.516^{* * *} \\
(25.279)\end{array}$ & $\begin{array}{c}-67.996^{* * *} \\
(21.405)\end{array}$ \\
\hline \# Dist. & & & & & & & $\begin{array}{c}-1.221^{* * *} \\
(0.062)\end{array}$ & $\begin{array}{c}-0.959^{* * *} \\
(0.060)\end{array}$ \\
\hline Ave Obs. Per Dist. & & & & & & & $\begin{array}{c}-0.256^{* * *} \\
(0.053)\end{array}$ & $\begin{array}{c}-0.322^{* * *} \\
(0.050)\end{array}$ \\
\hline Std.Dev Obs. Per Dist. & & & & & & & $\begin{array}{c}-1.981^{* * *} \\
(0.159)\end{array}$ & $\begin{array}{c}-1.882^{* * *} \\
(0.156)\end{array}$ \\
\hline Std.Dev.TrdVol Per Dist. & & & & & & & & $\begin{array}{c}11.523^{* * *} \\
(0.610)\end{array}$ \\
\hline Firm FE & YES & YES & YES & YES & YES & YES & YES & YES \\
\hline Observations & $6,764,799$ & $6,764,799$ & $6,764,799$ & $6,764,799$ & $6,761,079$ & $6,761,079$ & $6,761,079$ & $6,320,307$ \\
\hline $\operatorname{Adj} R^{2}$ & 0.077 & 0.086 & 0.086 & 0.088 & 0.090 & 0.091 & 0.094 & 0.097 \\
\hline
\end{tabular}


Table 3: Investor Disagreement and Uncertainty of Beliefs (UOB)

This table reports findings of daily panel regressions of investor disagreement measures on UOB in trading days $t, t+1$, and $t+2$. Panel A considers Total Disagreement $(D I S)$ and Panel B considers Within Group Disagreement $(D W G)$ and Across Group Disagreement Across Groups Disagreement (DAG). Due to data availability of investor disagreement measures, the sample period is from January 2010 to December 2018. The regression tests control for RISK, additional proxies of uncertainty, and firm characteristics. Firm characteristics include the natural logarithm of of the firm's market cap (LnSize); the natural logarithm of book-to-market ratio $(L n B M)$; the cumulative returns (CumRet) over the past 21 trading days; the natural logarithm of one plus the number of analysts covering the firm (LnNumEst); average turnover (AveTURNOVER); institutional holdings (InstHold); the natural logarithm of one over the stock's average price $\left(\ln \frac{1}{A v e P r c}\right)$; and the return on day $t(R E T)$. All variables are defined in Table B.1. For brevity, the table reports the main coefficients of interest. To address persistence in the uncertainty proxies, their rolling 21-day averages over trading days $t-27, \ldots, t-6$ are included. Table B.7 reports an example of the full set of coefficient estimates. (Z) stands for a Z-Score adjustment. Firm and date fixed effects are included in each specification. Standard errors are double clustered by firm and date and are reported in parentheses below the coefficient estimates. Statistical significance at the 10\%, 5\%, and $1 \%$ level is indicated with *, **, and $* * *$, respectively.

Panel A: Total Disagreement (DIS $(Z))$

\begin{tabular}{|c|c|c|c|c|c|c|c|c|c|}
\hline & \multicolumn{3}{|c|}{$\mathrm{t}$} & \multicolumn{3}{|c|}{$\mathrm{t}+1$} & \multicolumn{3}{|c|}{$t+2$} \\
\hline & (1) & $(2)$ & (3) & (4) & (5) & (6) & (7) & (8) & (9) \\
\hline$U O B(Z)$ & $\begin{array}{c}-0.082^{* * *} \\
(0.004)\end{array}$ & $\begin{array}{c}-0.095^{* * *} \\
(0.004)\end{array}$ & $\begin{array}{c}-0.083^{* * *} \\
(0.004)\end{array}$ & $\begin{array}{c}-0.053^{* * *} \\
(0.004)\end{array}$ & $\begin{array}{c}-0.054^{* * *} \\
(0.003)\end{array}$ & $\begin{array}{c}-0.046^{* * *} \\
(0.003)\end{array}$ & $\begin{array}{c}-0.032^{* * *} \\
(0.004)\end{array}$ & $\begin{array}{c}-0.027^{* * *} \\
(0.003)\end{array}$ & $\begin{array}{c}-0.022^{* * *} \\
(0.003)\end{array}$ \\
\hline$R I S K(Z)$ & & $\begin{array}{c}0.131^{* * *} \\
(0.006)\end{array}$ & $\begin{array}{c}0.079^{* * *} \\
(0.004)\end{array}$ & & $\begin{array}{c}0.082^{* * *} \\
(0.006)\end{array}$ & $\begin{array}{c}0.039^{* * *} \\
(0.005)\end{array}$ & & $\begin{array}{c}0.030^{* * *} \\
(0.005)\end{array}$ & $\begin{array}{c}0.003 \\
(0.005)\end{array}$ \\
\hline TURNOVER(Z) & & & $\begin{array}{c}0.237^{* * *} \\
(0.005)\end{array}$ & & & $\begin{array}{c}0.113^{* * *} \\
(0.003)\end{array}$ & & & $\begin{array}{c}0.068^{* * *} \\
(0.003)\end{array}$ \\
\hline Controls & NO & YES & YES & NO & YES & YES & $\mathrm{NO}$ & YES & YES \\
\hline Firm FE & YES & YES & YES & YES & YES & YES & YES & YES & YES \\
\hline Date FE & YES & YES & YES & YES & YES & YES & YES & YES & YES \\
\hline Observations & $1,041,991$ & $1,041,991$ & $1,039,068$ & 605,530 & 605,530 & 603,249 & 575,054 & 575,054 & 572,991 \\
\hline $\operatorname{Adj} R^{2}$ & 0.139 & 0.154 & 0.184 & 0.136 & 0.141 & 0.149 & 0.146 & 0.150 & 0.153 \\
\hline
\end{tabular}


Panel B: Within Group Disagreement $D W G(Z)$ and Across Group Disagreement $(D A G(Z))$

\begin{tabular}{|c|c|c|c|c|c|c|c|c|}
\hline & \multicolumn{4}{|c|}{$D W G(Z)$} & \multicolumn{4}{|c|}{$D A G(Z)$} \\
\hline & (1) & $(2)$ & (3) & $(4)$ & $(5)$ & (6) & (7) & (8) \\
\hline & $\mathrm{t}$ & $\mathrm{t}$ & $\mathrm{t}+1$ & $\mathrm{t}+2$ & $\mathrm{t}$ & $\mathrm{t}$ & $\mathrm{t}+1$ & $\mathrm{t}+2$ \\
\hline$U O B(Z)$ & $\begin{array}{c}-0.090^{* * *} \\
(0.008)\end{array}$ & $\begin{array}{c}-0.098^{* * *} \\
(0.009)\end{array}$ & $\begin{array}{c}-0.055^{* * *} \\
(0.006)\end{array}$ & $\begin{array}{c}-0.024^{* * *} \\
(0.004)\end{array}$ & $\begin{array}{c}-0.071^{* * *} \\
(0.006)\end{array}$ & $\begin{array}{c}-0.078^{* * *} \\
(0.006)\end{array}$ & $\begin{array}{c}-0.042^{* * *} \\
(0.004)\end{array}$ & $\begin{array}{c}-0.018^{* * *} \\
(0.004)\end{array}$ \\
\hline$R I S K(Z)$ & & $\begin{array}{c}0.041^{* * *} \\
(0.005)\end{array}$ & $\begin{array}{l}-0.005 \\
(0.006)\end{array}$ & $\begin{array}{c}-0.018^{* * *} \\
(0.006)\end{array}$ & & $\begin{array}{c}0.037^{* * *} \\
(0.004)\end{array}$ & $\begin{array}{l}-0.002 \\
(0.005)\end{array}$ & $\begin{array}{c}-0.016^{* * *} \\
(0.005)\end{array}$ \\
\hline TURNOVER(Z) & & $\begin{array}{c}0.244^{* * *} \\
(0.014)\end{array}$ & $\begin{array}{c}0.119^{* * *} \\
(0.009)\end{array}$ & $\begin{array}{c}0.074^{* * *} \\
(0.008)\end{array}$ & & $\begin{array}{c}0.200^{* * *} \\
(0.009)\end{array}$ & $\begin{array}{c}0.095^{* * *} \\
(0.006)\end{array}$ & $\begin{array}{c}0.059^{* * *} \\
(0.005)\end{array}$ \\
\hline Controls & $\mathrm{NO}$ & YES & YES & YES & $\mathrm{NO}$ & YES & YES & YES \\
\hline Firm FE & YES & YES & YES & YES & YES & YES & YES & YES \\
\hline Date FE & YES & YES & YES & YES & YES & YES & YES & YES \\
\hline Observations & $1,041,991$ & $1,039,068$ & 603,249 & 572,991 & $1,041,991$ & $1,039,068$ & 603,249 & 572,991 \\
\hline $\operatorname{Adj} R^{2}$ & 0.272 & 0.323 & 0.292 & 0.289 & 0.128 & 0.158 & 0.136 & 0.135 \\
\hline
\end{tabular}


Table 4: Turnover and Investor Disagreement conditional on Uncertainty of Beliefs (UOB)

This table reports findings of daily panel regressions of TURNOVER on disagreement measures in trading days $t, t+1$, and $t+2$. Panel A considers Total Disagreement $(D I S)$ and Panel B considers Within Group Disagreement $(D W G)$ and Across Groups Disagreement $(D A G)$. Due to data availability of investor disagreement measures, the sample period is from January 2010 to December 2018. Each regression tests includes UOB and its interaction with disagreement measures. The regression tests control for RISK, additional proxies of uncertainty, and firm characteristics. Firm controls are similar to those reported in Table 3. All variables are defined in Table B.1. For brevity, the table reports the main coefficients of interest. (Z) stands for a Z-Score adjustment. Firm and date fixed effects are included in each specification. Standard errors are double clustered by firm and date and are reported in parentheses below the coefficient estimates. Statistical significance at the $10 \%, 5 \%$, and $1 \%$ level is indicated with $* * *$, and $* * *$, respectively.

Panel A: TURNOVER(Z)

\begin{tabular}{|c|c|c|c|c|c|c|c|c|}
\hline & \multicolumn{4}{|c|}{$\mathrm{t}$} & \multicolumn{2}{|c|}{$\mathrm{t}+1$} & \multicolumn{2}{|c|}{$\mathrm{t}+2$} \\
\hline & $(1)$ & $(2)$ & $(3)$ & (4) & $(5)$ & (6) & (7) & (8) \\
\hline & $\mathrm{t}$ & $\mathrm{t}$ & $\mathrm{t}$ & $\mathrm{t}$ & $\mathrm{t}+1$ & $\mathrm{t}+1$ & $\mathrm{t}+2$ & $\mathrm{t}+2$ \\
\hline$D I S(Z)$ & $\begin{array}{c}0.183^{* * *} \\
(0.005)\end{array}$ & $\begin{array}{c}0.149^{* * *} \\
(0.004)\end{array}$ & $\begin{array}{c}0.149^{* * *} \\
(0.003)\end{array}$ & $\begin{array}{c}0.148^{* * *} \\
(0.003)\end{array}$ & $\begin{array}{c}0.102^{* * *} \\
(0.003)\end{array}$ & $\begin{array}{c}0.102^{* * *} \\
(0.003)\end{array}$ & $\begin{array}{c}0.065^{* * *} \\
(0.003)\end{array}$ & $\begin{array}{c}0.065^{* * *} \\
(0.003)\end{array}$ \\
\hline$U O B(Z)$ & $\begin{array}{c}-0.063^{* * *} \\
(0.006)\end{array}$ & $\begin{array}{c}-0.051^{* * *} \\
(0.005)\end{array}$ & $\begin{array}{c}-0.048^{* * *} \\
(0.005)\end{array}$ & $\begin{array}{c}-0.054^{* * *} \\
(0.005)\end{array}$ & $\begin{array}{c}-0.012^{* * *} \\
(0.004)\end{array}$ & $\begin{array}{c}-0.014^{* * *} \\
(0.004)\end{array}$ & $\begin{array}{l}-0.004 \\
(0.003)\end{array}$ & $\begin{array}{l}-0.005 \\
(0.003)\end{array}$ \\
\hline$U O B(Z) \times D I S(Z)$ & & & $\begin{array}{c}-0.064^{* * *} \\
(0.003)\end{array}$ & $\begin{array}{c}-0.025^{* * *} \\
(0.002)\end{array}$ & & $\begin{array}{c}-0.018^{* * *} \\
(0.002)\end{array}$ & & $\begin{array}{c}-0.011^{* * *} \\
(0.002)\end{array}$ \\
\hline$R I S K(Z)$ & & $\begin{array}{c}0.201^{* * *} \\
(0.013)\end{array}$ & $\begin{array}{c}0.197^{* * *} \\
(0.012)\end{array}$ & $\begin{array}{c}0.189^{* * *} \\
(0.012)\end{array}$ & $\begin{array}{c}0.109^{* * *} \\
(0.009)\end{array}$ & $\begin{array}{c}0.101^{* * *} \\
(0.009)\end{array}$ & $\begin{array}{c}0.053^{* * *} \\
(0.008)\end{array}$ & $\begin{array}{c}0.047^{* * *} \\
(0.007)\end{array}$ \\
\hline$R I S K(Z) \times D I S(Z)$ & & & & $\begin{array}{c}0.086^{* * *} \\
(0.004)\end{array}$ & & $\begin{array}{c}0.046^{* * *} \\
(0.003)\end{array}$ & & $\begin{array}{c}0.033^{* * *} \\
(0.002)\end{array}$ \\
\hline Controls & $\mathrm{NO}$ & YES & YES & YES & YES & YES & YES & YES \\
\hline Firm FEs & YES & YES & YES & YES & YES & YES & YES & YES \\
\hline Date FEs & YES & YES & YES & YES & YES & YES & YES & YES \\
\hline Observations & $1,039,068$ & $1,039,068$ & $1,039,068$ & $1,039,068$ & $1,039,444$ & $1,039,444$ & $1,039,130$ & $1,039,130$ \\
\hline $\operatorname{Adj} R^{2}$ & 0.396 & 0.487 & 0.491 & 0.496 & 0.458 & 0.461 & 0.466 & 0.467 \\
\hline
\end{tabular}


Panel B: TURNOVER(Z)

\begin{tabular}{|c|c|c|c|c|c|c|c|c|}
\hline & \multicolumn{4}{|c|}{$\mathrm{t}$} & \multicolumn{2}{|c|}{$\mathrm{t}+1$} & \multicolumn{2}{|c|}{$\mathrm{t}+2$} \\
\hline & (1) & $(2)$ & (3) & (4) & $(5)$ & (6) & $(7)$ & (8) \\
\hline & $\mathrm{t}$ & $\mathrm{t}$ & $\mathrm{t}$ & $\mathrm{t}$ & $t+1$ & $t+1$ & $t+2$ & $t+2$ \\
\hline \multicolumn{9}{|l|}{$\mathrm{t}$} \\
\hline$D W G(Z)$ & $\begin{array}{c}0.220^{* * *} \\
(0.020)\end{array}$ & $\begin{array}{c}0.189^{* * *} \\
(0.016)\end{array}$ & $\begin{array}{c}0.179^{* * *} \\
(0.014)\end{array}$ & $\begin{array}{c}0.177^{* * *} \\
(0.014)\end{array}$ & $\begin{array}{c}0.131^{* * *} \\
(0.011)\end{array}$ & $\begin{array}{c}0.123^{* * *} \\
(0.010)\end{array}$ & $\begin{array}{c}0.086^{* * *} \\
(0.009)\end{array}$ & $\begin{array}{c}0.081^{* * *} \\
(0.008)\end{array}$ \\
\hline$D A G(Z)$ & $\begin{array}{c}0.008 \\
(0.006)\end{array}$ & $\begin{array}{c}0.004 \\
(0.005)\end{array}$ & $\begin{array}{c}0.010^{* *} \\
(0.005)\end{array}$ & $\begin{array}{l}0.010^{*} \\
(0.005)\end{array}$ & $\begin{array}{c}0.002 \\
(0.004)\end{array}$ & $\begin{array}{c}0.005 \\
(0.004)\end{array}$ & $\begin{array}{l}-0.000 \\
(0.003)\end{array}$ & $\begin{array}{c}0.002 \\
(0.003)\end{array}$ \\
\hline$U O B(Z)$ & $\begin{array}{c}-0.058^{* * *} \\
(0.006)\end{array}$ & $\begin{array}{c}-0.043^{* * *} \\
(0.005)\end{array}$ & $\begin{array}{c}-0.041^{* * *} \\
(0.007)\end{array}$ & $\begin{array}{c}-0.047^{* * *} \\
(0.007)\end{array}$ & $\begin{array}{c}-0.008^{* *} \\
(0.004)\end{array}$ & $\begin{array}{c}-0.009^{* *} \\
(0.004)\end{array}$ & $\begin{array}{l}-0.000 \\
(0.003)\end{array}$ & $\begin{array}{l}-0.001 \\
(0.004)\end{array}$ \\
\hline$U O B(Z) \times D W G(Z)$ & & & $\begin{array}{c}-0.054^{* *} \\
(0.025)\end{array}$ & $\begin{array}{c}-0.052^{* *} \\
(0.024)\end{array}$ & & $\begin{array}{c}-0.029^{* *} \\
(0.012)\end{array}$ & & $\begin{array}{c}-0.023^{* * *} \\
(0.009)\end{array}$ \\
\hline$U O B(Z) \times D A G(Z)$ & & & $\begin{array}{c}-0.012 \\
(0.010)\end{array}$ & $\begin{array}{c}-0.009 \\
(0.010)\end{array}$ & & $\begin{array}{l}-0.004 \\
(0.005)\end{array}$ & & $\begin{array}{l}-0.001 \\
(0.004)\end{array}$ \\
\hline$R I S K(Z)$ & & $\begin{array}{c}0.203^{* * *} \\
(0.012)\end{array}$ & $\begin{array}{c}0.200^{* * *} \\
(0.012)\end{array}$ & $\begin{array}{c}0.189^{* * *} \\
(0.012)\end{array}$ & $\begin{array}{c}0.107^{* * *} \\
(0.009)\end{array}$ & $\begin{array}{c}0.098^{* * *} \\
(0.009)\end{array}$ & $\begin{array}{c}0.051^{* * *} \\
(0.007)\end{array}$ & $\begin{array}{c}0.044^{* * *} \\
(0.007)\end{array}$ \\
\hline$R I S K(Z) \times D I S(Z)$ & & & & $\begin{array}{c}0.092^{* * *} \\
(0.004)\end{array}$ & & $\begin{array}{c}0.050^{* * *} \\
(0.003)\end{array}$ & & $\begin{array}{c}0.035^{* * *} \\
(0.002)\end{array}$ \\
\hline Controls & $\mathrm{NO}$ & YES & YES & YES & YES & YES & YES & YES \\
\hline Firm FEs & YES & YES & YES & YES & YES & YES & YES & YES \\
\hline Date FEs & YES & YES & YES & YES & YES & YES & YES & YES \\
\hline Observations & $1,039,068$ & $1,039,068$ & $1,039,068$ & $1,039,068$ & $1,039,444$ & $1,039,444$ & $1,039,130$ & $1,039,130$ \\
\hline $\operatorname{Adj} R^{2}$ & 0.403 & 0.493 & 0.497 & 0.505 & 0.461 & 0.465 & 0.468 & 0.469 \\
\hline
\end{tabular}


Table 5: Uncertainty of Beliefs (UOB) and major firm public information events

This table reports findings of daily panel regressions of UOB on trading day $t-1$ to $t+5$ on day-t's firmspecific events. Panel A considers earnings announcements $(E A R N)$ and Panel B considers 8-K filings that are not associated with earnings announcements $(F 8 K)$. The sample period is from January 2002 to December 2018. The regression tests control for RISK, additional proxies of uncertainty, and firm characteristics. Firm controls are similar to those reported in Table 3. All variables are defined in Table B.1. For brevity, the table reports the main coefficients of interest. (Z) stands for a Z-Score adjustment. Firm and date fixed effects are included in each specification. Standard errors are double clustered by firm and date and are reported in parentheses below the coefficient estimates. Statistical significance at the $10 \%, 5 \%$, and $1 \%$ level is indicated with ${ }^{*},{ }^{* *}$, and ${ }^{* * *}$, respectively.

Panel A: $U O B(Z)$ and $E A R N$

\begin{tabular}{ccccccc}
\hline & $(1)$ & $(2)$ & $(3)$ & $(4)$ & $(5)$ & $(6)$ \\
& $\mathrm{t}-1$ & $\mathrm{t}$ & $\mathrm{t}+1$ & $\mathrm{t}+2$ & $\mathrm{t}+3$ & $\mathrm{t}+5$ \\
\hline EARN & $-0.098^{* * *}$ & $-0.199^{* * *}$ & $-0.080^{* * *}$ & $-0.022^{* * *}$ & $-0.008^{* * *}$ & -0.001 \\
& $(0.004)$ & $(0.009)$ & $(0.005)$ & $(0.003)$ & $(0.003)$ & $(0.003)$ \\
\hline
\end{tabular}

Panel B: $U O B(Z)$ and $F 8 K$

\begin{tabular}{ccccccc}
\hline & $(1)$ & $(2)$ & $(3)$ & $(4)$ & $(5)$ & $(6)$ \\
& $\mathrm{t}-1$ & $\mathrm{t}$ & $\mathrm{t}+1$ & $\mathrm{t}+2$ & $\mathrm{t}+3$ & $\mathrm{t}+5$ \\
\hline$F 8 K$ & -0.002 & $-0.005^{* *}$ & $0.007^{* * *}$ & $0.008^{* * *}$ & $0.007^{* * *}$ & $0.006^{* * *}$ \\
& $(0.002)$ & $(0.003)$ & $(0.002)$ & $(0.002)$ & $(0.002)$ & $(0.002)$ \\
\hline
\end{tabular}


Table 6: UOB and EARN Conditioning on Firm Earnings Guidance

This table extends the analysis reported in Table 5 by exploring the relation between UOB and firm earnings announcements $(E A R N)$ conditioning on firm earnings guidance information. Firm data is obtained from the I/B/E/S Guidance database. We construct two measures and interact them with EARN. In Panel A, we interact $E A R N$ with a dummy variable, $E G$, that receives a value of one, if the firm issued an earnings guidance over the previous 90 days up to and including the earnings announcement day, and zero otherwise. In Panel B, we dig into the content of earnings guidance and take into account the dispersion reflected in earnings guidance values provided by the firm. To have a fair comparison, we focus on a normalized earnings guidance dispersion measure calculated as the High-minus-Low guidance values (the guidance spread) divided by their average. We then define High EG Dispersion (Low EG Dispersion) as a dummy variable that receives a value of one if the firm's normalized earnings guidance dispersion measure is at the top tercile (bottom two terciles) across all firms, and zero otherwise. Firm controls are similar to those reported in Table 3. All variables are defined in Table B.1. For brevity, the table reports the main coefficients of interest. (Z) stands for a Z-Score adjustment. Firm and date fixed effects are included in each specification. Standard errors are double clustered by firm and date and are reported in parentheses below the coefficient estimates. Statistical significance at the $10 \%, 5 \%$, and $1 \%$ level is indicated with $*,{ }^{* *}$, and ${ }^{* * *}$, respectively.

Panel A: UOB and Firm Earnings Guidance

\begin{tabular}{lcccccc}
\hline & $(1)$ & $(2)$ & $(3)$ & $(4)$ & $(5)$ & $(6)$ \\
& $\mathrm{t}-1$ & $\mathrm{t}$ & $\mathrm{t}+1$ & $\mathrm{t}+2$ & $\mathrm{t}+3$ & $\mathrm{t}+5$ \\
\hline$E A R N$ & $-0.083^{* * *}$ & $-0.143^{* * *}$ & $-0.060^{* * *}$ & $-0.014^{* * *}$ & -0.005 & 0.003 \\
& $(0.004)$ & $(0.007)$ & $(0.004)$ & $(0.003)$ & $(0.003)$ & $(0.003)$ \\
$E A R N \times E G$ & -0.009 & $-0.222^{*}$ & -0.091 & -0.022 & -0.103 & -0.160 \\
& $(0.065)$ & $(0.121)$ & $(0.067)$ & $(0.081)$ & $(0.124)$ & $(0.160)$ \\
Controls & & & & & & \\
Firm FEs & YES & YES & YES & YES & YES & YES \\
Date FEs & YES & YES & YES & YES & YES & YES \\
Observations & $6,750,823$ & $6,764,799$ & YES & YES & YES & YES \\
Adj $R^{2}$ & 0.609 & 0.610 & $0.750,152$ & $6,749,414$ & $6,748,637$ & $6,747,110$ \\
\hline
\end{tabular}

Panel B: UOB and Firm Earnings Guidance Dispersion

\begin{tabular}{lcccccc}
\hline & $(1)$ & $(2)$ & $(3)$ & $(4)$ & $(5)$ & $(6)$ \\
& $\mathrm{t}-1$ & $\mathrm{t}$ & $\mathrm{t}+1$ & $\mathrm{t}+2$ & $\mathrm{t}+3$ & $\mathrm{t}+5$ \\
\hline EARN & $-0.083^{* * *}$ & $-0.142^{* * *}$ & $-0.060^{* * *}$ & $-0.014^{* * *}$ & -0.005 & 0.003 \\
& $(0.004)$ & $(0.007)$ & $(0.004)$ & $(0.003)$ & $(0.003)$ & $(0.003)$ \\
EARN $\times$ & -0.029 & $-0.362^{* *}$ & -0.124 & -0.025 & -0.162 & -0.192 \\
Low EG Dispersion & $(0.072)$ & $(0.144)$ & $(0.078)$ & $(0.098)$ & $(0.166)$ & $(0.219)$ \\
EARN & 0.028 & 0.080 & -0.029 & -0.019 & 0.054 & $-0.075^{* *}$ \\
High EG Dispersion & $(0.106)$ & $(0.080)$ & $(0.055)$ & $(0.066)$ & $(0.035)$ & $(0.034)$ \\
& & & & & YES & YES \\
Controls & YES & YES & YES & YES & YES & YES \\
Firm FEs & YES & YES & YES & YES & YES & YES \\
Date FEs & YES & YES & YES & YES & & \\
& & & & & & \\
Observations & $6,750,823$ & $6,764,799$ & $6,750,152$ & $6,749,414$ & $6,748,637$ & $6,747,110$ \\
Adj $R^{2}$ & 0.609 & 0.610 & 0.598 & 0.590 & 0.583 & 0.572 \\
\hline
\end{tabular}


Table 7: Uncertainty of Beliefs (UOB) and firm 8-K filings

This table reports findings of daily panel regressions of UOB on trading day $t-1$ to $t+5$ on day-t's 8-K filings by item type, refining Panel B of Table 5. Panel A considers Regulation FD (ITEM 7.01). Panel B considers material changes in firm operation (ITEM 1.01). Panel $\mathrm{C}$ considers voluntary disclosure that the firms finds to be material (ITEM 8.01) The sample period is from January 2002 to December 2018. Firm controls are similar to those reported in Table 3. For brevity, the table reports the main coefficients of interest. All variables are defined in Table B.1. (Z) stands for a Z-Score adjustment. Firm and date fixed effects are included in each specification. Standard errors are double clustered by firm and date and are reported in parentheses below the coefficient estimates. Statistical significance at the $10 \%, 5 \%$, and $1 \%$ level is indicated with $*, * *$, and ${ }^{* * *}$, respectively.

Panel A: $U O B(Z)$ and Regulation FD (ITEM 7.01)

\begin{tabular}{|c|c|c|c|c|c|c|}
\hline & (1) & $(2)$ & $(3)$ & $(4)$ & $(5)$ & $(6)$ \\
\hline & $\mathrm{t}-1$ & $\mathrm{t}$ & $\mathrm{t}+1$ & $\mathrm{t}+2$ & $t+3$ & $t+5$ \\
\hline ITEM $\% .01$ & $\begin{array}{c}-0.014^{* * *} \\
(0.004)\end{array}$ & $\begin{array}{c}-0.040^{* * *} \\
(0.005)\end{array}$ & $\begin{array}{l}-0.002 \\
(0.005)\end{array}$ & $\begin{array}{c}-0.002 \\
(0.005)\end{array}$ & $\begin{array}{l}-0.003 \\
(0.005)\end{array}$ & $\begin{array}{c}-0.001 \\
(0.006)\end{array}$ \\
\hline
\end{tabular}

Panel B: $\operatorname{UOB}(Z)$ and Material changes in firm operations (ITEM 1.01)

\begin{tabular}{ccccccc}
\hline & $(1)$ & $(2)$ & $(3)$ & $(4)$ & $(5)$ & $(6)$ \\
$\mathrm{t}-1$ & $\mathrm{t}$ & $\mathrm{t}+1$ & $\mathrm{t}+2$ & $\mathrm{t}+3$ & $0.011^{*}$ \\
& $\mathrm{t}$ & $0.011^{*}$ & $0.028^{* * *}$ & $0.019^{* * *}$ & $0.023^{* * *}$ & $(0.007)$ \\
\hline
\end{tabular}

Panel C: $\operatorname{UOB}(Z)$ and Voluntary Disclosure (ITEM 8.01)

\begin{tabular}{ccccccc}
\hline & $(1)$ & $(2)$ & $(3)$ & $(4)$ & $(5)$ & $(6)$ \\
$\mathrm{t}-1$ & $\mathrm{t}$ & $\mathrm{t}+1$ & $\mathrm{t}+2$ & $\mathrm{t}+3$ & $\mathrm{t}+5$ \\
\hline ITEM 8.01 & 0.005 & $0.018^{* * *}$ & $0.019^{* * *}$ & $0.022^{* * *}$ & $0.017^{* * *}$ & $0.022^{* * *}$ \\
& $(0.005)$ & $(0.005)$ & $(0.005)$ & $(0.005)$ & $(0.005)$ & $(0.005)$ \\
\hline
\end{tabular}


Table 8: Investor Disagreement, Turnover and Uncertainty of Beliefs (UOB) on earnings announcements and 8-K filing days

This table reports findings from daily panel regressions tests of the relation between Total Disagreement $(D I S)$, UOB and TURNOVER on earnings announcement and 8-K filing days, all measured on day $t$. Panel A considers the effect of UOB and TURNOVER on DIS. Panel B considers the effect of UOB and DIS on TURNOVER. Due to data availability of investor disagreement measures, the sample period is from January 2010 to December 2018. The regression tests control for RISK, additional proxies of uncertainty, and firm characteristics. Firm controls are similar to those reported in Table 3. All variables are defined in Table B.1. For brevity, the table reports the main coefficients of interest. (Z) stands for a Z-Score adjustment. Firm and date fixed effects are included in each specification. Standard errors are double clustered by firm and date and are reported in parentheses below the coefficient estimates. Statistical significance at the 10\%, $5 \%$, and $1 \%$ level is indicated with $*, * *$, and ${ }^{* * *}$, respectively.

Panel A: $D I S(Z)$ and $U O B(Z)$

\begin{tabular}{|c|c|c|c|c|c|c|}
\hline & \multicolumn{3}{|c|}{ EDAY } & \multicolumn{3}{|c|}{$8-\mathrm{K}$} \\
\hline & (1) & $(2)$ & (3) & (4) & $(5)$ & (6) \\
\hline $\operatorname{UOB}(Z)$ & $\begin{array}{c}-0.033^{* * *} \\
(0.009)\end{array}$ & $\begin{array}{c}-0.023^{* * *} \\
(0.008)\end{array}$ & $\begin{array}{c}-0.020^{* *} \\
(0.009)\end{array}$ & $\begin{array}{c}-0.061^{* * *} \\
(0.010)\end{array}$ & $\begin{array}{c}-0.068^{* * *} \\
(0.012)\end{array}$ & $\begin{array}{c}-0.062^{* * *} \\
(0.012)\end{array}$ \\
\hline$R I S K(Z)$ & & $\begin{array}{c}0.062^{* * *} \\
(0.011)\end{array}$ & $\begin{array}{c}0.033^{* * *} \\
(0.011)\end{array}$ & & $\begin{array}{c}0.109^{* * *} \\
(0.019)\end{array}$ & $\begin{array}{l}0.039^{* *} \\
(0.019)\end{array}$ \\
\hline TURNOVER(Z) & & & $\begin{array}{c}0.093^{* * *} \\
(0.004)\end{array}$ & & & $\begin{array}{c}0.202^{* * *} \\
(0.008)\end{array}$ \\
\hline Controls & $\mathrm{NO}$ & YES & YES & $\mathrm{NO}$ & YES & YES \\
\hline Firm FE & YES & YES & YES & YES & YES & YES \\
\hline Date FE & YES & YES & YES & YES & YES & YES \\
\hline Observations & 42,493 & 42,493 & 41,881 & 30,063 & 30,063 & 29,864 \\
\hline $\operatorname{Adj} R^{2}$ & 0.225 & 0.234 & 0.243 & 0.173 & 0.186 & 0.213 \\
\hline
\end{tabular}


Panel B: TURNOVER(Z), UOB(Z) and DIS(Z)

\begin{tabular}{|c|c|c|c|c|c|c|c|c|}
\hline & \multicolumn{4}{|c|}{ EARN } & \multicolumn{4}{|c|}{$8-\mathrm{K}$} \\
\hline & (1) & $(2)$ & (3) & (4) & $(5)$ & (6) & (7) & (8) \\
\hline$D I S(Z)$ & $\begin{array}{c}0.201^{* * *} \\
(0.009)\end{array}$ & $\begin{array}{c}0.153^{* * *} \\
(0.007)\end{array}$ & $\begin{array}{c}0.183^{* * *} \\
(0.010)\end{array}$ & $\begin{array}{c}0.138^{* * *} \\
(0.008)\end{array}$ & $\begin{array}{c}0.206^{* * *} \\
(0.010)\end{array}$ & $\begin{array}{c}0.172^{* * *} \\
(0.009)\end{array}$ & $\begin{array}{c}0.207^{* * *} \\
(0.010)\end{array}$ & $\begin{array}{c}0.173^{* * *} \\
(0.008)\end{array}$ \\
\hline$U O B(Z)$ & $\begin{array}{c}-0.094^{* * *} \\
(0.016)\end{array}$ & $\begin{array}{c}-0.113^{* * *} \\
(0.016)\end{array}$ & $\begin{array}{c}-0.069^{* * *} \\
(0.015)\end{array}$ & $\begin{array}{c}-0.092^{* * *} \\
(0.016)\end{array}$ & $\begin{array}{c}-0.055^{* * *} \\
(0.013)\end{array}$ & $\begin{array}{c}-0.049^{* * *} \\
(0.014)\end{array}$ & $\begin{array}{c}-0.044^{* * *} \\
(0.013)\end{array}$ & $\begin{array}{c}-0.038^{* * *} \\
(0.014)\end{array}$ \\
\hline$U O B(Z) \times D I S(Z)$ & & & $\begin{array}{c}-0.042^{* * *} \\
(0.012)\end{array}$ & $\begin{array}{c}-0.036^{* * *} \\
(0.010)\end{array}$ & & & $\begin{array}{c}-0.080^{* * *} \\
(0.007)\end{array}$ & $\begin{array}{c}-0.066^{* * *} \\
(0.006)\end{array}$ \\
\hline$R I S K(Z)$ & & $\begin{array}{c}0.294^{* * *} \\
(0.022)\end{array}$ & & $\begin{array}{c}0.293^{* * *} \\
(0.022)\end{array}$ & & $\begin{array}{c}0.296^{* * *} \\
(0.035)\end{array}$ & & $\begin{array}{c}0.293^{* * *} \\
(0.035)\end{array}$ \\
\hline Controls & $\mathrm{NO}$ & YES & $\mathrm{NO}$ & YES & $\mathrm{NO}$ & YES & $\mathrm{NO}$ & YES \\
\hline Firm FE & YES & YES & YES & YES & YES & YES & YES & YES \\
\hline Date FE & YES & YES & YES & YES & YES & YES & YES & YES \\
\hline Observations & 41,881 & 41,881 & 41,881 & 41,881 & 29,864 & 29,864 & 29,864 & 29,864 \\
\hline $\operatorname{Adj} R^{2}$ & 0.512 & 0.614 & 0.512 & 0.614 & 0.355 & 0.443 & 0.360 & 0.447 \\
\hline
\end{tabular}


Table 9: Uncertainty of Beliefs (UOB), media coverage and institutional attention

This table reports findings from daily panel regressions of $U O B(Z)$ in trading day $t-1$ to $t+5$ on day- $t$ 's news coverage $(N E W S)$, abnormal institutional investor attention $(A I A)$, and their interaction. Due to data availability of Bloomberg's institutional attention measure, the sample period is from January 2010 to December 2018. The regression tests control for RISK, additional proxies of uncertainty, and firm characteristics. Firm controls are similar to those reported in Table 3. All variables are defined in Table B.1. For brevity, the table reports the main coefficients of interest. (Z) stands for a Z-Score adjustment. Firm and date fixed effects are included in each specification. Standard errors are double clustered by firm and date and are reported in parentheses below the coefficient estimates. Statistical significance at the $10 \%, 5 \%$, and $1 \%$ level is indicated with ${ }^{*},{ }^{*}$, and ${ }^{* * *}$, respectively.

\begin{tabular}{lcccccc}
\hline & $(1)$ & $(2)$ & $(3)$ & $(4)$ & $(5)$ & $(6)$ \\
& $\mathrm{t}-1$ & $\mathrm{t}$ & $\mathrm{t}+1$ & $\mathrm{t}+2$ & $\mathrm{t}+3$ & $\mathrm{t}+5$ \\
\hline$N E W S$ & $-0.018^{* * *}$ & $-0.020^{* * *}$ & $-0.007^{* * *}$ & -0.003 & 0.000 & $0.004^{* *}$ \\
& $(0.002)$ & $(0.002)$ & $(0.002)$ & $(0.002)$ & $(0.002)$ & $(0.002)$ \\
AIA & $-0.032^{* * *}$ & $-0.109^{* * *}$ & $-0.085^{* * *}$ & $-0.053^{* * *}$ & $-0.044^{* * *}$ & $-0.033^{* * *}$ \\
& $(0.003)$ & $(0.005)$ & $(0.004)$ & $(0.003)$ & $(0.003)$ & $(0.003)$ \\
$N E W S \times A I A$ & $-0.036^{* * *}$ & $-0.089^{* * *}$ & -0.003 & $0.008^{* *}$ & $0.011^{* * *}$ & 0.006 \\
& $(0.004)$ & $(0.006)$ & $(0.004)$ & $(0.004)$ & $(0.004)$ & $(0.004)$ \\
Controls & & & & & & \\
Firm FE & YES & YES & YES & YES & YES & YES \\
Date FE & YES & YES & YES & YES & YES & YES \\
Observations & $3,260,063$ & $3,266,729$ & $3,259,928$ & $3,259,751$ & $3,259,580$ & $3,259,251$ \\
Adj $R^{2}$ & 0.723 & 0.709 & 0.714 & 0.709 & 0.705 & 0.697 \\
\hline
\end{tabular}


Table 10: Earnings announcements and Uncertainty of Beliefs (UOB) conditional on firm size

This table reports findings from daily panel regressions of $U O B(Z)$ from trading day $t-1$ to $t+5$ on day- $t$ firm earnings announcement events dummy $(E A R N)$ interacted with size tercile dummies. Size dummy variables - SMALL (Tercile 1), MEDIUM (Tercile 2), and LARGE (Tercile 3) - are constructed based upon day-stock market cap. The sample period is from January 2002 to December 2018. The regression tests control for RISK, additional proxies of uncertainty, and firm characteristics. Firm controls are similar to those reported in Table 3. All variables are defined in Table B.1. For brevity, the table reports the main coefficients of interest. (Z) stands for a Z-Score adjustment. Firm and date fixed effects are included in each specification. Standard errors are double clustered by firm and date and are reported in parentheses below the coefficient estimates. Statistical significance at the $10 \%, 5 \%$, and $1 \%$ level is indicated with *, $* *$, and ***, respectively.

\begin{tabular}{|c|c|c|c|c|c|c|}
\hline & $\begin{array}{l}(1) \\
\mathrm{t}-1\end{array}$ & $\begin{array}{c}(2) \\
\mathrm{t}\end{array}$ & $\begin{array}{c}(3) \\
t+1\end{array}$ & $\begin{array}{c}(4) \\
t+2\end{array}$ & $\begin{array}{c}(5) \\
\mathrm{t}+3\end{array}$ & $\begin{array}{c}(6) \\
t+5\end{array}$ \\
\hline $\begin{array}{l}E A R N \times \\
S M A L L\end{array}$ & $\begin{array}{c}-0.020^{* * *} \\
(0.006)\end{array}$ & $\begin{array}{c}0.068^{* * *} \\
(0.008)\end{array}$ & $\begin{array}{c}0.006 \\
(0.007)\end{array}$ & $\begin{array}{c}-0.015^{* *} \\
(0.006)\end{array}$ & $\begin{array}{c}0.000 \\
(0.006)\end{array}$ & $\begin{array}{c}0.015^{* *} \\
(0.006)\end{array}$ \\
\hline $\begin{array}{l}E A R N \times \\
M E D I U M\end{array}$ & $\begin{array}{c}-0.090^{* * *} \\
(0.004)\end{array}$ & $\begin{array}{c}-0.130^{* * *} \\
(0.007)\end{array}$ & $\begin{array}{c}-0.040^{* * *} \\
(0.005)\end{array}$ & $\begin{array}{c}-0.001 \\
(0.005)\end{array}$ & $\begin{array}{c}0.004 \\
(0.004)\end{array}$ & $\begin{array}{c}0.013^{* * *} \\
(0.005)\end{array}$ \\
\hline $\begin{array}{l}E A R N \times \\
L A R G E\end{array}$ & $\begin{array}{c}-0.181^{* * *} \\
(0.006)\end{array}$ & $\begin{array}{c}-0.435^{* * *} \\
(0.014)\end{array}$ & $\begin{array}{c}-0.165^{* * *} \\
(0.008)\end{array}$ & $\begin{array}{c}-0.034^{* * *} \\
(0.006)\end{array}$ & $\begin{array}{c}-0.015^{* * *} \\
(0.006)\end{array}$ & $\begin{array}{c}-0.017^{* * *} \\
(0.006)\end{array}$ \\
\hline $\begin{array}{l}\text { Controls } \\
\text { Firm FE } \\
\text { Date FE }\end{array}$ & $\begin{array}{l}\text { YES } \\
\text { YES } \\
\text { YES }\end{array}$ & $\begin{array}{l}\text { YES } \\
\text { YES } \\
\text { YES }\end{array}$ & $\begin{array}{l}\text { YES } \\
\text { YES } \\
\text { YES }\end{array}$ & $\begin{array}{l}\text { YES } \\
\text { YES } \\
\text { YES }\end{array}$ & $\begin{array}{l}\text { YES } \\
\text { YES } \\
\text { YES }\end{array}$ & $\begin{array}{l}\text { YES } \\
\text { YES } \\
\text { YES }\end{array}$ \\
\hline $\begin{array}{l}\text { Observations } \\
\operatorname{Adj} R^{2}\end{array}$ & $\begin{array}{c}6,750,823 \\
0.412\end{array}$ & $\begin{array}{c}6,764,799 \\
0.440\end{array}$ & $\begin{array}{c}6,750,152 \\
0.405\end{array}$ & $\begin{array}{c}6,749,414 \\
0.399\end{array}$ & $\begin{array}{c}6,748,637 \\
0.392\end{array}$ & $\begin{array}{c}6,747,110 \\
0.384\end{array}$ \\
\hline
\end{tabular}


Appendix B - Variable definitions and additional analysis 
Table B.1: Variable definitions

Variable

Definition

\begin{tabular}{|c|c|}
\hline$\overline{\mathrm{UOB}}$ & $\begin{array}{l}\text { The uncertainty of beliefs (outcome probabilities) measure is } \mathrm{d} \\
\text { tion } 2.1 \text {. To reduce noise due to outliers, the top and bottom } 0.1 \% \\
\text { are trimmed. }\end{array}$ \\
\hline$R I S K$ & $\begin{array}{l}\text { The risk measure as defined in detail in Section 2.1.1. To reduc } \\
\text { the top and bottom } 0.1 \% \text { of sample distribution are trimmed. }\end{array}$ \\
\hline$V O V$ & $\begin{array}{l}\text { Volatility-of-volatility, calculated as the daily variance of the v } \\
\text { intervals, where each interval's variance is computed using } 30-\mathrm{sec} \\
\text { noise due to outliers, the top and bottom } 0.1 \% \text { of sample distrib }\end{array}$ \\
\hline$V O M$ & $\begin{array}{l}\text { Volatility-of-mean, calculated as the daily variance of the avera } \\
\text { vals, where each interval's average is computed using } 30 \text {-second } \\
\text { due to outliers, the top and bottom } 0.1 \% \text { of sample distributior }\end{array}$ \\
\hline$D A F$ & $\begin{array}{l}\text { Disagreement of analysts' forecasts, obtained from } I B E S \text {, is con } \\
\text { deviation of the most recent next quarter's analysts' forecasts. } \\
\text { outliers, the top and bottom } 0.1 \% \text { of sample distribution are trir }\end{array}$ \\
\hline$S K E W$ & $\begin{array}{l}\text { Daily realized skewness, computed using } 30 \text {-second intraday } r \\
\text { due to outliers, the top and bottom } 0.1 \% \text { of sample distributio }\end{array}$ \\
\hline KURT & $\begin{array}{l}\text { Daily realized kurtosis, calculated using } 30 \text {-second intraday re } \\
\text { due to outliers, the top and bottom } 0.1 \% \text { of sample distributior }\end{array}$ \\
\hline$M k t U O B$ & UOB of the S\&P500 index (SPY ticker). \\
\hline$\triangle M k t U O B$ & Daily changes in $M k t U O B$, calculated as $M k t U O B_{t}-M k t U O B_{t}$ \\
\hline$V I X$ & $\begin{array}{l}\text { The CBOE volatility index, calculated based on the implied } \\
\text { options. }\end{array}$ \\
\hline$\Delta V I X$ & Daily changes in $V I X$, calculated as $V I X_{t}-V I X_{t-1}$. \\
\hline AveUOB & The 21 trading day average of UOB from day $t-27$ to $t-6$. \\
\hline AveRISK & The 21 trading day average of $R I S K$ from day $t-27$ to $t-6$. \\
\hline Ave VOV & The 21 trading day average of $V O V$ from day $t-27$ to $t-6$. \\
\hline AveVOM & The 21 trading day average of $V O M$ from day $t-27$ to $t-6$. \\
\hline AveSKEW & The 21 trading day average of $S K E W$ from day $t-27$ to $t-6$. \\
\hline AveKURT & The 21 trading day average of $K U R T$ from day $t-27$ to $t-6$ \\
\hline
\end{tabular}

Investor disagreement measures

$\overline{D I S}$ The daily disagreement measure for each firm and day constructed in Cookson and Niessner (2020), which is based on sentiment-stamped tweets posted to the investor social network StockTwits. Users self-classify individual tweets as bullish (sentiment $=1$ ) or bearish (sentiment $=-1$ ), and tweets are assigned to individual stocks by their "cashtag," which indicatesthe stock ticker. Given a set of tweets about a given firm on a trading day, the disagreement measure $(D I S)$ is the standard deviation of the underlying sentiment.

$D W G$ The within-group disagreement $(D W G)$ measure captures the dispersion of opinion of investors that share the same investment philosophy.

$D A G$ The across-group disagreement $(D A G)$ measure captures the dispersion of opinions of investors that are different in their investment philosophies and tend to express different opinions about the same firm at the same time. 


\section{Information Events} $E A R N$

$R E C$

$F 8 K$

MACRO_FOMC

MACRO_OTHER

News Coverage

News data

$N E W S$
A dummy variable equal to one on earnings announcement days for firm $j$ and zero otherwise. Earnings announcement data are from I/B/E/S.

A dummy variable equal to one on analyst recommendation days for firm $j$ and zero otherwise. Analyst recommendation data are from I/B/E/S. In constructing the sample, we follow Jegadeesh and Kim (2009), Loh and Stulz (2010), and Ben-Rephael et al. (2017). In particular, we: (1) remove recommendation changes that occur on the same day as, or the day following, earnings announcements; (2) remove recommendation changes on days when multiple analysts issue recommendations for the same firm; (3) require at least one analyst who to have issued a recommendation for the stock and revised the recommendation within 180 calendar days; (4) require at least two analysts to have active recommendations for the stock as of the day before the revision; (5) consider a recommendation to be active for up to 180 days after it is issued or until $\mathrm{I} / \mathrm{B} / \mathrm{E} / \mathrm{S}$ indicates that the analyst has stopped issuing recommendations for that stock. A dummy variable equal to one on Form 8-K filing days for firm $j$ and zero otherwise. Filing data are from WRDS SEC Suite.

A dummy variable equals to one on days with an announcement of the Federal Open Market Committee rate decision, and zero otherwise. FOMC announcement dates are from Bloomberg.

A dummy variable equals to one if at least one of NFP, PPI, GDP, and ISM is equal to one, and zero otherwise. Since there are macroeconomic announcements almost every day, we follow Ai and Bansal (2018) and limit ourselves to the five categories that draw the most attention from institutional investors on Bloomberg terminals: Nonfarm Payroll (NFP), Producer Price Index (PPI), FOMC, the advance estimate for GDP (GDP), and the ISM manufacturing index (ISM). For MACRO_OTHERwe exclude FOMC and keep all other MACRO announcements. The Macroeconomic announcement dates are from Bloomberg

Firm-specific news during 2002-2018 are taken from the Dow Jones News Wire of RavenPack Analytics. To capture fundamental news about the firm, the procedure reported in Engelberg et al. (2012), and Reed et al. (2018) is applied. First, to insure that the article is about the firm of interest, only articles with a relevance score of 100 are kept. Second, articles with the following news-types are kept: "News-Flash", "Hot-NewsFlash", "Full Article" and "Press Release". Third, articles with news categories related to market activity, which usually just report market statistics about the firm ("OrderImbalance", "Stock-Prices" and "Technical Analysis"), are exploded. Fourth, Redundancy earnings news are dropped by excluding categories, which are directly connected to Earnings ("Revenues", "Price-Targets" and "Investor-Relation"). Finally, news categories that have minimal representation in RavenPack (less than $0.1 \%$ of RavenPack's news stories) are exploded. Thirteen news categories remain: "AcquisitionsMergers" (MEAA), "Analyst-Ratings" (ANALRATE), "Assets" (ASSETS), "Credit" (CREDIT), "Credit-Ratings" (CREDRATE), "Dividends" (DIV), "Earnings" (EARN$I N G S)$, "Equity-Actions" (EQUITYACT), "Labor-Issues" (LABOR), "Legal" (LE$G A L)$, "Marketing" $(M K T G)$, "Products-Services" (PRODSERV), and "Partnerships" (PARTNER). This cleaned news archive is used to contract the news coverage variables. Following Engelberg et al. (2012) and others, news articles that occur after market close (i.e., 4pm-midnight) are treated as if they become available on the next trading day. $N E W S$ is dummy variable equal to one on a given day for a given firm if the number of news articles published on the Dow Jones newswire across the thirteen categories during the day is non-zero. $N E W S$ is set to zero otherwise. 


\section{Institutional Investor Attention Measure}

$A I A$

Ben-Rephael et al. (2017) abnormal institutional investor attention measure. Bloomberg records the number of times terminal users actively search for or read news articles on particular stocks, and places more emphasis on active demand for information for a specific firm by assigning a score of 10 when users search for news and 1 when users simply read a news article. These numbers are aggregated into hourly counts and Bloomberg creates an attention score by comparing the average hourly count during the previous 8 hours to all hourly counts over the previous month for the same stock. They assign a score of $0,1,2,3$ or 4 if the rolling average is in the lowest $80 \%$ of the hourly counts over the previous 30 days, between $80 \%$ and $90 \%, 90 \%$ and $94 \%, 94 \%$ and $96 \%$, or greater than $96 \%$ of the previous 30 days' hourly counts, respectively. AIA is a dummy variable that receives the value one if the Bloomberg score is 3 or 4 , and zero otherwise. Bloomberg's historical attention measures begin on 2/17/2010.

\section{Intraday Jump Control Variables}

\# Jumps The number of intrady jumps of firm $j$ on day $t$ following Lee and Mykland (2008).

Ave \# Jumps The average absolute intraday jump magnitude of firm $j$ on day $t$ following Lee and Mykland (2008).

Jump Intensity The intraday jump intensity of firm $j$ on day $t$ following Lee and Mykland (2008).

\section{Control Variables Based on UOB's Features}

\# Dist.

Ave Obs Per Dist.

Std.Dev Obs. Per Dist.

Std.Dev.TrdVol Per Dist.

The number of intraday distributions used in the calculation of UOB of firm $j$ on day $t$. The average number of observations per intraday distribution used in the calculation of UOB of firm $j$ on day $t$.

The standard deviation of the number of observations per distribution used in the calculation of UOB of firm $j$ on day $t$.

The standard deviation of the aggregate trading volume per distribution used in the calculation of $\mathrm{UOB}$ of firm $j$ on day $t$, normalized by day $t$ 's average trading volume per distribution.

\section{Other Control Variables}

LnSize

$\operatorname{LnBM}$

AveTURNOVER

RET

CumRet

LnNumEst

InstHold

$\ln \frac{1}{\text { AvePrc }}$

$E S$
The natural logarithm of the stock's size in millions of dollars following Fama-French (1992).

The natural logarithm of the firm's book-to-market ratio (BM) rebalanced every June following Fama-French (1992).

The previous 21 trading day average of TURNOVER, from day $t-27$ to $t-6$. TURNOVERin turn, is the daily stock turnover, calculated as the number of daily traded shares divided by outstanding shares.

The CRSP's daily stock return.

The stock cumulative returns over 21 trading days from day $t-27$ to $t-6$.

The natural logarithm of (1+NumEst), where NumEst is The number of analysts covering the stock using the most recent information from $\mathrm{I} / \mathrm{B} / \mathrm{E} / \mathrm{S}$.

Aggregate institutional investor holdings based on the most recent quarter prior to date t. The institutional holding data is from Thomson Reuters S34 file.

The natural logarithm of 1 over the stock average price (AvePrc), adjusted for splits. AvePrc is calculated from day $t-27$ to $t-6$.

The daily share-weighted average effective spread provided by WRDS Intraday Indicators Suite. Prior to 2004, ES is calculated based on the TAQ monthly database (WRDS variable ESPREADPCT_SWI). Starting 2004 ES is calculated based on the TAQ millisecond data (WRDS variable EFFECTIVESPREAD_PERCENT_SW). 
Table B.2: Investor disagreement and Uncertainty of Beliefs (UOB) - constant sample

This table replicates the analysis in Panel A of Table 3, enforcing the same number of observations across days $t, t+1$ and $t+2$. All variables are defined in Table B.1. For brevity, the table reports the main coefficients of interest. (Z) stands for a Z-Score adjustment. Firm and date fixed effects are included in each specification. Standard errors are double clustered by firm and date and are reported in parentheses below the coefficient estimates. Statistical significance at the $10 \%, 5 \%$, and $1 \%$ level is indicated with *, ${ }^{* *}$, and ${ }^{* * *}$, respectively.

\begin{tabular}{|c|c|c|c|c|c|c|c|c|c|}
\hline & \multicolumn{3}{|c|}{$\mathrm{t}$} & \multicolumn{3}{|c|}{$t+1$} & \multicolumn{3}{|c|}{$t+2$} \\
\hline & (1) & $(2)$ & (3) & (4) & (5) & (6) & (7) & (8) & (9) \\
\hline & $\mathrm{t}$ & $\mathrm{t}$ & $\mathrm{t}$ & $t+1$ & $t+1$ & $t+1$ & $t+2$ & $t+2$ & $t+2$ \\
\hline$U O B(Z)$ & $\begin{array}{c}-0.100^{* * *} \\
(0.006)\end{array}$ & $\begin{array}{c}-0.114^{* * *} \\
(0.007)\end{array}$ & $\begin{array}{c}-0.097^{* * *} \\
(0.006)\end{array}$ & $\begin{array}{c}-0.058^{* * *} \\
(0.004)\end{array}$ & $\begin{array}{c}-0.060^{* * *} \\
(0.004)\end{array}$ & $\begin{array}{c}-0.050^{* * *} \\
(0.004)\end{array}$ & $\begin{array}{c}-0.033^{* * *} \\
(0.004)\end{array}$ & $\begin{array}{c}-0.027^{* * *} \\
(0.003)\end{array}$ & $\begin{array}{c}-0.022^{* * *} \\
(0.003)\end{array}$ \\
\hline$R I S K(Z)$ & & $\begin{array}{c}0.164^{* * *} \\
(0.010)\end{array}$ & $\begin{array}{c}0.074^{* * *} \\
(0.007)\end{array}$ & & $\begin{array}{c}0.098^{* * *} \\
(0.008)\end{array}$ & $\begin{array}{c}0.044^{* * *} \\
(0.006)\end{array}$ & & $\begin{array}{c}0.034^{* * *} \\
(0.006)\end{array}$ & $\begin{array}{c}0.003 \\
(0.006)\end{array}$ \\
\hline TURNOVER(Z) & & & $\begin{array}{c}0.204^{* * *} \\
(0.007)\end{array}$ & & & $\begin{array}{c}0.109^{* * *} \\
(0.004)\end{array}$ & & & $\begin{array}{c}0.058^{* * *} \\
(0.003)\end{array}$ \\
\hline Controls & $\mathrm{NO}$ & YES & YES & $\mathrm{NO}$ & YES & YES & $\mathrm{NO}$ & YES & YES \\
\hline Firm FE & YES & YES & YES & YES & YES & YES & YES & YES & YES \\
\hline Date FE & YES & YES & YES & YES & YES & YES & YES & YES & YES \\
\hline Observations & 422,995 & 422,995 & 421,117 & 422,995 & 422,995 & 421,117 & 422,995 & 422,995 & 421,117 \\
\hline $\operatorname{Adj} R^{2}$ & 0.142 & 0.160 & 0.185 & 0.130 & 0.135 & 0.143 & 0.140 & 0.143 & 0.145 \\
\hline
\end{tabular}


Table B.3: Investor disagreement, turnover, and Uncertainty of Beliefs (UOB) - the same day dependent and independent variables

This table replicates the analysis in Panel A of Table 4, where the dependent and independent variables are in the same trading day subsequent to the event day. All variables are defined in Table B.1. For brevity, the table reports the main coefficients of interest. (Z) stands for a Z-Score adjustment. Firm and date fixed effects are included in each specification. Standard errors are double clustered by firm and date and are reported in parentheses below the coefficient estimates. Statistical significance at the $10 \%, 5 \%$, and $1 \%$ level is indicated with $*, * *$, and ${ }^{* * *}$, respectively.

\begin{tabular}{|c|c|c|c|c|c|c|c|c|}
\hline & \multicolumn{2}{|c|}{$\mathrm{t}$} & \multicolumn{2}{|c|}{$t+1$} & \multicolumn{2}{|c|}{$\mathrm{t}+2$} & \multicolumn{2}{|c|}{$\mathrm{t}+3$} \\
\hline & (1) & (2) & (3) & (4) & (5) & (6) & (7) & (8) \\
\hline & $\mathrm{t}$ & $\mathrm{t}$ & $t+1$ & $t+1$ & $t+2$ & $t+2$ & $t+3$ & $t+3$ \\
\hline$D I S(Z)$ & $\begin{array}{c}0.153^{* * *} \\
(0.007)\end{array}$ & $\begin{array}{c}0.138^{* * *} \\
(0.008)\end{array}$ & & & & & & \\
\hline$U O B(Z)$ & $\begin{array}{c}-0.113^{* * *} \\
(0.016)\end{array}$ & $\begin{array}{c}-0.092^{* * *} \\
(0.016)\end{array}$ & & & & & & \\
\hline$U O B(Z) \times D I S(Z)$ & & $\begin{array}{c}-0.036^{* * *} \\
(0.010)\end{array}$ & & & & & & \\
\hline$R I S K(Z)$ & $\begin{array}{c}0.294^{* * *} \\
(0.022)\end{array}$ & $\begin{array}{c}0.293^{* * *} \\
(0.022)\end{array}$ & & & & & & \\
\hline$D I S(Z) t+1$ & & & $\begin{array}{c}0.152^{* * *} \\
(0.007)\end{array}$ & $\begin{array}{c}0.140^{* * *} \\
(0.007)\end{array}$ & & & & \\
\hline$U O B(Z) t+1$ & & & $\begin{array}{l}-0.017 \\
(0.018)\end{array}$ & $\begin{array}{l}-0.013 \\
(0.019)\end{array}$ & & & & \\
\hline$U O B(Z) \times D I S(Z) t+1$ & & & & $\begin{array}{c}-0.070^{* * *} \\
(0.009)\end{array}$ & & & & \\
\hline$R I S K(Z) t+1$ & & & $\begin{array}{c}0.472^{* * *} \\
(0.032)\end{array}$ & $\begin{array}{c}0.469^{* * *} \\
(0.032)\end{array}$ & & & & \\
\hline$D I S(Z) t+2$ & & & & & $\begin{array}{c}0.121^{* * *} \\
(0.008)\end{array}$ & $\begin{array}{c}0.120^{* * *} \\
(0.007)\end{array}$ & & \\
\hline$U O B(Z) t+2$ & & & & & $\begin{array}{l}-0.021 \\
(0.019)\end{array}$ & $\begin{array}{l}-0.023 \\
(0.019)\end{array}$ & & \\
\hline$U O B(Z) \times D I S(Z) t+2$ & & & & & & $\begin{array}{c}-0.052^{* * *} \\
(0.007)\end{array}$ & & \\
\hline$R I S K(Z) t+2$ & & & & & $\begin{array}{c}0.301^{* * *} \\
(0.039)\end{array}$ & $\begin{array}{c}0.299^{* * *} \\
(0.039)\end{array}$ & & \\
\hline$D I S(Z) t+3$ & & & & & & & $\begin{array}{c}0.096^{* * *} \\
(0.008)\end{array}$ & $\begin{array}{c}0.096^{* * *} \\
(0.008)\end{array}$ \\
\hline$U O B(Z) t+3$ & & & & & & & $\begin{array}{c}-0.035^{* *} \\
(0.015)\end{array}$ & $\begin{array}{c}-0.039^{* *} \\
(0.016)\end{array}$ \\
\hline$U O B(Z) \times D I S(Z) t+3$ & & & & & & & & $\begin{array}{c}-0.044^{* * *} \\
(0.006)\end{array}$ \\
\hline$R I S K(Z) t+3$ & & & & & & & $\begin{array}{c}0.264^{* * *} \\
(0.040)\end{array}$ & $\begin{array}{c}0.263^{* * *} \\
(0.040)\end{array}$ \\
\hline Controls & YES & YES & YES & YES & YES & YES & YES & YES \\
\hline Firm FE & YES & YES & YES & YES & YES & YES & YES & YES \\
\hline Date FE & YES & YES & YES & YES & YES & YES & YES & YES \\
\hline Observations & 41,881 & 41,881 & 26,991 & 26,991 & 18,712 & 18,712 & 18,310 & 18,310 \\
\hline $\operatorname{Adj} R^{2}$ & 0.614 & 0.614 & 0.604 & 0.606 & 0.601 & 0.603 & 0.575 & 0.576 \\
\hline
\end{tabular}


Table B.4: CORR(TRDVOL,VAR) and UOB on firm earnings announcement days

This table reports findings from daily panel regressions of the intraday correlation between volatility and trading volume (CORR(TRDVOL,VAR)) on earnings announcement day $t$ and the subsequent five trading days $(t+1-t+5)$, on day- $t$ 's $U O B(Z)$. The sample period is from January 2002 to December 2018. The regression tests control for RISK, additional proxies of uncertainty, and firm characteristics. Firm controls are similar to those reported in Table 3. All variables are defined in Table B.1. For brevity, the table reports the main coefficients of interest. (Z) stands for a Z-Score adjustment. Firm and date fixed effects are included in each specification. Standard errors are double clustered by firm and date and are reported in parentheses below the coefficient estimates. Statistical significance at the $10 \%, 5 \%$, and $1 \%$ level is indicated with *, **, and ${ }^{* * *}$, respectively.

\begin{tabular}{lccccc}
\hline & $(1)$ & $(2)$ & $(3)$ & $(4)$ & $(5)$ \\
& $\mathrm{t}$ & $\mathrm{t}+1$ & $\mathrm{t}+2$ & $\mathrm{t}+3$ & $\mathrm{t}+5$ \\
\hline$U O B(Z)$ & $-0.030^{* * *}$ & $-0.021^{* * *}$ & $-0.018^{* * *}$ & -0.006 & -0.005 \\
& $(0.004)$ & $(0.005)$ & $(0.004)$ & $(0.004)$ & $(0.004)$ \\
Controls & & & & YES & YES \\
Firm FE & YES & YES & YES & YES & YES \\
Date FE & YES & YES & YES & YES & YES \\
& YES & YES & YES & & 101,131 \\
Observations & & & & 0.272 & 101,039 \\
$\operatorname{Adj} R^{2}$ & 100,400 & 101,121 & 101,157 & 0.272 \\
\hline
\end{tabular}


Table B.5: Uncertainty of Beliefs (UOB) and macroeconomic announcements

This table reports findings from daily panel regressions of $U O B(Z)$ from trading day $t-1$ to $t+3$ on day$t$ 's macroeconomic announcements. The sample period is from January 2002 to December 2018. Ourselves are limited to the five categories that draw the most attention from institutional investors on Bloomberg terminals Ai and Bansal (2018): Nonfarm Payroll (NFP), Producer Price Index (PPI), FOMC, the advance estimate for GDP (GDP), and the ISM manufacturing index (ISM). Specifications 1-4 only include the FOMC announcements, and specifications 5-8 include the other non-FOMC announcements. The regression tests control for $R I S K$, additional proxies of uncertainty, and firm characteristics. Firm controls are similar to those reported in Table 3. All variables are defined in Table B.1. For brevity, the table reports the main coefficients of interest. (Z) stands for a Z-Score adjustment.Firm and day-of-the-week fixed effects are included in each specification. Standard errors are double clustered by firm and date and are reported in parentheses below the coefficient estimates. Statistical significance at the $10 \%, 5 \%$, and $1 \%$ level is indicated with *, **, and $* * *$, respectively.

\begin{tabular}{|c|c|c|c|c|c|c|c|c|}
\hline & \multicolumn{4}{|c|}{ FOMC } & \multicolumn{4}{|c|}{ OTHER } \\
\hline & (1) & $(2)$ & (3) & (4) & (5) & $(6)$ & $(7)$ & $(8)$ \\
\hline & $\mathrm{t}$ & $\mathrm{t}+1$ & $\mathrm{t}+2$ & $\mathrm{t}+3$ & $\mathrm{t}$ & $\mathrm{t}+1$ & $t+2$ & $\mathrm{t}+3$ \\
\hline$M A C R O$ & $\begin{array}{c}-0.060^{* * *} \\
(0.011)\end{array}$ & $\begin{array}{c}-0.047^{* * *} \\
(0.013)\end{array}$ & $\begin{array}{c}-0.031^{* *} \\
(0.015)\end{array}$ & $\begin{array}{c}-0.010 \\
(0.016)\end{array}$ & $\begin{array}{c}-0.046^{* * *} \\
(0.007)\end{array}$ & $\begin{array}{c}0.001 \\
(0.009)\end{array}$ & $\begin{array}{c}-0.005 \\
(0.009)\end{array}$ & $\begin{array}{l}-0.005 \\
(0.009)\end{array}$ \\
\hline Controls & YES & YES & YES & YES & YES & YES & YES & YES \\
\hline Firm FE & YES & YES & YES & YES & YES & YES & YES & YES \\
\hline Day-of-Week FE & YES & YES & YES & YES & YES & YES & YES & YES \\
\hline Observations & $6,764,799$ & $6,750,152$ & $6,749,414$ & $6,748,637$ & $6,764,799$ & $6,750,152$ & $6,749,414$ & $6,748,637$ \\
\hline $\operatorname{Adj} R^{2}$ & 0.586 & 0.565 & 0.556 & 0.547 & 0.586 & 0.565 & 0.556 & 0.547 \\
\hline
\end{tabular}


Table B.6: Uncertainty of Beliefs (UOB) and time of event

This table refines the analysis in Table 5. Firm information events are split into events that occurred before market opening $(B M O)$ and event that occurred during market hours $(D M H)$. For brevity, the table reports the main coefficients of interest. (Z) stands for a Z-Score adjustment.

Panel A: $U O B(Z)$ and $E A R N$

\begin{tabular}{ccccccc}
\hline & $(1)$ & $(2)$ & $(3)$ & $(4)$ & $(5)$ & $(6)$ \\
& $\mathrm{t}-1$ & $\mathrm{t}$ & $\mathrm{t}+1$ & $\mathrm{t}+2$ & $\mathrm{t}+3$ & $\mathrm{t}+5$ \\
\hline$E A R N_{-} B M O$ & $-0.104^{* * *}$ & $-0.220^{* * *}$ & $-0.085^{* * *}$ & $-0.026^{* * *}$ & $-0.011^{* * *}$ & -0.003 \\
& $(0.00)$ & $(0.01)$ & $(0.01)$ & $(0.00)$ & $(0.00)$ & $(0.00)$ \\
$E A R N_{-} D M H$ & $-0.074^{* * *}$ & $-0.121^{* * *}$ & $-0.061^{* * *}$ & -0.008 & 0.002 & 0.002 \\
& $(0.01)$ & $(0.01)$ & $(0.01)$ & $(0.00)$ & $(0.00)$ & $(0.00)$ \\
\hline
\end{tabular}

Panel B: $U O B(Z)$ and $F 8 K$

\begin{tabular}{|c|c|c|c|c|c|c|}
\hline & $\begin{array}{l}(1) \\
\mathrm{t}-1 \\
\end{array}$ & $\begin{array}{c}(2) \\
\mathrm{t}\end{array}$ & $\begin{array}{c}(3) \\
\mathrm{t}+1\end{array}$ & $\begin{array}{c}(4) \\
\mathrm{t}+2\end{array}$ & $\begin{array}{c}(5) \\
t+3\end{array}$ & $\begin{array}{c}(6) \\
t+5\end{array}$ \\
\hline$F 8 K_{-} B M O$ & $\begin{array}{r}-0.001 \\
(0.00)\end{array}$ & $\begin{array}{c}-0.005 \\
(0.00)\end{array}$ & $\begin{array}{c}0.010^{* * *} \\
(0.00)\end{array}$ & $\begin{array}{c}0.009^{* * *} \\
(0.00)\end{array}$ & $\begin{array}{c}0.010^{* * *} \\
(0.00)\end{array}$ & $\begin{array}{c}0.009^{* * *} \\
(0.00)\end{array}$ \\
\hline$F 8 K_{-} D M H$ & $\begin{array}{c}-0.005 \\
(0.00)\end{array}$ & $\begin{array}{c}-0.007^{*} \\
(0.00)\end{array}$ & $\begin{array}{c}-0.001 \\
(0.00)\end{array}$ & $\begin{array}{l}0.005 \\
(0.00)\end{array}$ & $\begin{array}{c}-0.001 \\
(0.00)\end{array}$ & $\begin{array}{l}0.002 \\
(0.00)\end{array}$ \\
\hline
\end{tabular}


Table B.7: Investor disagreement and Uncertainty of Beliefs (UOB) - full set of controls

This table reports the full set of controls from Panel A of Table 3. (Z) stands for a Z-Score adjustment. Firm and date fixed effects are included in each specification. Standard errors are double clustered by firm and date and are reported in parentheses below the coefficient estimates. Statistical significance at the $10 \%$, $5 \%$, and $1 \%$ level is indicated with $* * *$, and $* * *$, respectively.

\begin{tabular}{|c|c|c|c|c|c|c|c|c|c|}
\hline & \multicolumn{3}{|c|}{$\mathrm{t}$} & \multicolumn{3}{|c|}{$\mathrm{t}+1$} & \multicolumn{3}{|c|}{$t+2$} \\
\hline & $\begin{array}{c}(1) \\
t\end{array}$ & $\begin{array}{c}(2) \\
\mathrm{t}\end{array}$ & $\begin{array}{c}(3) \\
\mathrm{t}\end{array}$ & $\begin{array}{c}(4) \\
t+1\end{array}$ & $\begin{array}{c}(5) \\
t+1\end{array}$ & $\begin{array}{c}(6) \\
t+1\end{array}$ & $\begin{array}{c}(7) \\
t+2\end{array}$ & $\begin{array}{c}(8) \\
t+2\end{array}$ & $\begin{array}{c}(9) \\
t+2\end{array}$ \\
\hline$U O B(Z)$ & $\begin{array}{c}-0.082^{* * *} \\
(0.004)\end{array}$ & $\begin{array}{c}-0.095^{* * *} \\
(0.004)\end{array}$ & $\begin{array}{c}-0.083^{* * *} \\
(0.004)\end{array}$ & $\begin{array}{c}-0.053^{* * *} \\
(0.004)\end{array}$ & $\begin{array}{c}-0.054^{* * *} \\
(0.003)\end{array}$ & $\begin{array}{c}-0.046^{* * *} \\
(0.003)\end{array}$ & $\begin{array}{c}-0.032^{* * *} \\
(0.004)\end{array}$ & $\begin{array}{c}-0.027^{* * *} \\
(0.003)\end{array}$ & $\begin{array}{c}-0.022^{* * *} \\
(0.003)\end{array}$ \\
\hline$R I S K(Z)$ & & $\begin{array}{c}0.131^{* * *} \\
(0.006)\end{array}$ & $\begin{array}{c}0.079^{* * *} \\
(0.004)\end{array}$ & & $\begin{array}{c}0.082^{* * *} \\
(0.006)\end{array}$ & $\begin{array}{c}0.039^{* * *} \\
(0.005)\end{array}$ & & $\begin{array}{c}0.030^{* * *} \\
(0.005)\end{array}$ & $\begin{array}{c}0.003 \\
(0.005)\end{array}$ \\
\hline TURNOVER(Z) & & & $\begin{array}{c}0.237^{* * *} \\
(0.005)\end{array}$ & & & $\begin{array}{c}0.113^{* * *} \\
(0.003)\end{array}$ & & & $\begin{array}{c}0.068^{* * *} \\
(0.003)\end{array}$ \\
\hline$V O V$ & & $\begin{array}{c}-0.008^{* * *} \\
(0.001)\end{array}$ & $\begin{array}{c}-0.002^{* *} \\
(0.001)\end{array}$ & & $\begin{array}{c}-0.009^{* * *} \\
(0.001)\end{array}$ & $\begin{array}{c}-0.008^{* * *} \\
(0.001)\end{array}$ & & $\begin{array}{c}-0.006^{* * *} \\
(0.001)\end{array}$ & $\begin{array}{c}-0.006^{* * *} \\
(0.001)\end{array}$ \\
\hline$V O M$ & & $\begin{array}{c}0.064^{* * *} \\
(0.002)\end{array}$ & $\begin{array}{c}0.031^{* * *} \\
(0.001)\end{array}$ & & $\begin{array}{c}0.017^{* * *} \\
(0.002)\end{array}$ & $\begin{array}{c}-0.004^{* *} \\
(0.002)\end{array}$ & & $\begin{array}{c}0.009^{* * *} \\
(0.002)\end{array}$ & $\begin{array}{c}-0.004^{* *} \\
(0.002)\end{array}$ \\
\hline$D A F$ & & $\begin{array}{c}0.025 \\
(0.016)\end{array}$ & $\begin{array}{c}0.000 \\
(0.015)\end{array}$ & & $\begin{array}{c}0.028 \\
(0.020)\end{array}$ & $\begin{array}{c}0.007 \\
(0.021)\end{array}$ & & $\begin{array}{c}0.026 \\
(0.022)\end{array}$ & $\begin{array}{c}0.011 \\
(0.022)\end{array}$ \\
\hline$S K E W$ & & $\begin{array}{c}0.013^{* * *} \\
(0.004)\end{array}$ & $\begin{array}{c}0.016^{* * *} \\
(0.004)\end{array}$ & & $\begin{array}{c}0.006 \\
(0.005)\end{array}$ & $\begin{array}{c}0.010^{* *} \\
(0.005)\end{array}$ & & $\begin{array}{c}0.007 \\
(0.006)\end{array}$ & $\begin{array}{c}0.009 \\
(0.006)\end{array}$ \\
\hline$K U R T$ & & $\begin{array}{c}-0.022^{* * *} \\
(0.002)\end{array}$ & $\begin{array}{c}-0.002 \\
(0.002)\end{array}$ & & $\begin{array}{c}-0.011^{* * *} \\
(0.003)\end{array}$ & $\begin{array}{c}0.003 \\
(0.003)\end{array}$ & & $\begin{array}{c}-0.011^{* * *} \\
(0.003)\end{array}$ & $\begin{array}{l}-0.003 \\
(0.003)\end{array}$ \\
\hline$E S$ & & $\begin{array}{c}0.645 \\
(0.734)\end{array}$ & $\begin{array}{c}1.607^{* *} \\
(0.683)\end{array}$ & & $\begin{array}{c}-3.205^{* * *} \\
(1.146)\end{array}$ & $\begin{array}{c}-2.480^{* * *} \\
(0.908)\end{array}$ & & $\begin{array}{c}-3.445^{* * *} \\
(1.140)\end{array}$ & $\begin{array}{c}-2.749^{* * *} \\
(0.902)\end{array}$ \\
\hline AveUOB & & $\begin{array}{c}0.000^{* * *} \\
(0.000)\end{array}$ & $\begin{array}{c}0.000^{* * *} \\
(0.000)\end{array}$ & & $\begin{array}{c}0.000^{* * * *} \\
(0.000)\end{array}$ & $\begin{array}{c}0.000^{* *} \\
(0.000)\end{array}$ & & $\begin{array}{l}-0.000 \\
(0.000)\end{array}$ & $\begin{array}{c}-0.000^{*} \\
(0.000)\end{array}$ \\
\hline AveRISK & & $\begin{array}{c}-0.016^{* * *} \\
(0.001)\end{array}$ & $\begin{array}{c}-0.011^{* * *} \\
(0.001)\end{array}$ & & $\begin{array}{c}-0.008^{* * *} \\
(0.002)\end{array}$ & $\begin{array}{c}-0.004^{* *} \\
(0.002)\end{array}$ & & $\begin{array}{l}-0.002 \\
(0.002)\end{array}$ & $\begin{array}{l}-0.000 \\
(0.002)\end{array}$ \\
\hline AveVOV & & $\begin{array}{c}-1.649^{* * *} \\
(0.404)\end{array}$ & $\begin{array}{c}0.288 \\
(0.324)\end{array}$ & & $\begin{array}{c}-2.341^{* * *} \\
(0.484)\end{array}$ & $\begin{array}{c}-0.860^{* *} \\
(0.433)\end{array}$ & & $\begin{array}{c}-2.891^{* * *} \\
(0.519)\end{array}$ & $\begin{array}{c}-1.751^{* * *} \\
(0.484)\end{array}$ \\
\hline AveVOM & & $\begin{array}{c}0.329 \\
(0.725)\end{array}$ & $\begin{array}{c}0.514 \\
(0.632)\end{array}$ & & $\begin{array}{c}3.419^{* * *} \\
(0.916)\end{array}$ & $\begin{array}{c}3.210^{* * *} \\
(0.822)\end{array}$ & & $\begin{array}{c}4.441^{* * *} \\
(0.926)\end{array}$ & $\begin{array}{c}3.990^{* * *} \\
(0.857)\end{array}$ \\
\hline AveSKEW & & $\begin{array}{c}0.013 \\
(0.017)\end{array}$ & $\begin{array}{l}-0.000 \\
(0.016)\end{array}$ & & $\begin{array}{c}0.022 \\
(0.024)\end{array}$ & $\begin{array}{c}0.011 \\
(0.023)\end{array}$ & & $\begin{array}{c}0.041 \\
(0.025)\end{array}$ & $\begin{array}{c}0.035 \\
(0.025)\end{array}$ \\
\hline AveKURT & & $\begin{array}{c}-0.065^{* * *} \\
(0.011)\end{array}$ & $\begin{array}{c}-0.028^{* * *} \\
(0.009)\end{array}$ & & $\begin{array}{c}-0.071^{* * *} \\
(0.013)\end{array}$ & $\begin{array}{c}-0.047^{* * *} \\
(0.011)\end{array}$ & & $\begin{array}{c}-0.077^{* * *} \\
(0.013)\end{array}$ & $\begin{array}{c}-0.055^{* * *} \\
(0.012)\end{array}$ \\
\hline
\end{tabular}




\begin{tabular}{|c|c|c|c|c|c|c|c|c|c|}
\hline & \multicolumn{3}{|c|}{$\mathrm{t}$} & \multicolumn{3}{|c|}{$\mathrm{t}+1$} & \multicolumn{3}{|c|}{$\mathrm{t}+2$} \\
\hline & (1) & (2) & (3) & $\begin{array}{c}(4) \\
t+1\end{array}$ & $\begin{array}{c}(5) \\
t+1\end{array}$ & $\begin{array}{c}(6) \\
t+1\end{array}$ & $\begin{array}{c}(7) \\
t+2\end{array}$ & $\begin{array}{c}(8) \\
t+2\end{array}$ & $\begin{array}{c}(9) \\
t+2\end{array}$ \\
\hline LnSize & & $\begin{array}{c}0.011 \\
(0.011)\end{array}$ & $\begin{array}{c}0.035^{* * *} \\
(0.012)\end{array}$ & & $\begin{array}{c}0.003 \\
(0.012)\end{array}$ & $\begin{array}{l}0.021^{*} \\
(0.012)\end{array}$ & & $\begin{array}{l}-0.005 \\
(0.012)\end{array}$ & $\begin{array}{c}0.009 \\
(0.012)\end{array}$ \\
\hline $\operatorname{LnBM}$ & & $\begin{array}{c}-0.017^{* *} \\
(0.008)\end{array}$ & $\begin{array}{l}-0.010 \\
(0.008)\end{array}$ & & $\begin{array}{c}-0.021^{* *} \\
(0.009)\end{array}$ & $\begin{array}{c}-0.017^{* *} \\
(0.009)\end{array}$ & & $\begin{array}{c}-0.022^{* *} \\
(0.009)\end{array}$ & $\begin{array}{c}-0.018^{* *} \\
(0.009)\end{array}$ \\
\hline CumRet & & $\begin{array}{c}0.001^{* * *} \\
(0.000)\end{array}$ & $\begin{array}{c}0.002^{* * *} \\
(0.000)\end{array}$ & & $\begin{array}{c}0.001^{* * *} \\
(0.000)\end{array}$ & $\begin{array}{c}0.001^{* * *} \\
(0.000)\end{array}$ & & $\begin{array}{c}0.000 \\
(0.000)\end{array}$ & $\begin{array}{c}0.000^{* *} \\
(0.000)\end{array}$ \\
\hline LnNumEst & & $\begin{array}{c}0.001 \\
(0.011)\end{array}$ & $\begin{array}{c}-0.022^{* *} \\
(0.010)\end{array}$ & & $\begin{array}{c}0.014 \\
(0.014)\end{array}$ & $\begin{array}{l}-0.005 \\
(0.013)\end{array}$ & & $\begin{array}{c}0.015 \\
(0.015)\end{array}$ & $\begin{array}{c}0.002 \\
(0.014)\end{array}$ \\
\hline InstHold & & $\begin{array}{c}-0.081^{* * *} \\
(0.024)\end{array}$ & $\begin{array}{c}-0.118^{* * *} \\
(0.023)\end{array}$ & & $\begin{array}{c}-0.100^{* * *} \\
(0.032)\end{array}$ & $\begin{array}{c}-0.124^{* * *} \\
(0.031)\end{array}$ & & $\begin{array}{c}-0.106^{* * *} \\
(0.035)\end{array}$ & $\begin{array}{c}-0.123^{* * *} \\
(0.034)\end{array}$ \\
\hline AveTURNOVER & & $\begin{array}{c}1.998^{* * *} \\
(0.754)\end{array}$ & $\begin{array}{l}-0.562 \\
(0.353)\end{array}$ & & $\begin{array}{c}1.325^{* *} \\
(0.532)\end{array}$ & $\begin{array}{c}0.929^{* * *} \\
(0.347)\end{array}$ & & $\begin{array}{c}1.288^{* *} \\
(0.531)\end{array}$ & $\begin{array}{c}1.807^{* * *} \\
(0.501)\end{array}$ \\
\hline $\ln \frac{1}{A v e P r c}$ & & $\begin{array}{c}-0.090^{* * *} \\
(0.013)\end{array}$ & $\begin{array}{c}-0.107^{* * *} \\
(0.012)\end{array}$ & & $\begin{array}{c}-0.078^{* * *} \\
(0.015)\end{array}$ & $\begin{array}{c}-0.088^{* * *} \\
(0.014)\end{array}$ & & $\begin{array}{c}-0.087^{* * *} \\
(0.016)\end{array}$ & $\begin{array}{c}-0.094^{* * *} \\
(0.015)\end{array}$ \\
\hline$R E T$ & & $\begin{array}{c}0.009^{* * *} \\
(0.001)\end{array}$ & $\begin{array}{c}0.010^{* * *} \\
(0.000)\end{array}$ & & $\begin{array}{c}0.004^{* * *} \\
(0.000)\end{array}$ & $\begin{array}{c}0.004^{* * *} \\
(0.001)\end{array}$ & & $\begin{array}{c}0.001^{* *} \\
(0.000)\end{array}$ & $\begin{array}{l}0.001^{*} \\
(0.001)\end{array}$ \\
\hline Controls & $\mathrm{NO}$ & YES & YES & $\mathrm{NO}$ & YES & YES & NO & YES & YES \\
\hline Firm FE & YES & YES & YES & YES & YES & YES & YES & YES & YES \\
\hline Date FE & YES & YES & YES & YES & YES & YES & YES & YES & YES \\
\hline Observations & $1,041,991$ & $1,041,991$ & $1,039,068$ & 605,530 & 605,530 & 603,249 & 575,054 & 575,054 & 572,991 \\
\hline $\operatorname{Adj} R^{2}$ & 0.139 & 0.154 & 0.184 & 0.136 & 0.141 & 0.149 & 0.146 & 0.150 & 0.153 \\
\hline
\end{tabular}


Table B.8: Uncertainty of Beliefs (UOB) and major firm public information events - full set of controls

This table reports the full set of controls from Panel A of Table 5. (Z) stands for a Z-Score adjustment. Firm and date fixed effects are included in each specification. Standard errors are double clustered by firm and date and are reported in parentheses below the coefficient estimates. Statistical significance at the $10 \%$, $5 \%$, and $1 \%$ level is indicated with $* * *$, and $* * *$, respectively.

\begin{tabular}{|c|c|c|c|c|c|c|}
\hline & $\begin{array}{l}(1) \\
\mathrm{t}-1\end{array}$ & $\begin{array}{c}(2) \\
\mathrm{t}\end{array}$ & $\begin{array}{c}(3) \\
\mathrm{t}+1\end{array}$ & $\begin{array}{c}(4) \\
\mathrm{t}+2\end{array}$ & $\begin{array}{c}(5) \\
\mathrm{t}+3\end{array}$ & $\begin{array}{c}(6) \\
\mathrm{t}+5\end{array}$ \\
\hline$E A R N$ & $\begin{array}{c}-0.098^{* * *} \\
(0.004)\end{array}$ & $\begin{array}{c}-0.199^{* * *} \\
(0.009)\end{array}$ & $\begin{array}{c}-0.080^{* * *} \\
(0.005)\end{array}$ & $\begin{array}{c}-0.022^{* * *} \\
(0.003)\end{array}$ & $\begin{array}{c}-0.008^{* * *} \\
(0.003)\end{array}$ & $\begin{array}{l}-0.001 \\
(0.003)\end{array}$ \\
\hline AveUOB & $\begin{array}{c}0.009^{* * *} \\
(0.000)\end{array}$ & $\begin{array}{c}0.009^{* * *} \\
(0.000)\end{array}$ & $\begin{array}{c}0.009^{* * *} \\
(0.000)\end{array}$ & $\begin{array}{c}0.009^{* * *} \\
(0.000)\end{array}$ & $\begin{array}{c}0.009^{* * *} \\
(0.000)\end{array}$ & $\begin{array}{c}0.009^{* * *} \\
(0.000)\end{array}$ \\
\hline AveRISK & $\begin{array}{c}-0.003^{* * *} \\
(0.001)\end{array}$ & $\begin{array}{c}0.018^{* * *} \\
(0.001)\end{array}$ & $\begin{array}{c}-0.000 \\
(0.001)\end{array}$ & $\begin{array}{c}-0.001 \\
(0.001)\end{array}$ & $\begin{array}{c}-0.001^{*} \\
(0.001)\end{array}$ & $\begin{array}{c}-0.001^{* *} \\
(0.001)\end{array}$ \\
\hline AveVOV & $\begin{array}{c}0.118 \\
(0.140)\end{array}$ & $\begin{array}{c}-1.493^{* * *} \\
(0.138)\end{array}$ & $\begin{array}{c}-0.062 \\
(0.140)\end{array}$ & $\begin{array}{c}-0.027 \\
(0.141)\end{array}$ & $\begin{array}{c}0.090 \\
(0.142)\end{array}$ & $\begin{array}{c}0.135 \\
(0.145)\end{array}$ \\
\hline AveVOM & $\begin{array}{c}-1.180^{* * *} \\
(0.268)\end{array}$ & $\begin{array}{c}-3.813^{* * *} \\
(0.268)\end{array}$ & $\begin{array}{c}-1.205^{* * *} \\
(0.269)\end{array}$ & $\begin{array}{c}-1.282^{* * *} \\
(0.272)\end{array}$ & $\begin{array}{c}-1.338^{* * *} \\
(0.276)\end{array}$ & $\begin{array}{c}-1.465^{* * *} \\
(0.279)\end{array}$ \\
\hline AveSKEW & $\begin{array}{c}0.007 \\
(0.007)\end{array}$ & $\begin{array}{c}0.004 \\
(0.007)\end{array}$ & $\begin{array}{c}0.005 \\
(0.007)\end{array}$ & $\begin{array}{c}0.006 \\
(0.008)\end{array}$ & $\begin{array}{c}0.008 \\
(0.008)\end{array}$ & $\begin{array}{c}0.006 \\
(0.008)\end{array}$ \\
\hline AveKURT & $\begin{array}{c}-0.012^{* * *} \\
(0.004)\end{array}$ & $\begin{array}{c}-0.055^{* * *} \\
(0.004)\end{array}$ & $\begin{array}{c}-0.044^{* * *} \\
(0.004)\end{array}$ & $\begin{array}{c}-0.039^{* * *} \\
(0.004)\end{array}$ & $\begin{array}{c}-0.037^{* * *} \\
(0.004)\end{array}$ & $\begin{array}{c}-0.036^{* * *} \\
(0.004)\end{array}$ \\
\hline LnSize & $\begin{array}{c}0.012^{* * *} \\
(0.004)\end{array}$ & $\begin{array}{c}0.010^{* * *} \\
(0.004)\end{array}$ & $\begin{array}{c}0.015^{* * *} \\
(0.004)\end{array}$ & $\begin{array}{c}0.014^{* * *} \\
(0.004)\end{array}$ & $\begin{array}{c}0.014^{* * *} \\
(0.004)\end{array}$ & $\begin{array}{c}0.014^{* * *} \\
(0.004)\end{array}$ \\
\hline $\operatorname{LnBM}$ & $\begin{array}{l}0.004^{*} \\
(0.002)\end{array}$ & $\begin{array}{l}0.004^{*} \\
(0.002)\end{array}$ & $\begin{array}{l}0.005^{*} \\
(0.002)\end{array}$ & $\begin{array}{c}0.005^{* *} \\
(0.002)\end{array}$ & $\begin{array}{c}0.005^{* *} \\
(0.002)\end{array}$ & $\begin{array}{c}0.005^{* *} \\
(0.002)\end{array}$ \\
\hline CumRet & $\begin{array}{c}0.001^{* * *} \\
(0.000)\end{array}$ & $\begin{array}{c}0.000^{* * *} \\
(0.000)\end{array}$ & $\begin{array}{c}0.001^{* * *} \\
(0.000)\end{array}$ & $\begin{array}{c}0.001^{* * *} \\
(0.000)\end{array}$ & $\begin{array}{c}0.001^{* * *} \\
(0.000)\end{array}$ & $\begin{array}{c}0.001^{* * *} \\
(0.000)\end{array}$ \\
\hline LnNumEst & $\begin{array}{c}0.005 \\
(0.003)\end{array}$ & $\begin{array}{c}-0.003 \\
(0.003)\end{array}$ & $\begin{array}{c}0.002 \\
(0.003)\end{array}$ & $\begin{array}{c}0.000 \\
(0.003)\end{array}$ & $\begin{array}{c}-0.000 \\
(0.004)\end{array}$ & $\begin{array}{c}-0.001 \\
(0.004)\end{array}$ \\
\hline InstHold & $\begin{array}{l}0.010^{*} \\
(0.006)\end{array}$ & $\begin{array}{c}0.005 \\
(0.006)\end{array}$ & $\begin{array}{c}0.009 \\
(0.006)\end{array}$ & $\begin{array}{c}0.010 \\
(0.006)\end{array}$ & $\begin{array}{c}0.013^{* *} \\
(0.006)\end{array}$ & $\begin{array}{c}0.013^{*} \\
(0.006)\end{array}$ \\
\hline AveTURNOVER & $\begin{array}{c}0.126 \\
(0.108)\end{array}$ & $\begin{array}{l}-0.152 \\
(0.107)\end{array}$ & $\begin{array}{c}-0.080 \\
(0.108)\end{array}$ & $\begin{array}{c}-0.099 \\
(0.104)\end{array}$ & $\begin{array}{l}-0.023 \\
(0.104)\end{array}$ & $\begin{array}{c}-0.093 \\
(0.105)\end{array}$ \\
\hline $\ln \frac{1}{A v e P r c}$ & $\begin{array}{c}-0.042^{* * *} \\
(0.004)\end{array}$ & $\begin{array}{c}-0.038^{* * *} \\
(0.004)\end{array}$ & $\begin{array}{c}-0.041^{* * *} \\
(0.004)\end{array}$ & $\begin{array}{c}-0.040^{* * *} \\
(0.005)\end{array}$ & $\begin{array}{c}-0.041^{* * *} \\
(0.005)\end{array}$ & $\begin{array}{r}-0.040^{* * *} \\
(0.005)\end{array}$ \\
\hline
\end{tabular}




\begin{tabular}{|c|c|c|c|c|c|c|}
\hline & $\begin{array}{l}(1) \\
\mathrm{t}-1\end{array}$ & $\begin{array}{c}(2) \\
\mathrm{t}\end{array}$ & $\begin{array}{c}(3) \\
\mathrm{t}+1\end{array}$ & $\begin{array}{c}(4) \\
t+2\end{array}$ & $\begin{array}{c}(5) \\
\mathrm{t}+3\end{array}$ & $\begin{array}{c}(6) \\
t+5\end{array}$ \\
\hline$R I S K$ & & $\begin{array}{c}-0.027^{* * *} \\
(0.001)\end{array}$ & $\begin{array}{c}-0.004^{* * *} \\
(0.000)\end{array}$ & $\begin{array}{c}-0.003^{* * *} \\
(0.000)\end{array}$ & $\begin{array}{c}-0.003^{* * *} \\
(0.000)\end{array}$ & $\begin{array}{c}-0.003^{* * *} \\
(0.000)\end{array}$ \\
\hline$V O V$ & & $\begin{array}{c}0.022^{* * *} \\
(0.000)\end{array}$ & $\begin{array}{c}0.005^{* * *} \\
(0.000)\end{array}$ & $\begin{array}{c}0.004^{* * *} \\
(0.000)\end{array}$ & $\begin{array}{c}0.003^{* * *} \\
(0.000)\end{array}$ & $\begin{array}{c}0.003^{* * *} \\
(0.000)\end{array}$ \\
\hline$V O M$ & & $\begin{array}{c}0.037^{* * *} \\
(0.001)\end{array}$ & $\begin{array}{c}0.002^{* * *} \\
(0.000)\end{array}$ & $\begin{array}{c}0.002^{* * *} \\
(0.000)\end{array}$ & $\begin{array}{c}0.002^{* * *} \\
(0.000)\end{array}$ & $\begin{array}{c}0.002^{* * *} \\
(0.000)\end{array}$ \\
\hline$D A F$ & & $\begin{array}{c}-0.001 \\
(0.001)\end{array}$ & $\begin{array}{l}-0.002 \\
(0.002)\end{array}$ & $\begin{array}{l}-0.001 \\
(0.002)\end{array}$ & $\begin{array}{l}-0.000 \\
(0.002)\end{array}$ & $\begin{array}{l}-0.002 \\
(0.002)\end{array}$ \\
\hline$S K E W$ & & $\begin{array}{c}-0.009^{* * *} \\
(0.001)\end{array}$ & $\begin{array}{c}-0.005^{* * *} \\
(0.001)\end{array}$ & $\begin{array}{c}-0.003^{* *} \\
(0.001)\end{array}$ & $\begin{array}{c}0.001 \\
(0.001)\end{array}$ & $\begin{array}{l}-0.000 \\
(0.001)\end{array}$ \\
\hline KURT & & $\begin{array}{c}0.053^{* * *} \\
(0.001)\end{array}$ & $\begin{array}{c}0.042^{* * *} \\
(0.001)\end{array}$ & $\begin{array}{c}0.035^{* * *} \\
(0.001)\end{array}$ & $\begin{array}{c}0.032^{* * *} \\
(0.001)\end{array}$ & $\begin{array}{c}0.026^{* * *} \\
(0.001)\end{array}$ \\
\hline TURNOVER & & $\begin{array}{c}0.520^{* * *} \\
(0.072)\end{array}$ & $\begin{array}{c}0.551^{* * *} \\
(0.070)\end{array}$ & $\begin{array}{c}0.607^{* * *} \\
(0.068)\end{array}$ & $\begin{array}{c}0.571^{* * *} \\
(0.067)\end{array}$ & $\begin{array}{c}0.653^{* * *} \\
(0.074)\end{array}$ \\
\hline$E S$ & & $\begin{array}{c}-0.050 \\
(0.047)\end{array}$ & $\begin{array}{c}-0.068 \\
(0.042)\end{array}$ & $\begin{array}{c}-0.069^{*} \\
(0.038)\end{array}$ & $\begin{array}{l}-0.071 \\
(0.043)\end{array}$ & $\begin{array}{l}-0.052 \\
(0.036)\end{array}$ \\
\hline$R E T$ & & $\begin{array}{c}-0.002^{* * *} \\
(0.000)\end{array}$ & $\begin{array}{l}-0.000 \\
(0.000)\end{array}$ & $\begin{array}{c}0.001^{* *} \\
(0.000)\end{array}$ & $\begin{array}{c}0.001^{* * *} \\
(0.000)\end{array}$ & $\begin{array}{c}0.001^{* * *} \\
(0.000)\end{array}$ \\
\hline Controls & YES & YES & YES & YES & YES & YES \\
\hline Firm FE & YES & YES & YES & YES & YES & YES \\
\hline Date FE & YES & YES & YES & YES & YES & YES \\
\hline Observations & $6,750,823$ & $6,764,799$ & $6,750,152$ & $6,749,414$ & $6,748,637$ & $6,747,110$ \\
\hline $\operatorname{Adj} R^{2}$ & 0.609 & 0.610 & 0.598 & 0.590 & 0.583 & 0.572 \\
\hline
\end{tabular}


Table B.9: RISK, $V O V$, and $V O M$ on $E A R N$ days

This table repeats the analysis conducted in Table 5A replacing UOB with RISK, VOV, and VOM. The sample period is from January 2002 to December 2018. Firm controls are similar to those reported in Table 3. All variables are defined in Table B.1. For brevity, the table reports the main coefficients of interest. (Z) stands for a Z-Score adjustment. Firm and date fixed effects are included in each specification. Standard errors are double clustered by firm and date and are reported in parentheses below the coefficient estimates. Statistical significance at the $10 \%, 5 \%$, and $1 \%$ level is indicated with $*,{ }^{* *}$, and ${ }^{* * *}$, respectively.

Panel A: $R I S K(Z)$ and $E A R N$

\begin{tabular}{lcccccc}
\hline & $(1)$ & $(2)$ & $(3)$ & $(4)$ & $(5)$ & $(6)$ \\
& $\mathrm{t}-1$ & $\mathrm{t}$ & $\mathrm{t}+1$ & $\mathrm{t}+2$ & $\mathrm{t}+3$ & $\mathrm{t}+5$ \\
\hline EARN & $0.079^{* * *}$ & $0.130^{* * *}$ & $-0.101^{* * *}$ & $-0.129^{* * *}$ & $-0.114^{* * *}$ & $-0.102^{* * *}$ \\
& $(0.00)$ & $(0.00)$ & $(0.00)$ & $(0.00)$ & $(0.00)$ & $(0.00)$ \\
Controls & & & & & \\
Firm FE & YES & YES & YES & YES & YES & YES \\
Date FE & YES & YES & YES & YES & YES & YES \\
& YES & YES & YES & YES & YES & YES \\
Observations & & & & & & \\
$\operatorname{Adj} R^{2}$ & $6,751,178$ & $6,764,799$ & $6,750,525$ & $6,749,801$ & $6,749,051$ & $6,747,538$ \\
& 0.819 & 0.896 & 0.823 & 0.816 & 0.812 & 0.805 \\
\hline
\end{tabular}

Panel B: $\operatorname{VOV}(Z)$ and $E A R N$

\begin{tabular}{lcccccc}
\hline & $(1)$ & $(2)$ & $(3)$ & $(4)$ & $(5)$ & $(6)$ \\
& $\mathrm{t}-1$ & $\mathrm{t}$ & $\mathrm{t}+1$ & $\mathrm{t}+2$ & $\mathrm{t}+3$ & $\mathrm{t}+5$ \\
\hline EARN & $0.017^{* * *}$ & $0.061^{* * *}$ & $-0.165^{* * *}$ & $-0.165^{* * *}$ & $-0.129^{* * *}$ & $-0.097^{* * *}$ \\
& $(0.00)$ & $(0.00)$ & $(0.00)$ & $(0.00)$ & $(0.00)$ & $(0.00)$ \\
& & & & & \\
Controls & YES & YES & YES & YES & YES & YES \\
Firm FE & YES & YES & YES & YES & YES & YES \\
Date FE & YES & YES & YES & YES & YES & YES \\
& & & & & & \\
Observations & $6,751,268$ & $6,764,799$ & $6,750,637$ & $6,749,972$ & $6,749,278$ & $6,747,831$ \\
$\operatorname{Adj} R^{2}$ & 0.475 & 0.596 & 0.485 & 0.478 & 0.475 & 0.469 \\
\hline
\end{tabular}

Panel C: $\operatorname{VOM}(Z)$ and $E A R N$

\begin{tabular}{lcccccc}
\hline & $(1)$ & $(2)$ & $(3)$ & $(4)$ & $(5)$ & $(6)$ \\
& $\mathrm{t}-1$ & $\mathrm{t}$ & $\mathrm{t}+1$ & $\mathrm{t}+2$ & $\mathrm{t}+3$ & $\mathrm{t}+5$ \\
\hline EARN & $0.047^{* * *}$ & $0.256^{* * *}$ & $-0.043^{* * *}$ & $-0.125^{* * *}$ & $-0.128^{* * *}$ & $-0.120^{* * *}$ \\
& $(0.00)$ & $(0.00)$ & $(0.00)$ & $(0.00)$ & $(0.00)$ & $(0.00)$ \\
& & & & & \\
Controls & YES & YES & YES & YES & YES & YES \\
Firm FE & YES & YES & YES & YES & YES & YES \\
Date FE & YES & YES & YES & YES & YES & YES \\
& & & & & & \\
Observations & $6,751,270$ & $6,764,799$ & $6,750,637$ & $6,749,973$ & $6,749,278$ & $6,747,832$ \\
$\operatorname{Adj} R^{2}$ & 0.597 & 0.702 & 0.607 & 0.600 & 0.597 & 0.591 \\
\hline
\end{tabular}


Figure B.1: Investor Disagreement measures conditional on RISK

This figure plots averages of different investor Disagreement measures on day $t$ of portfolio sorts on within firm percentage changes in RISK, measured on day $t$. DIS is the investor total disagreement measure. $D W G$ is the "within group" investor disagreement measure, and $D A G$ is the "across group" investor disagreement measure. The percentage change in UOB is calculated relative to its 21-day trailing averages from day $t-27$ to $t-6$. All variables are defined in Table B.1. The sample period is from January 2002 to December 2018.

\section{Panel A: Total Disagreement $(D I S)$}

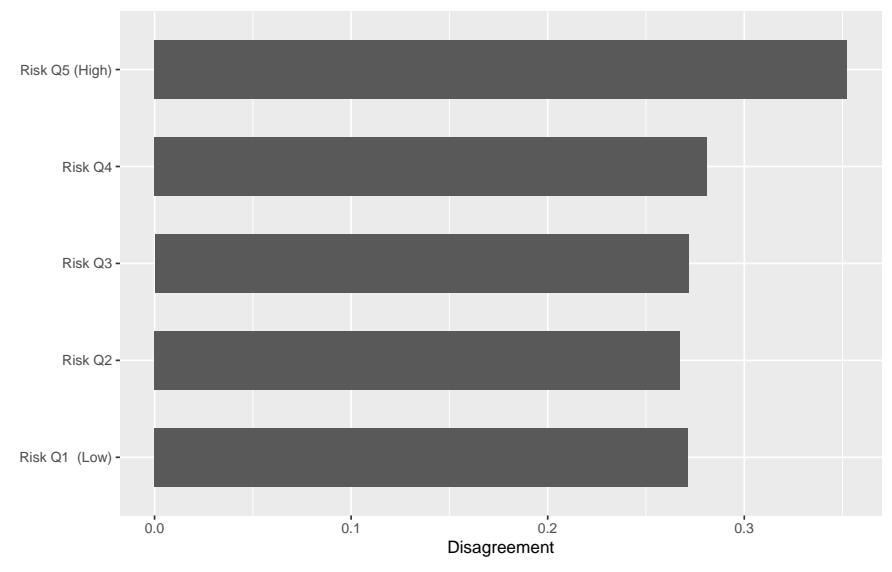

Panel B: Within Group Disagreement $(D W G)$

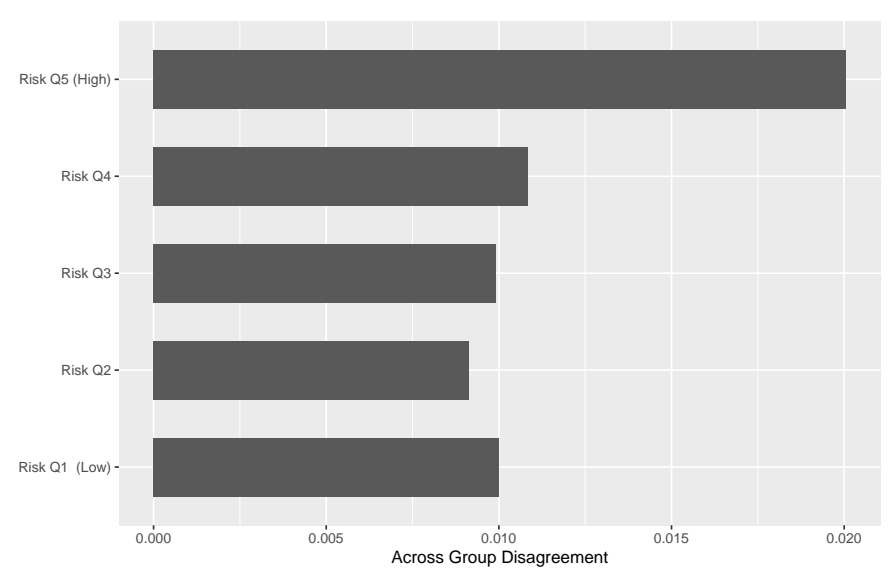

Panel C: Across Groups Disagreement $(D A G)$

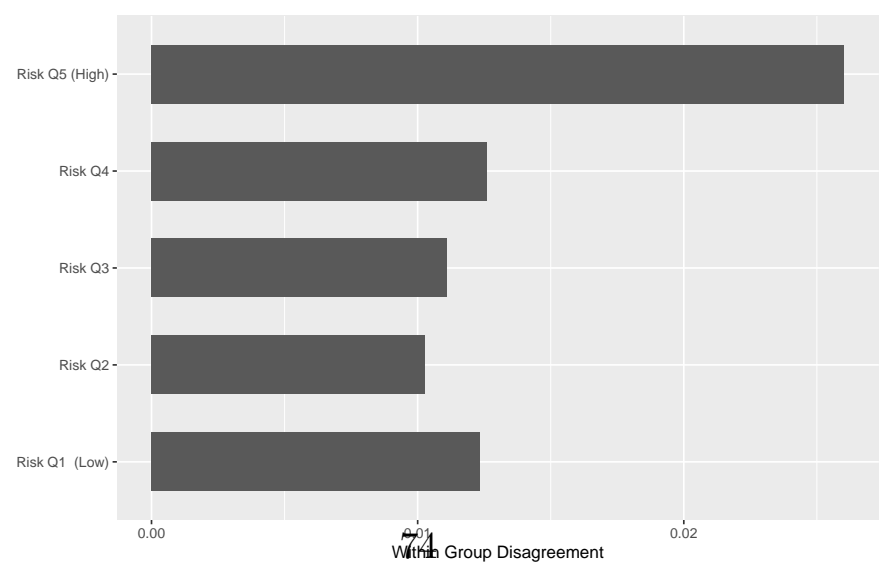


Figure B.2: Investor Disagreement Measures conditional on Uncertainty of Beliefs (UOB) conditional and RISK

This figure plots averages of different investor Disagreement measures on day $t$ of portfolio sorts on within firm percentage changes in UOB, conditional on within firm percentage changes in RISK, measured on day $t$. DIS is the investor total disagreement measure. $D W G$ is the "within group" investor disagreement measure, and $D A G$ is the "across group" investor disagreement measure. The percentage change in UOB is calculated relative to its 21-day trailing averages from day $t-27$ to $t-6$. All variables are defined in Table B.1. The sample period is from January 2002 to December 2018.

Panel A: Total Disagreement $(D I S)$

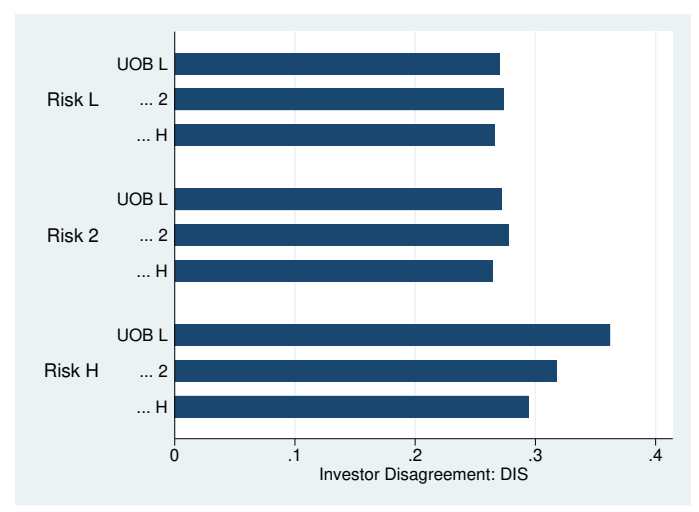

Panel B: Within Group Disagreement (DWG)

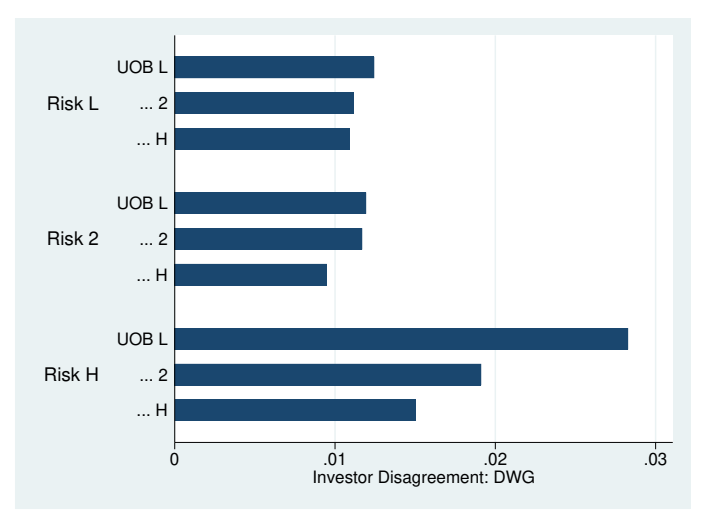

Panel C: Across Groups Disagreement
$(D A G)$

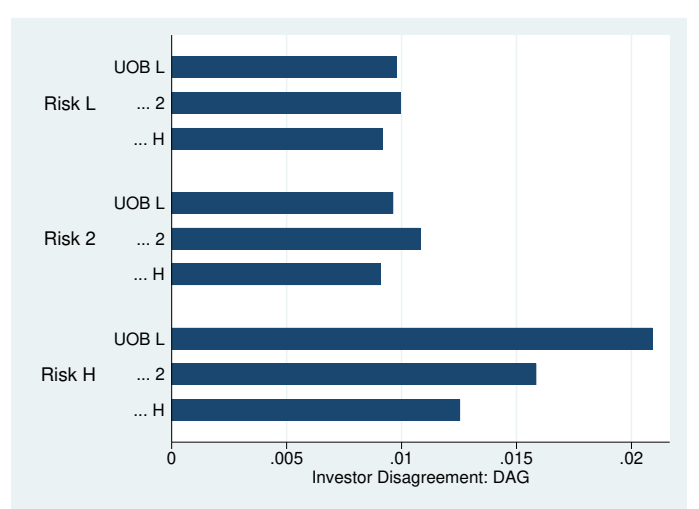


Figure B.3: UOB and Other Firm 8-K Filings

This Figure considers the effect of 8-K filings (that were not analyzed in Table 7) on UOB. It plots the coefficient estimates from the regressions of UOB on Item 5.02 (Panel A) and Item 5.07 (Panel B).

Panel A: UOB and ITEM 5.02 - Departure/election of directors or principal officers

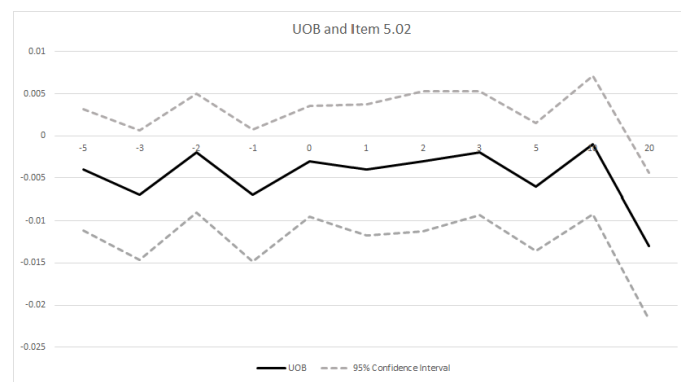

Panel B: UOB and ITEM 5.07 - Submission of matters to a vote of security holders

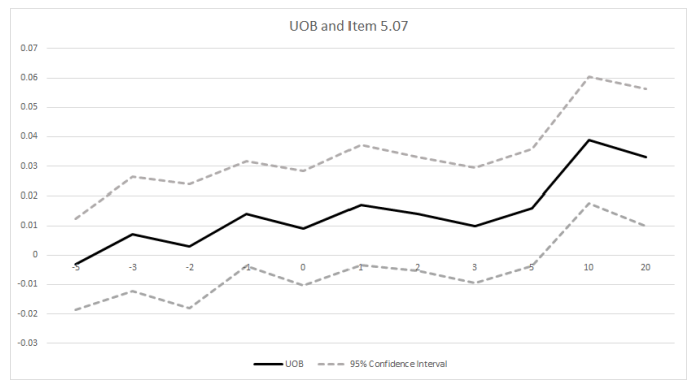


Figure B.4: Disagreement around Major Firm Specific Events

This figure plots the coefficient estimates of the effect of earnings announcements (Panel A) and firm 8-K filings (Panel B) on disagreement.

Panel A: Earnings Announcements

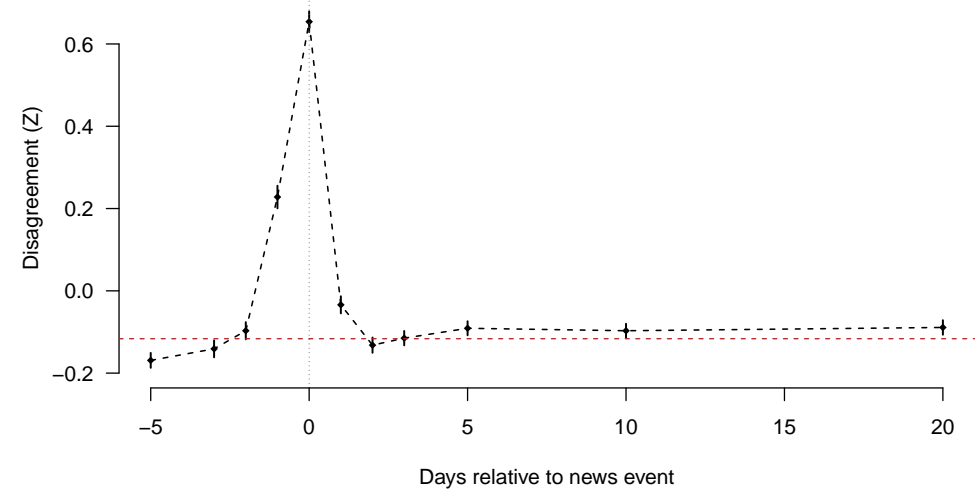

Panel B: Firm 8-K Filings

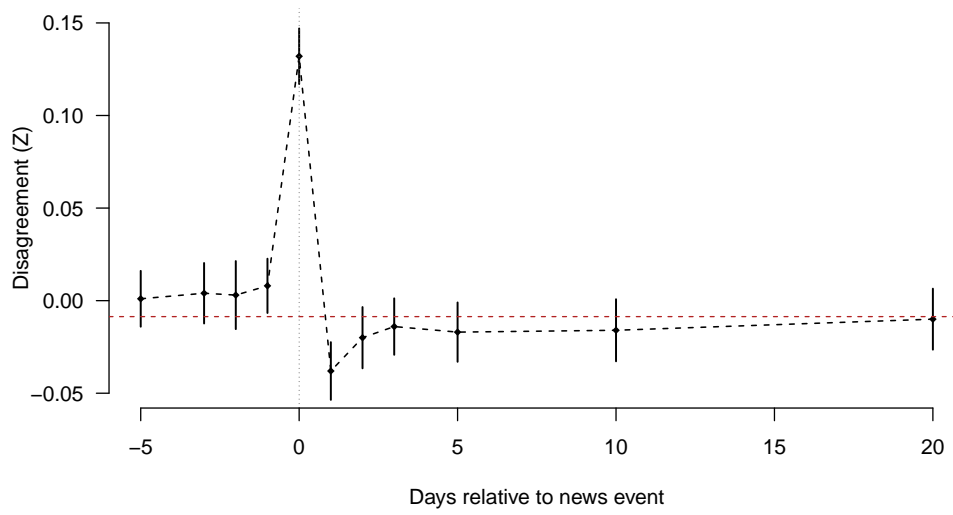

